NBER WORKING PAPER SERIES

\title{
PAY ME LATER: SAVINGS CONSTRAINTS AND THE DEMAND FOR DEFERRED PAYMENTS
}

\author{
Lasse Brune \\ Eric Chyn \\ Jason T. Kerwin \\ Working Paper 28611 \\ http://www.nber.org/papers/w28611 \\ NATIONAL BUREAU OF ECONOMIC RESEARCH \\ 1050 Massachusetts Avenue \\ Cambridge, MA 02138 \\ March 2021
}

We are grateful for insightful comments from Achyuta Adhvaryu, Emily Breza, Lorenzo Casaburi, Michael Callen, Esther Duflo, Marcel Fafchamps, Xavi Gine, Reshma Hussam, Kelsey Jack, Namrata Kala, Dean Karlan, Craig McIntosh, Doug Staiger, Chris Woodruff, Dean Yang, Jonathan Zinman, and from seminar participants at the IPA Researcher Gathering on Financial Inclusion, Yale University, the Consumer Financial Protection Bureau, the University of Hong Kong, HKUST, Peking University, China Agricultural University, the Federal Reserve Bank of Philadelphia, the University of Utah, the University of Washington, MIEDC, CSAE, NEUDC, and ASSA. We gratefully acknowledge support from the Financial Services for the Poor Research Fund at Innovations for Poverty Action, sponsored by a grant from the Bill and Melinda Gates Foundation. We thank Rachel Sander for providing excellent research assistance and Ndema Longwe for his outstanding diligent work in managing data collection. This project would not have been possible without the help of the management at the Lujeri Tea Estate and the employees who participated in the study, who generously shared their time with us. This work was supported by the USDA National Institute of Food and Agriculture, Hatch project MIN14-164. This study was reviewed and approved by IRBs in Malawi (NCRSH, protocol number P.08/16/131) and at IPA (protocol number 13888). This study is registered with the AEA RCT Registry under registration number AEARCTR-0001554. The views expressed herein are those of the authors and do not necessarily reflect the views of the National Bureau of Economic Research.

NBER working papers are circulated for discussion and comment purposes. They have not been peer-reviewed or been subject to the review by the NBER Board of Directors that accompanies official NBER publications.

(C) 2021 by Lasse Brune, Eric Chyn, and Jason T. Kerwin. All rights reserved. Short sections of text, not to exceed two paragraphs, may be quoted without explicit permission provided that full credit, including $(\odot$ notice, is given to the source. 
Pay Me Later: Savings Constraints and the Demand for Deferred Payments

Lasse Brune, Eric Chyn, and Jason T. Kerwin

NBER Working Paper No. 28611

March 2021

JEL No. D14,D9,D90,D91,J22,J33,O12,O15

\begin{abstract}
$\underline{\text { ABSTRACT }}$
We study a simple savings scheme that allows workers to defer receipt of part of their wages for three months at zero interest. The scheme significantly increases savings during the deferral period, leading to higher post-disbursement spending on lumpy goods. Two years later, after two additional rounds of the savings scheme, we find that treated workers have made permanent improvements to their homes. The popularity of the scheme implies a lack of good alternative savings options. The results of a follow-up experiment suggest that demand for the scheme is partly due to its ability to address self-control issues.

Lasse Brune

Northwestern University

Scott Hall

Evanston, IL

lasse.brune@northwestern.edu

Eric Chyn

Department of Economics

Dartmouth College

6106 Rockefeller Hall

Hanover, NH 03755

and NBER

eric.t.chyn@dartmouth.edu

Jason T. Kerwin

Department of Applied Economics

University of Minnesota

1994 Buford Ave.

316C Ruttan Hall

Falcon Heights, MN 55108

jkerwin@umn.edu
\end{abstract}


A key prediction of standard economic models is that individuals should prefer to be paid early. However, an emerging literature documents notable demand for deferred payments for goods and services in developing countries (Casaburi and Macchiavello, 2019; Brune and Kerwin, 2019; Kramer and Kunst, 2020). Similarly, millions in developed countries choose to defer income by opting to overwithhold on tax payments that are later returned as refunds (Thaler, 1994).

There are three main benefits to deferred payments. First, deferring pay naturally generates lump sums that can be used to purchase durable goods, make business investments, or buy in bulk. This may be particularly important given qualitative evidence that suggests poor households exert substantial effort to generate lump sums (Collins et al., 2009). Second, deferred payments may be a relatively safer savings option because access to high-quality formal banking is limited and informal saving options can be risky (Karlan, Ratan and Zinman, 2014; Dupas et al., 2016). Third, delaying pay can help address behavioral constraints such as time-inconsistency (Laibson, 1997; Ashraf, Karlan and Yin, 2006; Bryan, Karlan and Nelson, 2010; DellaVigna, 2018).

This paper provides evidence on the demand for deferred payments and the first experimental estimates of the impact of this savings method on downstream outcomes. Our analysis is based on a sample of full-time workers at a large agricultural employer in rural Malawi. We study a savings scheme that allowed workers to defer a fraction of their pay for three months at zero interest. Access to this scheme was randomized for a sample of 870 workers who were interested in participating. All payments were provided in cash through the firm's regular payroll infrastructure. The scheme created a simple, no-frills option for workers to save for lumpy purchases by piggybacking on existing firm payroll infrastructure to shift the timing of payments.

Our analysis shows that the savings scheme was popular and changed worker behavior. Nearly half of all workers who were contacted as part of outreach activities signed up for the scheme. ${ }^{1}$ Those who enrolled had high rates of account usage (92 percent made more

\footnotetext{
${ }^{1}$ We conducted outreach by having field staff visit divisions of the firm. The staff held information sessions with all permanent, full-time workers who were present on the day of the visit. We did not provide subsidies
} 
than one deposit) and saved 14 percent of their wages on average. We find that the scheme appears to have increased overall savings during the accumulation period, rather than just substituting for other forms of savings. Much of the reported money saved was spent on lumpy purchases: two-thirds of treatment workers' additional spending in the two weeks after payout goes toward lumpy purchases, including for durable purchases related to housing investment.

Participation in the deferred wages scheme had significant effects on downstream outcomes. Four months after the end of the scheme, a broad measure of the value of durable assets increased by 10 percent. This increase was concentrated in stored materials for house improvements such as sheets of metal roofing. The main threat to the interpretation of this result is that we do not find impacts on asset purchases, which was one of our pre-specified outcomes. However, we find further downstream effects on asset outcomes in long-run followup data, after treatment-group workers were offered the scheme two more times. Specifically, two years after the initial round of the scheme (and nine months after the last round), treatment-group workers were 7.7 percentage points more likely to have metal roofs on their homes. This result is robust to adjustment for multiple hypothesis testing.

The popularity and effectiveness of the deferred wages savings scheme implies a lack of safe and convenient alternative savings options. Evidence from a follow-up experiment supports this view and is also consistent with the idea that the scheme helps workers with behavioral constraints. We randomly offered a new sample of workers either the original scheme or a modified version of the product that required manual deposits at an easy-toreach workplace location. The manual deposits scheme resulted in substantially lower savings. While initial sign-up rates were similar for the two schemes, workers in the manual deposits scheme saved 50 percent less. We find suggestive evidence that these reductions are smaller in magnitude for workers with higher reported self-control. ${ }^{2}$ At the same time, enrollment in

or conduct other marketing for the deferred wages scheme. A total of 1,897 workers were contacted through outreach. We subsequently followed up with interested workers and ultimately 870 workers agreed to enroll in the scheme if they were to receive an offer to participate. Thus, the final sign-up rate for all contacted workers was 46 percent $(=870 / 1,897)$.

${ }^{2}$ We conducted a pre-treatment survey that included questions on whether the respondent had feelings of regret in consumption choices. We use the responses to this question as a measure of self-control problems. 
the automatic deposits version is high even for people without reported self-control problems, perhaps suggesting that there are benefits of the deferred wages scheme beyond addressing self-control problems. In particular, workers may also lack safe places to store money.

Overall, this paper contributes to recent work on payment deferral in developing countries (Casaburi and Macchiavello, 2019; Brune and Kerwin, 2019; Kramer and Kunst, 2020). We build on prior studies in four main ways. First, we show robust demand for deferred payments: workers sign up for a real-world savings scheme that pays them later, deposits are sizeable, and the repeat sign-up rate is high. ${ }^{3}$ Second, we demonstrate sustained downstream impacts. This finding suggests that deferring payments can substantially relax existing constraints. In addition, the impact on downstream outcomes and the high repeat sign-up rate suggest that deferred pay is welfare-enhancing in our setting (Chetty, 2015). Third, we provide new evidence on the mechanisms driving demand for deferred payments. Consistent with Casaburi and Macchiavello (2019), we find evidence that suggests self-control problems are important. At the same time, our results show this is likely not the only explanation; the evidence suggests that workers also lack safe and convenient ways to store money. Fourth, we use the firm's administrative records to show that the deferred wages scheme increases worker productivity. This last result is in line with other recent work that suggests savings products can increase labor supply by generating an increase in the effective interest rate (Callen et al., 2019).

In addition, our findings contribute to the broader literature on savings interventions. Prior studies have studied the impacts of providing subsidized bank accounts (Prina, 2015; Dupas and Robinson, 2013a; Dupas et al., 2018), using automatic deposits (Breza, Kanz and Klapper, 2020; Somville and Vandewalle, 2018), setting defaults (Brune et al., 2017; Blumenstock, Callen and Ghani, 2018) or offering commitment savings schemes (Ashraf,

Our results should be interpreted cautiously given the potential measurement error in this proxy for selfcontrol.

${ }^{3}$ Prior research by John (2019) suggests that individuals may sign up for savings products with commitment features by mistake. The finding of high re-enrollment in our sample largely rules out this possibility: people might enroll in a commitment product that is a bad idea one time, but they are not likely to reenroll in it a second time. Our reasoning is similar to Schilbach (2019), which also studies a product with commitment features and finds high rates of repeat enrollment. 
Karlan and Yin, 2006; Karlan and Zinman, 2012; Dupas and Robinson, 2013b; Karlan and Linden, 2014; Beshears et al., 2015; Brune et al., 2016). Compared to this literature, we study a product that has relatively high account sign-up and more-extensive account usage. ${ }^{4}$ This paper also stands as one of the few evaluations of a savings product that finds detectable impacts on downstream outcomes. Alongside Dupas and Robinson (2013a) and Schaner (2018), we find important effects on assets.

Finally, our results offer two potential insights on the optimal design of savings products in developing countries. First, we provide suggestive evidence that time and transaction costs are important determinants of product take-up and account usage. Demand for the deferred wages scheme and contributions fell considerably when workers had to self-enroll at a payroll office or make manual deposits, respectively. These findings on the importance of time and transaction costs are consistent with Dupas and Robinson (2013a) and Prina (2015). Second, this paper provides evidence that soft commitment features can be an important aspect of the design of savings products. This finding aligns with previous studies that show commitment devices can have important impacts in a range of contexts (Ashraf, Karlan and Yin, 2006; Giné, Karlan and Zinman, 2010; Duflo, Kremer and Robinson, 2011; Dupas and Robinson, 2013b; Karlan and Linden, 2014; Brune et al., 2016; Kaur, Kremer and Mullainathan, 2015; Royer, Stehr and Sydnor, 2015; Schilbach, 2019). ${ }^{5}$

\footnotetext{
${ }^{4}$ For example, Karlan, Ratan and Zinman (2014) survey studies of savings interventions and note that take-up rates for commitment savings products are often 20 to 30 percent. In addition, they note that usage rates (defined as making two or more deposits within a year of account opening) are typically less than half of the take-up rate. In our study, 92 percent of workers who sign up for the scheme make at least two deposits within the twelve-week deduction period.

${ }^{5}$ For reviews of the broader literature on commitment devices, see Bryan, Karlan and Nelson (2010). Studies of commitment products do not always find evidence of positive impacts on welfare (Kremer, Rao and Schilbach, 2019). For example, John (2019) finds that many individuals who demand commitment savings fail to follow through with their commitments and incur financial penalties. Bai et al. (2020) also provide evidence that commitment devices can have negative impacts on welfare in the context of a healthcare product.
} 


\section{Background and Experimental Design}

\section{A Study Setting}

This study took place in partnership with Lujeri Tea Estates, a large agricultural firm in Malawi. The target population for our study comprises two broad categories of employees: "pluckers" and "non-pluckers." "Pluckers" pick tea for a piece rate per kilogram of tea they harvest. They earn approximately PPP USD $\$ 7$ (MK 5,400) per day on average during the main agricultural season. The local currency is the Malawian Kwacha (MK). During the study period the exchange rate was approximately MK 750 per USD. Pluckers can increase their earnings by working harder because they are paid a piece rate. Other workers do jobs like pruning, weeding, applying fertilizer, and tasks related to monitoring and management. We refer to these other employees as "non-pluckers." Non-pluckers receive fixed daily wages based on the task they are performing. ${ }^{6}$ Lujeri is divided geographically and administratively into 20 divisions; we use 11 of these in our main experiment. For all employees, Lujeri pays earnings every two weeks.

Over the course of a year, workers at Lujeri experience substantial variation in income. This is illustrated in the timeline illustrated in the top portion of Figure 1. The main tea season typically lasts from December to April, and worker incomes are high during this period. In the off-season, worker incomes are lower because tea growth is limited. Thus, the main season is when workers have relatively high demand to save. Savings from the main tea season can be used to smooth consumption across seasons and facilitate lumpy purchases of durable goods (e.g., iron roof sheets or other building materials) and other indivisible investments such as school fees. In addition, the end of the tea season coincides with the harvest period for maize. Workers may wish to spend their savings on maize at this time because prices are lower.

As in many developing countries, workers at Lujeri have limited savings options. Informal

\footnotetext{
${ }^{6}$ Non-pluckers occasionally pick tea and pluckers occasionally do other tasks. A worker's pay is based on the task she does on a specific day: if a plucker spends a day doing pruning, she gets the fixed daily wage for pruning, and if a non-plucker spends a day plucking tea, she is paid based on the number of kilograms of tea she harvests.
} 
methods such as hiding cash at home and participating in savings groups are the most popular choices. Savings groups are organized both in the form of Rotating Savings and Loan Associations (ROSCAs), mostly with co-workers, or in the form of Accumulating Savings and Loan Associations (ASCAs), mostly with other households in workers' villages. In our baseline survey, we found that workers held less than five percent of their total reported savings in formal savings accounts (see Appendix Table A1). At the time of our study, workers did have access to formal savings through a bank branch that was located on the premises of the firm. The bank offered fee-free bank accounts that were subsidized by the firm. Despite the physical proximity and low-cost of accounts, there was very little utilization of formal savings through the bank branch. One possible explanation for this is that, according to reports from our field staff, many workers found that the branch had inconvenient hours and long wait times. ${ }^{7}$

\section{B Main Intervention}

Our main intervention provided a group of workers with the option of receiving a portion of their earnings as a deferred lump-sum payment at the end of the main season in May 2017. As detailed further below, we randomly assigned this option to a set of workers who were interested in participating. Savings in the scheme earned no interest. ${ }^{8}$ Participants determined their contributions to the scheme by setting two parameters for each two-week pay period: a minimum level of take-home pay and maximum deferral amount. For example, a worker might set a minimum take-home pay of MK 9,000 per payday and a maximum deduction of MK 3,000. If this worker earned MK 10,000 in a pay period, they would contribute MK 1,000 to the scheme and take home the remaining MK 9,000. If this worker instead earned MK 14,000, they would contribute MK 3,000 to the scheme and take home the remaining MK 11,000. Workers could only receive early access to the balance in the deferred wages scheme by exiting the program permanently. We explained that this process applied to cases of emergency and emphasized that no future deductions through the deferred wages scheme

\footnotetext{
${ }^{7}$ Several years after our study, the branch closed as a result of low utilization.

${ }^{8}$ Inflation was roughly 15 percent per year during the study period, or 3.75 percent over the course of the deduction period, so the real interest rate on savings was negative (Reserve Bank of Malawi, 2019).
} 
would take place after exit. However, there were no procedures in place for verifying that the reasons for exiting qualified as actual emergencies.

\section{Sample Recruitment for the Main Intervention}

We provide a timeline for the main intervention in Figure 1. Research assistants conducted outreach on behalf of the firm and held information sessions explaining the main intervention from October 31 to December 29, 2016. Specifically, field staff visited divisions at the firm, and conducted product information sessions with all full-time workers who were present at work on the day of the visit. Information sessions were typically held in small groups, with four participants on average. About 17 percent of sessions were conducted one-on-one. Most information sessions lasted between 10 and 30 minutes. Online Appendix B provides the guide that field staff used during these sessions.

Our staff contacted 1,897 workers through the information sessions. All workers who attended the sessions were full-time employees who had also worked full time during the previous main tea season. From this group of full-time workers, 1,240 (65.4 percent) indicated that they would be interested in participating in the deferred wages scheme.

In January 2017, we followed up with workers who had indicated interest in the scheme and conducted baseline and social network surveys (discussed further in Section II). At this stage, 1,092 workers could be contacted and consented to be surveyed. The remaining 148 workers could either not be found because they no longer worked at the firm or were temporarily absent during fieldwork $(n=109)$, or did not consent to participate in the study $(n=39)$.

As shown in Figure 2, the final sample for the analysis consists of 870 workers who remained interested in the program in January 2017, during the social network survey. We told workers that we would randomly select half of those who were interested in the product to actually receive it. Sign-up for the program occurred on the spot for those who remained interested and were randomly chosen to participate. All workers who were chosen for implementation actually enrolled in the deferred wages scheme. The 222 workers who were not included in the randomization were no longer interested in the scheme. This 20.3 percent 
$(=222 / 1,092)$ decline in interest was partially due to the delay between the initial elicitation of demand (which started in November 2016) and the point of contact for randomization in January.

\section{Randomization Details for Main Intervention and Balance Analysis}

We randomized enrollment in the deferred wages scheme among the 870 workers in the final sample. We did this using pre-specified lists of treatment allocations for all workers who were contacted at the sign-up stage, with 50 percent assigned to treatment. Randomization was carried out using re-randomization, which aims to achieve allocations of treatment that are balanced across a number of baseline characteristics. Our approach is similar to prior experiments that use re-randomization (Ashraf, Berry and Shapiro, 2010; Fryer, 2011; Behrman et al., 2015; Banerjee et al., 2015b; Royer, Stehr and Sydnor, 2015; Carvalho, Meier and Wang, 2016; Brownback and Sadoff, 2020; Fink, Jack and Masiye, 2020). ${ }^{9}$ Using the baseline survey and pre-treatment administrative data, we stratified workers by the division of the estate and randomly assigned each to either the treatment or the control group. We checked for balance on a set of 18 variables, repeating this process 1,000 times. We selected the randomization with the lowest maximal $t$-statistic across the 18 balance variables. ${ }^{10}$

\footnotetext{
${ }^{9}$ Bruhn and McKenzie (2009) assess the performance of six different randomization methods (including re-randomization) using Monte Carlo simulations. Specifically, they examine performance across six outcome variables drawn from four datasets and three sample sizes (30, 100, and 300 observations). Two main results from their analysis have bearing on our analysis. First, they show that all six methods perform similarly in terms of statistical power in samples of 300 or more. This is reassuring given that our sample size exceeds this threshold. Second, Bruhn and McKenzie make recommendations for how to approach inference. When randomization is not a single random draw, their simulation results lead them to write: "We recommend that the standard should be to control for the method of randomization" (p. 229). For re-randomization, they recommend controlling for all the variables used to check balance in the re-randomization procedure. As detailed in Section III, we follow this recommendation, controlling for all of the covariates that we used in the re-randomization approach.

${ }^{10}$ The variables we used included the following administrative variables measured from October 3rd 2016 up to the baseline survey: attendance rate, average number of KGs of tea harvested, the share of days on which they plucked tea, and total net pay. They also included the following variables captured on the baseline survey: total expenditures in the past 14 days, total value of stored food, total income in the past 14 days, a PCA index of asset values, a PCA index of work motivation questions, savings motivation scale, participation in a savings group in the previous season, average daily number of meals eaten in past week, age, years of education, and indicators for being married and female. Finally, we included two savings scheme preference variables captured for all workers in our experimental sample, since everyone expressed initial interest in the product: desired minimum take-home pay and maximum deduction.
} 
Appendix Table A1 reports summary statistics and balance test results for the final experimental sample of 870 workers. In terms of demographics, a minority of the sample is female (around 35 percent), the average age is nearly 40, and most workers are married (70 percent). We also collected information on financial behaviors. We find that workers typically have about USD $\$ 42$ (MK 30,000) in savings, predominantly held informally. Column 3 shows that there are no statistically-significant differences between the treatment and control groups for any of these characteristics. We fail to reject the null hypothesis in a test of joint significance $(p$-value $=0.437)$.

\section{E Supplemental Experiments}

To study features that drive demand for the deferred wages scheme, we also conducted the following three supplementary experiments after the main intervention:

1. Re-enrollment. We study whether mistakes or seasonality drive demand for the deferred wages scheme. To do this, we offered workers in the treatment group the option to re-enroll in the savings scheme for part of the off-season and for the next main season. Sign-up for this repeat enrollment experiment occurred in September 2017, and took place during a follow-up survey.

2. Automatic versus manual deposits. We study how the method of deposit matters for the take-up and usage of the deferred wages scheme. For this analysis, we recruited a new sample of 186 workers who were not involved in the main intervention. We randomized workers into two groups. One group received offers to enroll in the original scheme. The other group received offers to enroll in a version of the scheme with manual deposits: workers had to make deposits manually by handing cash to a project employee stationed next to the payroll site. Workers' choices were actually implemented. Recruitment and sign-up for this experiment occurred in February 2018. Deductions took place from February to March 2018, and the payout occurred in May 2018.

3. Preferences over payout and access. We study whether the mode of payout matters 
for the take-up of the deferred wages scheme. Again, we recruited a new sample of 542 workers who were not recruited for the initial experiment. We elicited preferences over enrolling in (a) the original scheme, (b) a "smooth payout" version of the scheme, or (c) a version that provided "more access" to the funds. The "smooth payout" version paid out the savings smoothly over a period of several weeks instead of in a lump sum; the "more access" version relaxed the restrictions on accessing savings during the scheme. Workers' responses were incentivized: they were asked about whether they preferred each option to no savings scheme at all, and were told that one randomly-selected worker in this experiment would have one of their choices implemented. ${ }^{11}$ Recruitment and sign-up for this experiment occurred in February 2018. Deductions took place from February to March 2018, and the payout occurred in May 2018.

\section{Data for Main Analysis}

To study the effects of deferred wages, we use two sources of data for the workers who were included in the main intervention $(N=870)$. First, we use individual-level administrative data from Lujeri (Lujeri Tea Estates 2017). ${ }^{12}$ This administrative data includes daily attendance and activity records for all workers at the firm, including how much tea a worker harvested (if applicable). The dataset also contains payroll data that shows earnings, taxes paid, deductions, and take-home pay for each two-week pay period. Finally, the payroll data reports the balances the workers held in the deferred wages scheme.

Second, we collected several rounds of survey data. The lower portion of Figure 1 reports the timeline for the surveys. As discussed in Section I, we fielded an information session, baseline, and social network surveys from November 2016 to January 2017. We collected social network information to investigate potential spillover effects (a point we discuss in detail in Section III). After randomization and sign-up, we fielded a first (FS1) and second (FS2) follow-up surveys during the main tea season. This data allows us to measure treatment

\footnotetext{
${ }^{11}$ Each worker was asked about all three potential options, with the order randomized. We analyze only the first option each worker was asked about for simplicity, and to avoid potential question-order effects.

${ }^{12} \mathrm{An}$ anonymized version of this administrative data is available as part of our replication materials on openICPSR (Brune, Chyn and Kerwin (2021a)).
} 
effects during the deduction period of the intervention. After the lump-sum payout of the deferred wages scheme, we collected a third follow-up survey (FS3) to measure post-payout outcomes. We fielded the survey over four weeks and designed questions to capture the effects of the lump-sum payout over time. ${ }^{13}$ A fourth follow-up survey (FS4) took place in August and September of 2017 to measure impacts after the scheme had completely ended. This lets us test for downstream effects beyond mere shifts in the timing of expenditures caused by the specific timing of the scheme. Finally, we conducted a fifth follow-up survey (FS5) (not shown in Figure 1) in February through April of 2019. This data allows us to measure longer-run outcomes a little over two years after the start of the first round of the scheme. All the data and code used in the paper are available via openICPSR as Brune, Chyn and Kerwin (2021a).

A key objective of our experiment is to evaluate the impact of the savings scheme on financial behaviors and downstream outcomes, particularly asset accumulation. With this in mind, we designed the surveys to measure expenditures, savings, and assets. While much of our analysis focuses on aggregate measures, we asked individuals to report on specific items or sub-categories. We did this to reduce measurement error in the aggregate measures and to provide details about changes within the broad categories. For example, we asked about detailed expenditures within the last two weeks on specific items such as maize, house improvements, and purchases of household items.

Appendix Table A2 provides statistics and an analysis of attrition in the follow-up surveys. Attrition is low for the surveys we collected during the main season and immediately after the payout (FS1-FS3) — we located 91 to 96 percent of the experimental sample in each of these follow-up surveys. For the longer-run surveys, attrition is higher: we located 81 and 75 percent of the original sample for the fourth and fifth follow-up surveys, respectively. Overall, we find little evidence that attrition rates are correlated with treatment in the

\footnotetext{
${ }^{13}$ As detailed further in Section IV, the recall period for flow measures on this survey varied based on the day of the survey. To experimentally vary the timing of surveys, we partially randomized the order in which workers were surveyed for FS3. First, to vary timing, we randomized the order in which surveyors visited the different divisions of the firm. Second, within each division, we randomly assigned workers to a first or second wave of surveying.
} 
follow-up surveys. In four of the five surveys, there is no statistically-significant relationship between treatment status and attrition. For the second follow-up survey, treated individuals are slightly more likely $(3.0$ percentage points; $p$-value $<0.10)$ to be included in the survey. Across all survey waves, we consistently find that individuals who attrit do not detectably differ by treatment status in terms of their baseline characteristics.

\section{Empirical Strategy}

To estimate the impact of the deferred wages scheme offered in our main intervention, we rely on the following specification:

$$
y_{i s t}=\alpha+\beta \text { Treat }_{i}+\delta_{s}+\gamma Z_{i}+y_{i s b}+\epsilon_{i s t}
$$

where $y_{i s t}$ is the outcome of interest (e.g., total assets) for individual $i$ measured at time $t$ in stratum $s$. The variable Treat $_{i}$ is an indicator that takes the value of 1 if the individual was given the option of participating in the deferred wages scheme. Fixed effects for randomization strata (i.e., divisions of the tea estate) are included as $\delta_{s}$. Following the recommendation of Bruhn and McKenzie (2009), we control for all of the individual covariates $Z_{i}$ that we used in the re-randomization procedure. In Equation 1, our parameter of interest is $\beta$, which gives the effect of the deferred wages scheme on the outcome variable. Our random experiment ensures that the treatment is uncorrelated with the error term in expectation, so Equation 1 yields unbiased estimates of $\beta$. As detailed in Section I above, all workers assigned to the deferred wages treatment group enrolled. This complete compliance with the treatment implies that $\hat{\beta}$ is an estimate of the treatment-on-the-treated (TOT) effect of participating in the deferred wages scheme. ${ }^{14}$

We also estimate an augmented version of Equation 1 for our analyses of the effects of the deferred wages scheme on labor supply (e.g., daily output or attendance). To provide increased precision for these analyses, we use additional controls for workers' pre-experiment

\footnotetext{
${ }^{14}$ The intention-to-treat (ITT) effects for the broader population of all contacted workers would be smaller in magnitude than the estimated TOT impacts. This point should be kept in mind when comparing our results for savings and downstream outcomes to other studies that report ITT estimates.
} 
performance based on administrative records. Specifically, we control for the following variables measured in the period before treatment status was assigned: the average, standard deviation, 25th, 50th, and 75th percentiles of their daily kilograms (kg) of tea plucked (including days with no tea plucking as zero $\mathrm{kg}$ ), as well the share of work days they attended work and the share of work days they plucked tea. ${ }^{15}$

\section{A Multiple Hypothesis Testing Adjustment}

One concern for our analysis is that we study many outcomes, and any single statisticallysignificant result could be due to multiple hypothesis testing. In our section on robustness, we address this concern by implementing adjustments on our main downstream outcomes of interest, which are asset ownership and home improvements. Consistent with our preregistered analysis plan, we adjust for multiple testing only within domains of outcomes.

Since we are interested in the effects of the savings scheme on asset ownership outcomes across the last two waves of the survey, we use a conservative approach and conduct adjustments using the set of pre-specified main asset and house improvement outcomes covered in both waves. ${ }^{16}$ Specifically, the full list of variables that we use for the adjustments is as follows: number of assets (PCA index), number of assets purchased since baseline (PCA index), stored building materials (PCA index), house improvements (PCA index), purchased any asset, made any house improvements, improved wall material, started a new house, or installed an iron sheet roof. Each index variable is a weighted average, where the weights are the first principal component of the number of items owned in the control group. We implement multiple-testing adjustment using the Haushofer and Shapiro (2016) implementation of the Anderson (2008) method of controlling the family-wise error rate (FWER).

\footnotetext{
${ }^{15}$ All our choices of control variables are laid out in our pre-specified analysis plans, which are available via our AEA trial registration (Brune, Chyn and Kerwin 2021b): https://www.socialscienceregistry . org/trials/1554.

${ }^{16}$ All these outcomes are measured in both waves, but the adjustments are conducted separately by wave.
} 


\section{$B$ Spillovers}

As in many studies with individual-level randomization, there is concern as to whether there are spillover effects on workers in the control group. A large literature suggests that financial decisions may be subject to peer effects (Duflo and Saez, 2003; Banerjee et al., 2013; Bursztyn et al., 2014). In our setting, this is a potential concern because all workers are employees of the same firm, and they interact socially and financially. To address this issue, we collected social network data prior to assigning workers to treatment. This data allows us to conduct robustness tests that control for peer effects and test for potential spillovers, by following the approach of Kremer and Miguel (2007) and Blumenstock, Callen and Ghani (2018). Specifically, we augment Equation 1 by including terms for a worker's total number of peers and number of treated peers. We define peers as any coworker who was identified by a worker as a friend or someone that they interact with financially. ${ }^{17}$

\section{Impacts of Main Intervention}

\section{A Enrollment, Account Use, and Dropout}

Panel A of Table 1 reports statistics on stated interest and eventual enrollment in the deferred wages scheme. The first and second rows review the statistics that we introduced in Section I. Namely, our project staff met with 1,897 workers during information sessions and found that 65.4 percent of workers were interested in the scheme at this initial point of contact. When we subsequently followed up with these workers, we found that nearly 80 percent agreed to enroll in deferred wages if offered the opportunity. We randomly assigned 50 percent of these interested workers to the treatment group using the approach detailed previously. All workers who were assigned to the treatment group actually followed through and enrolled in the deferred wages scheme. Overall, we estimate that the sign-up rate was 46 percent $(=870 / 1,897)$ for all workers that participated in the information sessions. ${ }^{18}$

\footnotetext{
${ }^{17}$ Appendix $\mathrm{C} 1$ provides further details on the data we collected in the social network survey and how we define peers.

${ }^{18}$ This a conservative estimate of the sign-up rate: there was attrition of 148 workers who had initially expressed interest in deferred payments but could not be found during the data collection for the baseline
} 
Next, we summarize the account choices and usage for the deferred wages treatment group in Panel B of Table 1. The first two rows report the averages for the minimum takehome pay (before any deductions for the scheme) and maximum deferred wages deduction from any given paycheck. As noted in Section I, treated workers chose their own thresholds. On average, workers opted for a minimum take-home pay of MK 8,239 and a maximum deduction of MK 2,832. The amount deducted depended on these parameters as well as a worker's earnings in a given pay period. Table 1 shows that the average earnings and deferred wages deductions for each two-week pay period were MK 14,552 and MK 2,054, respectively.

Figure 3 provides further insight into account use by reporting the distribution of the total savings in the deferred wages scheme at the end of the entire main season (during which there were a total of six deductions). The dashed line on the figure shows that the average balance just before the lump-sum payout was MK 12,092, a sizable amount that equals 82 percent of the average payday for workers in our sample (i.e., two weeks of wages).

The last set of statistics reported in Table 1 show that there was minimal exit and high satisfaction with the program during the main season. During the deduction period, workers could not access their savings except in the case of an emergency (which they had report in person at the division office). Anyone who pursued the emergency option was required to exit the program, and their balance would be paid out at the payday associated with their current pay period (between one and three weeks later). The first row in Panel $\mathrm{C}$ shows that less than three percent of workers exited the scheme early. In line with this low observed exit rate, we also see that few workers expressed a desire to leave the scheme or reduce their savings contributions. The last three rows of Panel $\mathrm{C}$ show the results of an incentivized survey with 50 percent of the treated workers (selected at random) after two deductions had taken place. We asked these workers whether they wanted to exit the scheme or change their contributions; workers were told there was a five percent chance their choice would actually be implemented. Only about four percent of the sampled workers wanted to exit immediately, which is broadly consistent with the rate of actual early exit from the scheme. Approximately 10 percent of workers (including those who wanted to immediately exit) wanted to reduce and social network surveys $(\mathrm{n}=109)$ or did not consent to participate in the study $(\mathrm{n}=39)$. 
their contributions to the scheme. Consistent with most workers being highly satisfied with the savings scheme, 15 percent wanted to increase their contributions.

How do these results compare to prior studies? Broadly speaking, the rates of sign-up and account usage in our sample are relatively high. Karlan, Ratan and Zinman (2014) survey the literature on savings interventions and note that sign-up rates for products with commitment features are often 20 to 30 percent. Rates of sign-up are often higher in studies of interventions that feature basic savings products (e.g., standard bank accounts), but account activity is often low for treated study participants. For example, Dupas et al. (2018) conduct a multi-country study of the impact of reducing fees for bank accounts. They find that 69 and 54 percent of treated households open accounts in Malawi and Uganda, respectively. Only 17 and 10 percent of account holders became active users, defined as having made at least five deposits in the first two years. ${ }^{19}$ In our study, 73 percent of those who enrolled made at least five deposits during the 12-week deduction period.

\section{$B$ Determinants of Enrollment}

Appendix Table A3 provides further details on the correlates of enrollment in the deferred wages scheme. This analysis relies on survey data collected during the short survey that was conducted for all 1,897 workers that we reached through the information sessions. We rely on this data since it is the only source of detailed information for individuals who indicated that they were not interested in enrolling in the scheme. The data includes information on basic demographics, economic status, and measures of savings-related behavior. To analyze determinants of enrollment, we run a linear regression of an indicator for being interested in enrolling in the scheme on each variable in the survey.

\footnotetext{
${ }^{19}$ While many studies find low take-up or little account use, two notable exceptions are work by Dupas and Robinson (2013a) and Prina (2015). Dupas and Robinson (2013a) covered bank account fees and helped people open accounts, finding a take-up rate of 87 percent with 41 percent of people making more than one deposit; average weekly deposits averaged 12 percent of weekly income. Studying a no-fee savings account, Prina (2015) found that 84 percent of those offered took up the account, and 80 percent made more than one deposit. The average weekly amount deposited was about 8 percent of average weekly income among those who were offered the account. Both studies find usage numbers comparable to what we find for the deferred wages scheme. In our study, 46 percent of workers enroll in the scheme; of those who enrolled, 92 percent made more than one deposit, and workers in the scheme saved an average of 14 percent of their wages.
} 
The results reveal two notable findings. First, we find that interest in the program varies with savings goals. Workers who reported that saving to build or improve their house was their main savings goal are eight percentage points more likely to express interest in signing up. The table also shows that home building and improvement is the most popular savings goal in our sample. Second, we also find that self-reported savings challenges are important predictors of interest in the deferred wages scheme. Individuals who find temptation spending to be their biggest challenge are 12 percentage points more likely to enroll in the scheme.

\section{$C$ The Total Amount and Composition of Savings}

The analysis of program participation reveals that the treatment group deposited substantial amounts into their deferred wages accounts. Next, we study how the availability of the scheme affected the total amount of savings as well as its composition. Our analysis is based on savings measures from both administrative data and follow-up surveys collected during the deductions period. To improve precision, we pool observations across the two rounds for flow variables (e.g., whether the worker had any deposits in formal savings accounts in the past 14 days). Stock variables, such as a worker's overall savings balance, were collected in the second follow-up, which took place around the time of the final deduction for the deferred wages scheme (but before the final lump-sum payout in May 2017). One caveat for our analysis of this data is that the surveys may not fully capture all forms of savings because respondents may under-report some forms of savings, such as cash kept at home or by other household members. Previous studies of savings interventions in Malawi have documented under-reporting of savings in survey data (Dupas et al., 2018).

Our main finding is that the deferred wages scheme appears to have had large positive impacts on total reported savings and some composition effects. Table 2 shows estimated effects on savings behavior using the specification from Equation 1. Columns 1-3 examine the extensive margin of saving in the 14 days prior to the survey interviews. In line with the results from the previous section, Column 1 shows that treated workers have a high probability of making a deposit into their deferred wages account. Columns 2 and 3 show that this was paralleled by negative impacts on the use of other types of saving. The scheme 
reduced the likelihood of reporting another type of formal savings deposit by 1.5 percentage points $(p$-value $<0.10)$, a 41 percent decrease relative to the control-group average. For informal financial savings, we see a seven percentage-point (10 percent) reduction. Columns 4-8 show impacts on reported savings balances, which were measured during the second follow-up survey. We find that the deferred wages treatment increased reported total savings by MK 6,816 ( $p$-value < 0.01), a 23 percent increase over the control group average. While total savings appears to have increased, we see partial crowd-out of other forms of reported savings, in particular informal savings, which decreased by MK 3,609 ( $p$-value < 0.10) for the treatment group. ${ }^{20}$

We show evidence on the distributional impact of the deferred wages scheme in Figure 4, which plots the cumulative density functions (CDFs) for total reported savings separately for the treatment and control groups. Notably, we see that the treatment group has higher reported savings throughout most of the distribution, in particular at the bottom end. This suggests that the scheme had impacts on workers who do not normally accumulate savings. Appendix Figure A3 further quantifies the distributional results by reporting quantile treatment effects (QTEs) on total reported savings. The point estimates are statistically significant at the five percent level and similar in magnitude across a wide range of quantiles.

\section{Labor Supply}

Access to the deferred wages savings scheme could have impacts on labor supply outcomes. As noted by Callen et al. (2019), a standard neoclassical model predicts that labor supply will respond to the introduction of better savings options that change the effective interest rate. This is relevant in our context because the demand for the deferred wages scheme, as well as the effects it has on savings, suggest that it represents an improved savings option. If the deferred wages scheme increases the effective return on savings by providing a safer option with lower transaction costs, we might expect labor supply to increase. Similarly, the

\footnotetext{
${ }^{20}$ Appendix Table A4 examines treatment effects on all the subcategories of informal savings. Two results stand out. First, the treatment group reduced their likelihood of making at least one deposit in an informal savings group (Panel A, Column 6; $p$-value $<0.05$ ). Second, treated workers also had lower balances for maize, a form of non-financial, stored food savings (Panel B, Column 10; $p$-value $<0.05$ ). This effect on maize balances drives the effect on total food storage savings (Table 2, Column $8 ; p$-value $<0.05$ ).
} 
commitment aspect of the scheme may reduce the cost of saving specifically for workers with self-control problems. Again, this could lead to an increase in labor supply due to an increase in the effective rate of return on savings. ${ }^{21}$

Table 3 reports estimates of the effects of the deferred wages treatment on work outcomes based on administrative panel data covering the deductions period. We study daily productivity and earned income per two-week pay period. The odd-numbered columns (1, 3, etc.) report estimates based on Equation 1; the even-numbered columns $(2,4$, etc.) report estimates based on an augmented specification that includes interactions between the treatment indicator and indicators for the worker being classified as a plucker or non-plucker based on their work history before the treatment was assigned. This analysis is motivated by the fact that pluckers receive piece-rate earnings, whereas workers employed in non-plucking jobs have fixed daily wages. This implies that only workers employed as pluckers could have adjusted their productivity in response to the treatment. ${ }^{22}$

Column 1 shows that the deferred wages scheme increased productivity on average by $1.6 \mathrm{~kg}(p$-value $<0.05)$. Relative to the control-group average, this represents a 4.9 percent increase. As expected, Column 2 shows that there is a larger impact for pluckers $(1.8 \mathrm{~kg}$, $p$-value $<0.05)$ and no detectable impact for non-pluckers. The results for income earned in Columns 3 and 4 are consistent with the positive impacts on productivity. Specifically, we see that pluckers in the treatment group have MK 342 higher average earnings ( $p$-value $<0.05)$ per two-week pay period in the payroll data. The results in Columns 5-8 show that the impacts on productivity are driven by significant effects on the intensive margin: there are no effects on attendance or on whether the worker plucked any tea. ${ }^{23}$

These findings are in line with the mechanism highlighted above from Callen et al. (2019).

\footnotetext{
${ }^{21}$ As highlighted by Banerjee et al. (2015 $a$ ) in the context of access to credit, improved access to finance might also lead households to increase labor supply, for example in order to purchase durable goods that are otherwise out of reach due to savings or credit constraints.

${ }^{22}$ Approximately 77 percent of workers in the sample are coded as pluckers based on their pre-treatment work history, but non-pluckers are sometimes tasked with plucking tea on a specific work day (and thus earn piece rates on that day). Note that our analysis plan specified that we would examine effects of the deferred wages scheme separately for pluckers and non-pluckers.

${ }^{23}$ Conditional on plucking any tea there are strong effects on the quantity plucked (results available upon request).
} 
Callen et al. experimentally study the impact of providing unbanked households with weekly deposit collection services from a local bank. They find that this treatment had large and statistically-significant positive impacts on formal savings and household income. Consistent with our results, they also find increases in labor supply, in particular for wage work. ${ }^{24}$ Furthermore, Callen et al. (2019) also find that treatment effects on income and labor supply are immediate in their sample. Appendix Figure A1 shows that we find the same pattern: the treatment appears to affect productivity even in the initial weeks of deductions.

Finally, it is worth noting that our findings do not align with the results from Kaur et al. (2020)'s study of financial strain and worker productivity. They find that early payment increases the productivity of skilled workers and show that this effect is due to improved attentiveness. Why does delaying a sizable fraction of pay for treated workers in our sample not generate negative impacts on productivity? Potential explanations stem from two differences in study contexts. First, Kaur et al. (2020) conduct their intervention during the lean season and document high levels of financial worry for their sample. Second, they study the impact of financial strain for workers who perform cognitively-demanding tasks. Our study differs in both these dimensions since we study productivity during the main season (when there is relatively high income) and focus on a sample of workers who perform tasks that use physical rather than cognitive skills. ${ }^{25}$

\section{E Expenditures During the Deduction Period}

Table 4 reports results from our analysis of expenditures during the deduction period (from late January through mid-April 2017). The first two follow-up surveys collected measures of total expenditures and categories of expenditures during the 14 days prior to the

\footnotetext{
${ }^{24}$ Dupas and Robinson (2013a) also study the relationship between savings options and labor supply. They estimate the impact of providing a non-interest-bearing account to self-employed workers in Kenya. They find economically-meaningful impacts on incomes, but their estimates are not statistically significant.

${ }^{25}$ An additional point of interest concerns payday effects. Kaur, Kremer and Mullainathan (2015) study productivity for piece-rate workers who work for seven days and receive payment on the final day of the pay period during the evening. They find that workers are least productive on days early in their pay period, and production rises through the pay cycle. We analyze productivity over the two-week pay period and find no evidence of payday effects in our context. One notable difference between the contexts of the two studies is that paydays in our study occur seven days after the final work day in a two-week pay period, whereas workers in Kaur, Kremer and Mullainathan are paid immediately at the end of the pay period.
} 
interview. We also collected information on bulk purchases within the past 30 days. To increase precision, our analysis pools observations from both survey waves.

The results show that the estimated effects on expenditures are never statistically significant. However, the confidence intervals are sufficiently wide that we cannot rule out effects that are large enough to be economically important. For example, Column 1 shows that the 95-percent confidence interval for the impact on total expenditures ranges from a decrease of MK 1,343 (7.1 percent relative to the control-group average) up to an increase of MK 1,965 (10.4 percent). As such, we can only confidently rule relatively large negative effects on expenditures. Similar points apply to the results for detailed expenditure categories (Column 2-6) and the measures of bulk purchases during the past 30 days (Columns 7 and 8).

How should we interpret these results? Given the positive and statistically-significant impacts on total reported savings, it is natural to expect that the deferred wages treatment would reduce expenditures during the deductions period. The point estimates for the expenditure categories in Table 4 run counter to this in that they are consistently positive, although small in magnitude. There are two points to consider for understanding these results. First, the point estimates for the labor supply effects documented above can provide a partial explanation of the lack of a statistically-significant decline in spending. Using the estimates from Table 3, we calculate that increased productivity over the entire deduction period for the treatment group generated an additional MK 1,326 (= six pay periods $\times$ MK 221 per pay period). This amount is 20 percent of the estimated MK 6,816 increase in reported savings (Table 2, Column 4) for the treatment group. Second, the remainder of the impact on savings is sufficiently small that it could be entirely accounted for by a decline in expenditures that is within the confidence interval in Table 4. Specifically, our estimates suggest that the increase in savings net of labor supply effects is equal to MK 5,490 (=MK 6,816 - MK 1,326). To account for this solely through a reduction in expenditures implies that we should see a reduction of MK 915 in expenditures every two weeks. This amount is smaller in magnitude than the negative MK 1,343 lower bound of the 95-percent confidence interval for total expenditures. ${ }^{26}$ The confidence intervals on the expenditure estimates are

\footnotetext{
${ }^{26} \mathrm{An}$ additional explanation could be that members of the treatment group avoided reductions in expen-
} 
wider than we anticipated ex ante, and mean the study is underpowered to detect plausible magnitudes of the effect of the treatment on expenditures. Our minimum detectable effect size at 80 percent power for changes in total expenditures is 2.8 times the standard error (Ioannidis, Stanley and Doucouliagos, 2017), which is $2.8 \times 844=\mathrm{MK} 2,363$. The total increase in reported savings due to the deferred wages scheme is MK 6,816 (Table 2, Column 4), or is MK 1,136 per two-week period. We are thus only powered to detect effects on expenditures that are twice as large as what we would expect based on the estimated changes in savings.

\section{F Expenditures After Payout}

Next, we consider impacts on expenditures after treated workers received the lumpsum payout of their savings. We anticipated that most spending would occur shortly after the payout and began collecting surveys almost immediately after the payment in May 2017. To improve the precision of flow measures and focus respondent attention on the post-disbursement period, we varied the recall period based on the timing of the survey. Specifically, for surveys collected within the first 14 days of the lump-sum payout, the recall period covered the time from the payout until the day of the survey; this recall period ranged from four to 14 days, with a median of seven and an average of 8.4. For surveys after the first 14 days following the lump-sum payout, we used a 14-day recall window, which is consistent with what we had used in the preceding rounds and matches the two-week pay periods at Lujeri. As noted in Section II, we partially randomized the order of surveying to balance the characteristics of respondents surveyed earlier and later. Given that the recall window changes for individuals surveyed during the first 14 days and afterward, we conduct separate analyses for those interviewed within 14 days of the lump-sum payout and for those interviewed afterward.

Panel A of Table 5 begins with results for total expenditures for the sample of respondents interviewed within the first 14 days following the lump-sum payout. Column 1 shows that

ditures by taking on more loans or transfers. However, supplementary analyses show no detectable impacts on these additional sources of income. These results can be provided on request. 
the deferred wages treatment increased total expenditures by MK 5,787 ( $p$-value < 0.01), a 36 percent increase relative to the control-group average. ${ }^{27}$ This impact is driven by large and statistically-significant positive impacts on expenditures in major categories such as food (column 2) and durables (column 5). The impacts on food spending are driven by a MK 2,404 increase in maize purchases. This is a notable finding given that maize prices are typically low at the end of the main tea season. ${ }^{28}$ Columns 7 and 8 show that we find large and statistically-significant effects on the incidence and sum of spending on bulk purchases (single purchases that amount to more than MK 5,000). Panel B reports effects for the sample of respondents interviewed after the first 14 days after payout. The point estimate indicates that total expenditures declined by MK 772 for the treatment group, but this result is not statistically significant. We also find no detectable impacts on the categories of expenditures or large purchase measures. Appendix Table A6 provides an alternative analysis of treatment effects after the lump-sum payout. Specifically, we estimate impacts separately for each week. In this analysis, we estimate effects on daily spending instead of total expenditures within a recall window. The results yield very similar patterns to Table 5.

In sum, this analysis yields two main findings. First, the results suggest that workers spent a large portion of their saved funds within the first 14 days after receiving the lumpsum payout. Specifically, the MK 5,787 effect on total expenditures within the first 14 days after the payout is equal to 85 percent of the estimated impact on total reported savings (Table 3, Column 4). The remainder of the reported savings do not appear to be spent after the first 14 days, although our power to detect effects on expenditures during this period is limited. Second, expenditures increase substantially for bulk purchases and durables that require lump sums. This result is consistent with the hypothesis that the deferred wages scheme addresses savings constraints.

\footnotetext{
${ }^{27}$ Appendix Table A5 shows that the treatment group also had a higher rate of saving, more net money loaned, and more net transfers made, but only the effect on net money loaned is statistically significant $(p$-value $<0.05)$.

${ }^{28}$ Maize is harvested in April and May, causing prices to fall. Our survey data shows that maize prices fell by 65 percent between February and May 2017.
} 


\section{G Long-Run Outcomes}

The evidence so far shows that the deferred wages treatment shaped savings behavior during the main deduction period and had large impacts on expenditures in the period immediately following payout of the lump sum. Our last analysis of the main intervention considers whether this translated into impacts on downstream outcomes. We rely on outcomes measured in the fourth and fifth follow-up surveys. These surveys were collected four months and a little less than two years after the payout of the main intervention, respectively.

Our analysis of assets is motivated by the fact that, at baseline, a substantial fraction of our sample had asset-related purchases as saving goals. Appendix Table A3 shows that the most common self-reported savings goals was improving or building a house (34 percent), and purchasing a household asset (12 percent) was also a popular goal. Table 6 reports results for assets. Columns 1-4 show impacts measured four months after the payout (i.e., the "medium run" period). The outcome in Column 1 is a PCA index of the number of assets owned in 54 durable asset and seven livestock categories, which is one of the main outcomes in our pre-registered analysis plan. The point estimate shows that the deferred wages scheme increased the index of assets by 0.164 standard deviations $(p$-value $<0.01) .{ }^{29}$ Column 2 reports impacts on the total value of assets for ease of interpretation. We find that there was an MK 11,362 ( $p$-value < 0.05) increase in the value of assets in the medium run. Column 3 indicates that this overall effect is driven by a MK 7,425 increase in stored building materials $(p$-value $<0.01)$, which accounts for 65 percent of the effect on total assets. In line with the pre-intervention survey responses on savings goals, Column 4 shows that there are large treatment effects on iron sheets, a key building material for homes.

To expand on these results, we explore the distributional impacts of the deferred wages scheme on the total value of reported assets four months after the payout. Figure 5 plots the CDFs of assets separately for the treatment and control groups, while Appendix Figure A5

\footnotetext{
${ }^{29}$ Our pre-registered plan also specified analysis of assets purchased since baseline. Column 2 of Appendix Table A7 shows that we find no detectable impacts on asset purchases. We include this outcome in the set of variables that we use for multiple hypothesis testing adjustment, as detailed in the section on robustness checks.
} 
presents estimated QTEs. These results show that the treatment group appears to have more assets throughout the distribution. The point estimates for the quantile treatment effects are consistently positive and range from about MK 5,000 to roughly MK 13,000.

Columns 5-7 of Table 6 provide results for outcomes measured in the fifth follow-up survey, just under two years after the main intervention - the longest-run data that we collected. The treatment group had been offered the deferred wages scheme two more times prior to the fifth follow-up survey, with roughly 80 percent signing up; the last of these schemes ended about nine months before the fifth follow-up survey. Column 7 shows that treated workers are 7.7 percentage points $(p$-value $<0.01)$ more likely to report that they have an improved type of roofing (iron sheets). To validate this result and obtain information about survey measurement error, we physically verified the roofing material for 74 percent of respondents during the fifth follow-up survey. We find that the field staff verification results match the survey responses for 95 percent of cases. ${ }^{30}$ The effect on improved roofing is a 9 percent increase relative to the control-group average. This impact on home improvements is in line with the pattern of results from the four month follow-up survey. Table 6 and Appendix Table A7 show that there are no detectable sustained impacts on any other type of asset in the long run.

Overall, we conclude that the deferred wages scheme appears to have had strong impacts on assets. Downstream effects on assets are fairly rare in the literature on savings interventions. Many interventions to increase savings have no effects on any other financial outcome (Dupas et al., 2018). To the best of our knowledge, there are only two prior studies that show effects on assets. Dupas and Robinson (2013a) find that access to savings accounts has impacts on business investments, but there are no detectable effects on household asset ownership. Schaner (2018) finds that short-term interest rate subsidies for bank accounts lead to short-run increases in savings and long-run increases in assets.

\footnotetext{
${ }^{30}$ The measurement error we find is both symmetrical in direction and orthogonal to treatment status, which suggests high reliability for the other stock variables measured in our surveys as well.
} 


\section{$H$ Robustness Checks}

In this section, we conduct three exercises to examine the robustness of our results. First, we address concerns over multiple hypothesis testing by calculating adjusted $p$-values using the Haushofer and Shapiro (2016) approach to FWER correction. Table 6 reports adjusted $p$-values taking into account all outcomes in Columns 1-7. Our main findings are generally robust, as nearly all outcomes that had statistically-significant naïve $p$-values are also significant at the ten percent level or lower after FWER adjustment. The only exception is the result for the value of assets owned (column 2) where the adjusted $p$-value equals 0.124. Appendix Table A7 goes further with the FWER adjustment by using a larger set of nine asset outcomes from the fourth and fifth follow-up surveys, as discussed in Section III. We find that, using this approach, the impact on the PCA index of the number of assets owned is still significant at the 10 percent level $(p$-value $=0.07$ ). The long-run effect on improved roofing is also robust to correcting for multiple testing $(p$-value $=0.041)$. Overall, these findings provide reassurance that the effects we detect on assets are not spurious.

Second, we test for spillovers between workers in the treatment and control groups. Appendix Table A8 presents results based on an augmented version of Equation 1 that includes terms for a worker's total number of peers and the number of treated peers, following Kremer and Miguel (2007). Appendix Table A9 presents the same specification for the extended set of assets shown in Appendix Table A7. We see little evidence of peer effects for these outcomes; the point estimates are generally small in magnitude and statistically insignificant. ${ }^{31}$ Critically, the estimates for the treatment group indicators are nearly unchanged for all outcomes, suggesting that our estimates of the effect of the savings scheme on asset ownership are not biased by spillovers.

Finally, our third robustness check is to adjust the treatment effect estimates for both potential spillovers and multiple hypothesis testing at the same time. Our approach here parallels the two approaches to multiple testing adjustments presented in Table 6. First,

\footnotetext{
${ }^{31}$ The two exceptions are in the extended set of assets shown in Appendix Table A9. There is evidence of negative spillovers on making any improvements to one's house in the short run (Panel A, Column 6) and positive spillovers on buying any asset in the long run (Panel B, Column 5).
} 
Appendix Table A8 reports adjustments for all outcomes within the table. These within-table FWER-adjusted $p$-values are still statistically significant for the number of assets owned $(p$-value $<0.05)$ and stored building materials $(p$-value $<0.05)$. For the effect on metal roofing, the FWER-adjusted $p$-value is higher than the naïve $p$-value, but remains statistically significant at the ten percent level $(p$-value $=0.056)$. Second, Appendix Table A8 also reports adjustments for the extended set of assets shown in Appendix Table A9. These extended FWER adjustments leave the effects on both the asset ownership index $(p$-value $<0.10)$ and metal roofing $(p$-value $<0.05)$ statistically significant at conventional levels.

\section{Explaining Take-up and Account Usage}

As noted above, we find relatively high rates of program enrollment and account usage when comparing our evaluation of the deferred wages scheme to prior studies of savings products. This section reports results from several analyses that further explore determinants of enrollment and utilization.

\section{A Re-enrollment, Mistakes, and Seasonality}

Mistakes may be one reason why we observe relatively high rates of participation in the deferred wages scheme. Prior research has found that some individuals make mistakes when signing up for products with commitment features (Bai et al., 2020; John, 2019). In addition,

seasonality and consumption smoothing is another potential reason that we might observe demand for deferred wages. That is, workers may seek to use the lump sum payout in May to help smooth consumption between the main season for tea and the off-season. Two factors make this a particularly relevant consideration in our setting. First, Fink, Jack and Masiye (2020) find high demand for credit during the lean season in Zambia, which neighbors Malawi. Second, the end of the main tea season (and thus the arrival of the deferred wages payout) coincides with the maize harvest, when maize prices are lowest. Workers may want to use their deferred wages for strategically-timed maize purchases; we do observe large increase in spending on maize just after the payout (Table 5, Column 4).

To explore the role of mistakes and seasonality in driving demand for the deferred wages 
scheme, we offered the treatment group the chance to re-enroll in the savings scheme two additional times: once during the ensuing off-season (from October to December 2017) and once during the next main season (from February to April 2018). Prior studies have similarly studied repeat enrollment to test for the possibility that mistakes drive take-up of commitment devices (e.g., Schilbach 2019). We offered the opportunity to sign up for the deferred wages scheme for the off-season and the next main season during the interviews for the fourth follow-up survey in September 2017. Interested workers were re-enrolled on the spot.

The results from this re-enrollment exercise provide no evidence that mistakes drive decisions in our setting. Appendix Table A10 reports the sign-up rate for the off-season and next main season savings schemes. Column 2 shows that 81 and 78 percent of the treatment group opted into the scheme for the off-season and the next main season respectively. The similarity in the sign-up rates also strongly rules out that seasonality plays a role in driving the demand for the deferred wages scheme. We fail to reject the hypothesis that the sign-up rates for the off-season and the next main season are equal ( $p$-value $=0.18)$.

\section{B Automatic versus Manual Deposits}

One potential explanation for the high enrollment in and use of the deferred wages scheme is that workers value having a savings product that features automatic deposits. In the main intervention, workers make an allocation decision once, and funds are automatically deducted each pay period. This feature could help workers meet savings goals by lowering transaction costs, addressing behavioral biases that constrain saving behavior, or reducing social pressure to share income with one's friends and family.

To explore the importance of automatic deposits, we conducted a supplementary experiment in February 2018 (after the main intervention). As previewed in Section I, this analysis was conducted with a sample of 186 workers who were not part of the earlier study. We randomly divided this new sample of workers into two groups. The first group received offers to participate in the original version of the deferred wages scheme. The second group received offers for a version of the deferred wages scheme that required participants to make manual 
deposits with a member of our research staff. The location for these manual deposits was easy to reach: workers could make deposits at a station next to the division office, which is the location where they already went on paydays to pick up their wages.

Our goal in this section is to estimate the impact of the manual deposit feature on savings behavior. We do this using the following specification:

$$
y_{i}=\pi+\tau \text { Manual }_{i}+\xi_{i}
$$

where $y_{i}$ is an outcome such as enrollment or account usage. The variable Manual $_{i}$ is equal to one if worker $i$ received the offer to join the manual deposit version of the deferred wages scheme and zero otherwise. The omitted group in our specification received offers to sign up for the original version of the deferred wages scheme (which featured automatic deposits). Our parameter of interest is $\tau$, which is the causal effect of offering the deferred wages scheme with the manual deposit feature on take-up and account usage outcomes (e.g., total savings balances). Random assignment in our experiment ensures that assignment to the group receiving manual offers is uncorrelated with the error term $\xi_{i}$ in expectation. ${ }^{32}$

Panel A of Table 7 reports estimates of the impact of the manual feature on enrollment and account usage, based on Equation 2. Column 1 shows that when we approached workers, those assigned to the manual deposits treatment group were not detectably less likely to express interest in enrolling than those assigned to receive offers for the original deferred wages scheme. However, we find that the manual treatment reduced the likelihood of making at least one deposit by 30.3 percentage points ( $p$-value $<0.01$, Column 2 ). Relative to the control group, which was offered the standard deferred wages scheme, this is a 60 percent decrease. Columns 3 and 4 show that manual deposit offers also led to reductions in the number of deposits by 1.9 ( $p$-value $<0.01)$ and the account balance by MK 3,516 ( $p$-value $<0.05)$.

\footnotetext{
${ }^{32}$ To provide evidence for our identifying assumption, we regress the indicator for receiving a manual deposit offer on fixed demographic characteristics (survey-based measures of the respondent's age, sex, marital status, and literacy status). The sample is well balanced: we are unable to reject the null hypothesis that the coefficients on these characteristics are jointly zero $(p$-value $=0.75)$.
} 
In light of these results demonstrating the importance of the automatic deposit feature, we turn to analyzing potential mechanisms for this result. As mentioned above, it is possible that demand in our context is driven by workers who face savings constraints in the form self-control issues or kin taxes. To test this hypothesis, Panel B of Table 7 reports estimates of heterogeneity in the effects of the manual deposit feature using an augmented version of Equation 2. Specifically, we include interactions between the indicator for a manual deposit offer with measures of whether the respondent reported having self-control problems, faced kin taxes, or had a formal savings account. ${ }^{33}$ We created three indicators for self-control problems based on a survey question with three answer choices about the frequency with which respondents regret past consumption choices. Similarly, we create a proxy for low, medium, or high levels of kin taxes based on responses to a set of three questions about whether the respondent would prefer to be receive a transfer privately or a higher amount publicly. This survey question is motivated by evidence that publicly-received money is more likely to be taxed by kin (Goldberg, 2017) and that people are willing to forgo part of their earnings in order to hide money from kin (Jakiela and Ozier, 2016). We specify the interaction terms such that the omitted group in the augmented model is the set of workers who have the lowest self-reported self-control, face high kin taxes, and do not have formal savings accounts.

The results in Panel B provide some evidence that the manual deposit feature has heterogeneous impacts in our sample. The main effect estimates in Column 1-4 show that workers in the manual deposit group who have the lowest measured self-control and face high kin taxes are 40 percentage points less likely to make at least one deposit $(p$-value $<0.05)$, make 2.6 fewer total deposits ( $p$-value $<0.01$ ), and have lower total savings balances by MK 8,215 $(p$-value $<0.05)$. While the interaction terms are imprecisely estimated on the extensive margin of making any deposits, we do find detectable effects on the number of deposits and on final balances. Columns 3 and 4 show that the manual deposit feature has a significantly

\footnotetext{
${ }^{33}$ Appendix $\mathrm{C}$ reproduces the exact text of the questions that we used to create proxy measures of selfcontrol problems (Appendix C2) and kin taxes (Appendix C3), along with the available answer choices and the frequencies of each response.
} 
less negative impact for workers with high self-control. For high self-control workers, the implied effect (based on the main effect and interaction term) is a small reduction in balances of MK 423 that is not statistically different from zero $(p$-value $=0.93)$. The estimates of the interaction terms that include proxies for kin taxes are never statistically significant and are relatively imprecisely estimated.

Overall, the results in this section lead us to two conclusions. First, the evidence is consistent with the hypothesis that automatic deposits are important to workers because this feature helps mitigate self-control problems. Workers in the two treatment arms expressed similar levels of interest, but the manual deposit group had difficulty building up savings, particularly if the worker reported having self-control issues. In this way, our results align with findings from Casaburi and Macchiavello (2019) that show individuals who have issues with self-control demand deferred payments. Second, there is suggestive evidence that the scheme is beneficial for workers beyond solving self-control problems. The sign-up rate for the original version of the scheme is fairly high (about 41 percent) for people who report no self-control problems. This would not be the case if self-control issues were the only reason people were interested in deferred wages. One plausible alternative reason people may be interested in deferred wages is a lack of alternative safe places to save.

An important caveat to this analysis of treatment effect heterogeneity is that we rely on proxies for kin taxes and self-control problems that are likely subject to substantial measurement error. Classical measurement error would attenuate the associated coefficients in our regression analyses, which might mean that kin taxes matter more than the estimated pattern of heterogeneity indicates. Misclassification could also mean that we underrate the importance of self-control problems. In particular, we note that a substantial fraction of people with high reported self-control sign up for the original deferred wages scheme. If selfcontrol is mismeasured, many of these apparently high self-control workers may actually have self-control issues. The results should also be interpreted cautiously given that we examine a number of outcomes and hypotheses in the heterogeneity analysis. 


\section{Preferences Over Payout and Access}

In addition to automatic deposits, the lump-sum payout and restricted access features of the original scheme may be particularly attractive to workers. To study the importance of these two features, we conducted an additional choice experiment in February 2018 (after

the main intervention). We recruited a new sample of 542 workers who were neither part of the earlier study nor part of the experiment to study the importance of automatic versus manual deposits.

In this experiment, all sampled workers received an overview of the original deferred wages product and two modified versions. The first modified version had a "smooth payout" feature: workers would receive six payments in two-week intervals after the end of the deduction period. The second modified version provided "more access": workers could withdraw accumulated funds at any point during the deduction period.

To study preferences over payout smoothness and ease of access, we randomly divided our sample into three groups that answered hypothetical enrollment questions. The first group was asked whether they would want to enroll in the original version of the deferred wages scheme. The second and third groups were asked whether they wanted to enroll in one of the two modified versions, respectively. We incentivized responses by informing workers that one randomly-selected worker from each division of the company would have their choice implemented.

Our goal in this section is to estimate the causal impact of the smooth-payout and moreaccess features on the enrollment decisions. To do this, we estimate the following specification:

$$
y_{i}=\rho+\sigma \text { SmoothPayouts }_{i}+\psi \text { MoreAccess }_{i}+\omega_{i}
$$

where $y_{i}$ is an indicator equal to one if respondent $i$ wanted to enroll in the deferred wages scheme that was offered to them in this incentivized-choice survey question. The variables SmoothPayouts $_{i}$ and MoreAccess $s_{i}$ are indicators equal to one if their question featured the smooth payout or more access versions of the deferred wages schemes. The omitted group 
is respondents who were asked about the original version. Our main parameters of interest are $\sigma$ and $\psi$, which are the causal effects on enrollment of offering deferred wages schemes with smooth payouts or more access. Random assignment in our experiment ensures that assignment to the group receiving smooth or more access questions is uncorrelated with the error term $\omega_{i}$ in expectation. ${ }^{34}$

Appendix Table A11 reports estimates from Equation 3. The control-group average shows that 55.9 percent of workers were interested in enrolling in the original version of the scheme, which is comparable to the sign-up rate that we observed for our main intervention. The estimate in the second row indicates that workers who received the smooth payout offer were about 20 percentage points less likely (a 35 percent decrease; $p$-value $<0.01$ ) to express interest in enrolling. The estimate in the third row suggests that the more access feature reduces enrollment by 4 percentage points, but this result is not statistically significant.

There are two main findings from these results. First, the evidence suggests that workers value the lump-sum payout in the original deferred wages scheme. An important caveat for this interpretation is that our evidence is based on a specific form of payout. We did not test other alternatives such as providing the ability to draw down the funds at any time. Second, the evidence implies that rigid restrictions on access do not meaningfully affect interest in enrolling. However, this does not rule out that workers value the commitment feature of deferred wages. The more access version of the scheme still involved substantial commitment, since funds could not be accessed for one to three weeks (until the payday associated with their current pay period).

\section{Conclusion}

Large shares of the population in developing countries face barriers to saving income. Market frictions hinder the supply of formal financial products, and nearly half of adults in

\footnotetext{
${ }^{34}$ To provide evidence on our identifying assumption, we regress the indicator for receiving the question on the original deferred wages scheme on fixed demographic characteristics (survey-based measures of the respondent's age, marital status, sex and literacy status). The sample is well balanced: we are unable to reject the null hypothesis that the coefficients on these characteristics are jointly zero ( $p$-value $=0.23)$. We observe similar balance in tests where the dependent variables are indicators for receiving the questions featuring smooth payout and more access versions of deferred wages, respectively.
} 
developing countries do not have access to an account at a bank or another formal financial institution (Demirgüç-Kunt et al., 2015). In addition, the ability to save could be depressed by demand-side constraints such as time-inconsistency and social pressure to share income.

This paper provides evidence that deferred payments can be a popular and effective savings device. Partnering with a tea firm in Malawi, we find that nearly half of workers would enroll in a simple savings scheme that allowed workers to defer a fraction of their pay for three months at zero interest. Figure 6 summarizes the main findings from our experimental evaluation of the scheme. Most notably, we find that the deferred wages scheme generates large positive impacts on reported savings and has impacts on downstream outcomes. In line with savings goals elicited prior to our intervention, we find that treatment-group workers were more likely to have made durable investments in their homes two years after the initial round of the scheme and nine months after the last round of the scheme.

These findings have implications for our understanding of savings behavior. Rationalizing the popularity of deferred wages requires modifying neoclassical models of intertemporal choice, potentially by introducing behavioral constraints and storage costs. Our supplementary experiments provide suggestive evidence for the importance of both factors. Requiring manual (rather than automatic) deposits reduces follow-through, particularly among workers who report having self-control problems. This result is consistent with previous studies that show products with commitment features can have important impacts (Ashraf, Karlan and Yin, 2006; Giné, Karlan and Zinman, 2010; Duflo, Kremer and Robinson, 2011; Dupas and Robinson, 2013b; Karlan and Linden, 2014; Brune et al., 2016; Kaur, Kremer and Mullainathan, 2015; Schilbach, 2019; Casaburi and Macchiavello, 2019). At the same time, the evidence also suggests that workers might value deferred payments for reasons other than self control. Workers without apparent self-control problems still sign up for the original, automatic-deposits scheme at high rates, which would not happen if demand came solely from self-control issues. ${ }^{35}$ A plausible alternative reason they might want to use the deferred wages scheme is that they need a safe place to store money.

\footnotetext{
${ }^{35} \mathrm{An}$ important caveat for this interpretation is that measurement error in our proxy for self-control could also explain this result.
} 
We conclude with the observation that further research is necessary to understand the benefits of deferred payments in other settings. This paper demonstrates that an employerbased deferred payment scheme can generate notable benefits for workers. An important feature of our study is that we study a sample of individuals who had relatively limited formal savings options prior to our intervention. It is an open question whether deferred payment schemes would be popular or effective in contexts where individuals can access other low-cost or high-quality savings products. 


\section{References}

Anderson, Michael L. 2008. "Multiple Inference and Gender Differences in the Effects of Early Intervention: A Reevaluation of the Abecedarian, Perry Preschool, and Early Training Projects." Journal of the American Statistical Association, 103(484): 1481-1495.

Ashraf, Nava, Dean Karlan, and Wesley Yin. 2006. "Tying Odysseus to the Mast: Evidence from a Commitment Savings Product in the Philippines." Quarterly Journal of Economics, 121(2): 635-672.

Ashraf, Nava, James Berry, and Jesse M Shapiro. 2010. "Can Higher Prices Stimulate Product Use? Evidence from a Field Experiment in Zambia." American Economic Review, 100(5): 2383-2413.

Bai, Liang, Benjamin Handel, Edward Miguel, and Gautam Rao. 2020. "SelfControl and Demand for Preventive Health: Evidence from Hypertension in India." Review of Economics and Statistics, forthcoming.

Banerjee, Abhijit, Arun G. Chandrasekhar, Esther Duflo, and Matthew O. Jackson. 2013. "The Diffusion of Microfinance." Science, 341(6144).

Banerjee, Abhijit, Esther Duflo, Rachel Glennerster, and Cynthia Kinnan. 2015a. "The Miracle of Microfinance? Evidence from a Randomized Evaluation." American Economic Journal: Applied Economics, 7(1): 22-53.

Banerjee, A., E. Duflo, N. Goldberg, D. Karlan, R. Osei, W. Pariente, J. Shapiro, B. Thuysbaert, and C. Udry. 2015b. "A multifaceted program causes lasting progress for the very poor: Evidence from six countries." Science, 348(6236): 1260799-1260799.

Behrman, Jere R., Susan W. Parker, Petra E. Todd, and Kenneth I. Wolpin. 2015. "Aligning Learning Incentives of Students and Teachers: Results from a Social Experiment in Mexican High Schools." Journal of Political Economy, 123(2): 325-364.

Beshears, John, James J Choi, Christopher Harris, David Laibson, Brigitte C Madrian, and Jung Sakong. 2015. "Self Control and Commitment: Can Decreasing the Liquidity of a Savings Account Increase Deposits?" National Bureau of Economic Research Working Paper 21474.

Blumenstock, Joshua, Michael Callen, and Tarek Ghani. 2018. "Why Do Defaults Affect Behavior? Experimental Evidence from Afghanistan." American Economic Review, 108(10): 2868-2901.

Breza, Emily, Martin Kanz, and Leora F. Klapper. 2020. "Learning to Navigate a New Financial Technology: Evidence from Payroll Accounts." National Bureau of Economic Research Working Paper 28249. 
Brownback, Andy, and Sally Sadoff. 2020. "Improving College Instruction through Incentives." Journal of Political Economy, 128(8): 48.

Bruhn, Miriam, and David McKenzie. 2009. "In Pursuit of Balance: Randomization in Practice in Development Field Experiments." American Economic Journal: Applied Economics, 1(4): 200-232.

Brune, Lasse, and Jason T. Kerwin. 2019. "Income timing and liquidity constraints: Evidence from a randomized field experiment." Journal of Development Economics, 138: 294308.

Brune, Lasse, Eric Chyn, and Jason Kerwin. 2021a. "Data and code for: Pay Me Later: Savings Constraints and the Demand for Deferred Payments." Nashville, TN: American Economic Association [publisher], Ann Arbor, MI: Inter-university Consortium for Political and Social Research [distributor]. https://doi.org/10.3886/E130367V1.

Brune, Lasse, Eric Chyn, and Jason Kerwin. 2021b. "Deferred Wages and Savings Constraints." AEA RCT Registry. March 10. https://doi.org/10.1257/rct.1554-16.0.

Brune, Lasse, Xavier Giné, Jessica Goldberg, and Dean Yang. 2016. "Facilitating Savings for Agriculture: Field Experimental Evidence from Malawi." Economic Development and Cultural Change, 64(2): 187-220.

Brune, Lasse, Xavier Giné, Jessica Goldberg, and Dean Yang. 2017. "Savings defaults and payment delays for cash transfers: Field experimental evidence from Malawi." Journal of Development Economics, 129: 1-13.

Bryan, Gharad, Dean Karlan, and Scott Nelson. 2010. "Commitment Devices." $A n$ nual Review of Economics, 2(1): 671-698.

Bursztyn, Leonardo, Florian Ederer, Bruno Ferman, and Noam Yuchtman. 2014. "Understanding Mechanisms Underlying Peer Effects: Evidence From a Field Experiment on Financial Decisions." Econometrica, 82(4): 1273-1301.

Callen, Michael, Suresh de Mel, Craig McIntosh, and Christopher Woodruff. 2019. "What Are the Headwaters of Formal Savings? Experimental Evidence from Sri Lanka." Review of Economic Studies, 86(6): 2491-2529.

Carvalho, Leandro S., Stephan Meier, and Stephanie W. Wang. 2016. "Poverty and Economic Decision-Making: Evidence from Changes in Financial Resources at Payday." American Economic Review, 106(2): 260-284.

Casaburi, Lorenzo, and Rocco Macchiavello. 2019. "Demand and Supply of Infrequent Payments as a Commitment Device: Evidence from Kenya." American Economic Review, 109(2): 523-555. 
Chetty, Raj. 2015. "Behavioral Economics and Public Policy: A Pragmatic Perspective." American Economic Review, 105(5): 1-33.

Collins, Daryl, Jonathan Morduch, Stuart Rutherford, and Orlanda Ruthven. 2009. Portfolios of the Poor: How the World's Poor Live on \$2 a Day. Princeton University Press.

DellaVigna, Stefano. 2018. "Structural Behavioral Economics." In Handbook of Behavioral Economics: Applications and Foundations 1. Vol. 1, 613-723. Elsevier.

Demirgüç-Kunt, Asli, Leora F. Klapper, Dorothe Singer, and Peter Van Oudheusden. 2015. "The Global Findex Database 2014: Measuring Financial Inclusion Around the World." Social Science Research Network Scholarly Paper 2594973.

Duflo, Esther, and Emmanuel Saez. 2003. "The Role of Information and Social Interactions in Retirement Plan Decisions: Evidence from a Randomized Experiment." Quarterly Journal of Economics, 118(3): 815-842.

Duflo, Esther, Michael Kremer, and Jonathan Robinson. 2011. "Nudging Farmers to Use Fertilizer: Theory and Experimental Evidence from Kenya." American Economic Review, 101(6): 2350-2390.

Dupas, Pascaline, and Jonathan Robinson. 2013a. "Savings Constraints and Microenterprise Development: Evidence from a Field Experiment in Kenya." American Economic Journal: Applied Economics, 5(1): 163-192.

Dupas, Pascaline, and Jonathan Robinson. 2013b. "Why Don't the Poor Save More? Evidence from Health Savings Experiments." American Economic Review, 103(4): 11381171.

Dupas, Pascaline, Dean Karlan, Jonathan Robinson, and Diego Ubfal. 2018. "Banking the Unbanked? Evidence from Three Countries." American Economic Journal: Applied Economics, 10(2): 257-297.

Dupas, Pascaline, Sarah Green, Anthony Keats, and Jonathan Robinson. 2016. "Challenges in Banking the Rural Poor: Evidence from Kenya's Western Province." In African Successes, Volume III: Modernization and Development. Chicago and London:University of Chicago Press.

Fink, Günther, B. Kelsey Jack, and Felix Masiye. 2020. "Seasonal Liquidity, Rural Labor Markets, and Agricultural Production." American Economic Review, 110(11): 33513392.

Fryer, Roland G. 2011. "Financial Incentives and Student Achievement: Evidence from Randomized Trials." Quarterly Journal of Economics, 126(4): 1755-1798. 
Giné, Xavier, Dean Karlan, and Jonathan Zinman. 2010. "Put Your Money Where Your Butt Is: A Commitment Contract for Smoking Cessation." American Economic Journal: Applied Economics, 2(4): 213-235.

Goldberg, Jessica. 2017. "The Effect of Social Pressure on Expenditures in Malawi." Journal of Economic Behavior \& Organization, 143: 173-185.

Haushofer, Johannes, and Jeremy Shapiro. 2016. "The Short-term Impact of Unconditional Cash Transfers to the Poor: Experimental Evidence from Kenya." Quarterly Journal of Economics, 131(4): 1973-2042.

Ioannidis, John P. A., T. D. Stanley, and Hristos Doucouliagos. 2017. "The Power of Bias in Economics Research." The Economic Journal, 127(605): F236-F265.

Jakiela, Pamela, and Owen Ozier. 2016. "Does Africa Need a Rotten Kin Theorem? Experimental Evidence from Village Economies." Review of Economic Studies, 83(1): 231268.

John, Anett. 2019. "When Commitment Fails: Evidence from a Field Experiment." Management Science, 66: 503-529.

Karlan, Dean, Aishwarya Lakshmi Ratan, and Jonathan Zinman. 2014. "Savings by and for the Poor: A Research Review and Agenda." Review of Income and Wealth, 60(1): 36-78.

Karlan, Dean, and Leigh L Linden. 2014. "Loose Knots: Strong versus Weak Commitments to Save for Education in Uganda." National Bureau of Economic Research Working Paper 19863.

Karlan, Dean S., and Jonathan Zinman. 2012. "Borrow Less Tomorrow: Behavioral Approaches to Debt Reduction." Social Science Research Network Scholarly Paper 2060548.

Kaur, Supreet, Michael Kremer, and Sendhil Mullainathan. 2015. "Self-Control at Work." Journal of Political Economy, 123(6): 1227-1277.

Kaur, Supreet, Sendhil Mullainathan, Suanna Oh, and Frank Schilbach. 2020. "Does Financial Strain Lower Productivity?" J-PAL Working Paper.

Kramer, Berber, and David Kunst. 2020. "Intertemporal Choice and Income Regularity: Non-Fungibility in the Timing of Income among Kenyan Farmers." Journal of Development Studies, 56(5): 1048-1064.

Kremer, Michael, and Edward Miguel. 2007. "The Illusion of Sustainability." Quarterly Journal of Economics, 122(3): 1007-1065.

Kremer, Michael, Gautam Rao, and Frank Schilbach. 2019. "Behavioral development economics." In Handbook of Behavioral Economics: Applications and Foundations 1. Vol. 2, 345-458. Elsevier. 
Laibson, David. 1997. "Golden Eggs and Hyperbolic Discounting." Quarterly Journal of Economics, 112(2): 443-477.

Lujeri Tea Estates. 2017. "Administrative Data on Worker Performance and Earnings."

Prina, Silvia. 2015. "Banking the Poor via Savings Accounts: Evidence from a Field Experiment." Journal of Development Economics, 115: 16-31.

Reserve Bank of Malawi. 2019. "Inflation Rates." https://www.rbm.mw/Statistics/ InflationRates.

Royer, Heather, Mark Stehr, and Justin Sydnor. 2015. "Incentives, Commitments, and Habit Formation in Exercise: Evidence from a Field Experiment with Workers at a Fortune-500 Company." American Economic Journal: Applied Economics, 7(3): 51-84.

Schaner, Simone. 2018. "The Persistent Power of Behavioral Change: Long-Run Impacts of Temporary Savings Subsidies for the Poor." American Economic Journal: Applied Economics, 10(3): 67-100.

Schilbach, Frank. 2019. "Alcohol and Self-Control: A Field Experiment in India." American Economic Review, 109(4): 1290-1322.

Somville, Vincent, and Lore Vandewalle. 2018. "Saving by Default: Evidence from a Field Experiment in Rural India." American Economic Journal: Applied Economics, 10(3): 39-66.

Thaler, Richard H. 1994. "Psychology and Savings Policies." American Economic Review, 84(2): 186-192. 


\section{Figures and Tables}

Figure 1: Timeline for Experiment and Survey Collection

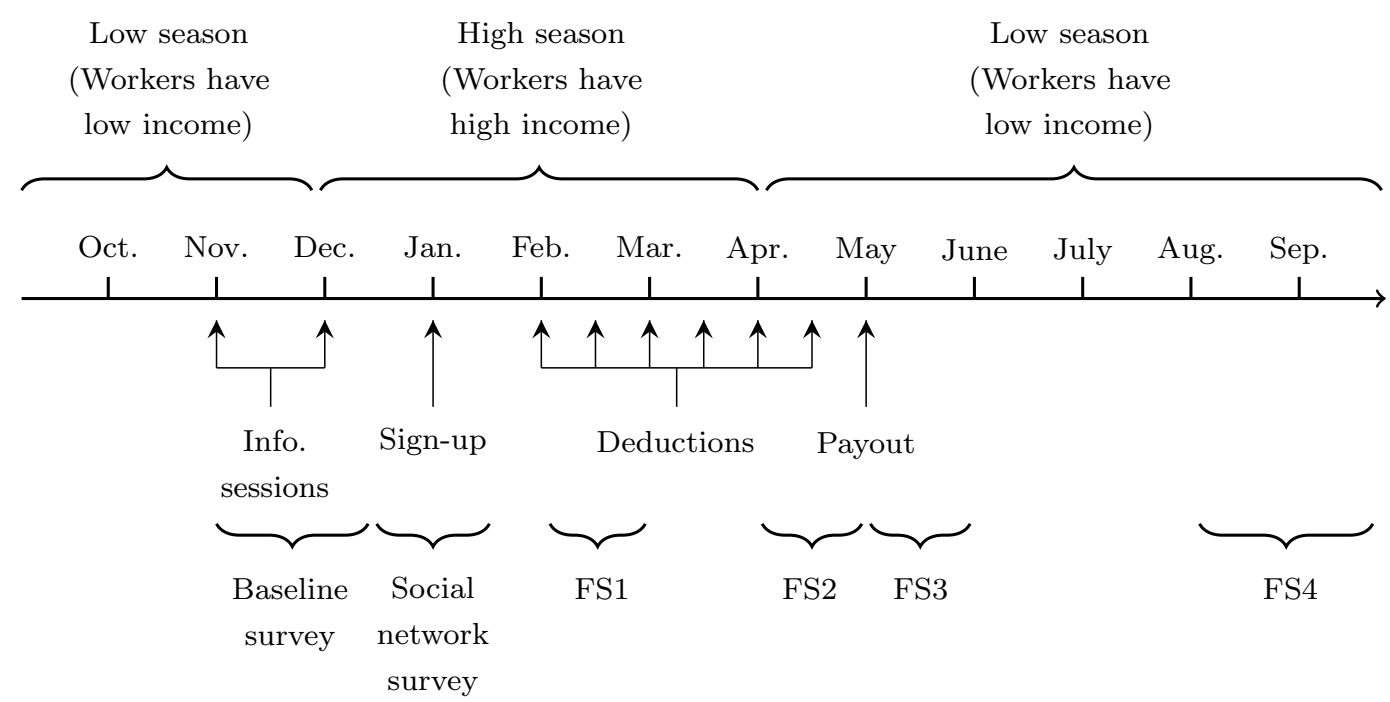

Notes: This figure illustrates the timeline for three types of events that are relevant to our study. First, the timeline shows the timing of tea seasons in Malawi. Second, the figure shows the timing of the sample recruitment and main deferred wages intervention during the period from October 2016 to September 2017. Third, the figure provides details on the timing of survey data collection. 


\section{Figure 2: Sample Recruitment Flow Diagram}

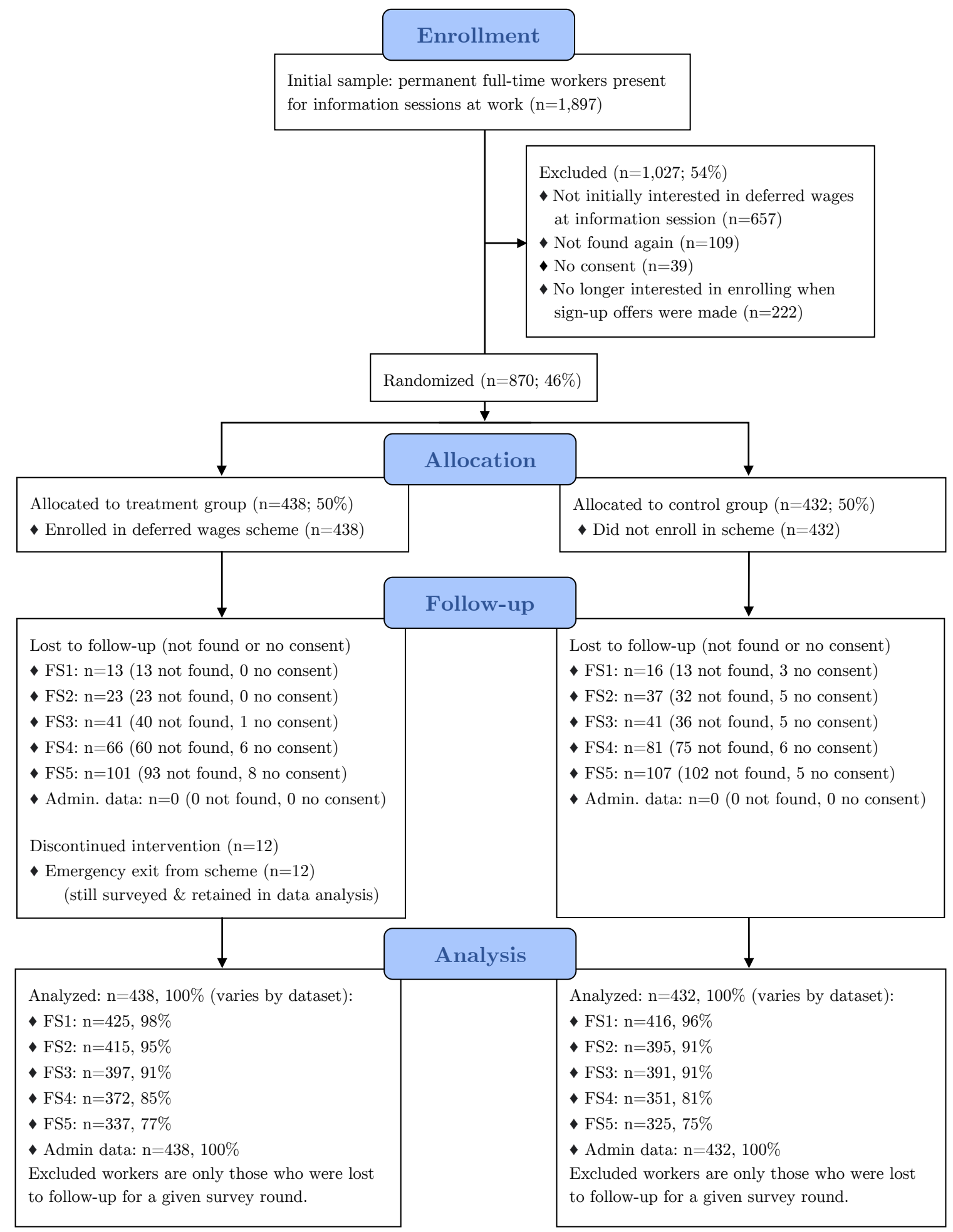

Notes: CONSORT Flow Diagram of sample selection, randomization, follow-up, and analysis. The 12 workers who discontinued the intervention were still retained in the survey sample and included in data analysis. 
Figure 3: Deferred Wages Balances After the Final Deduction

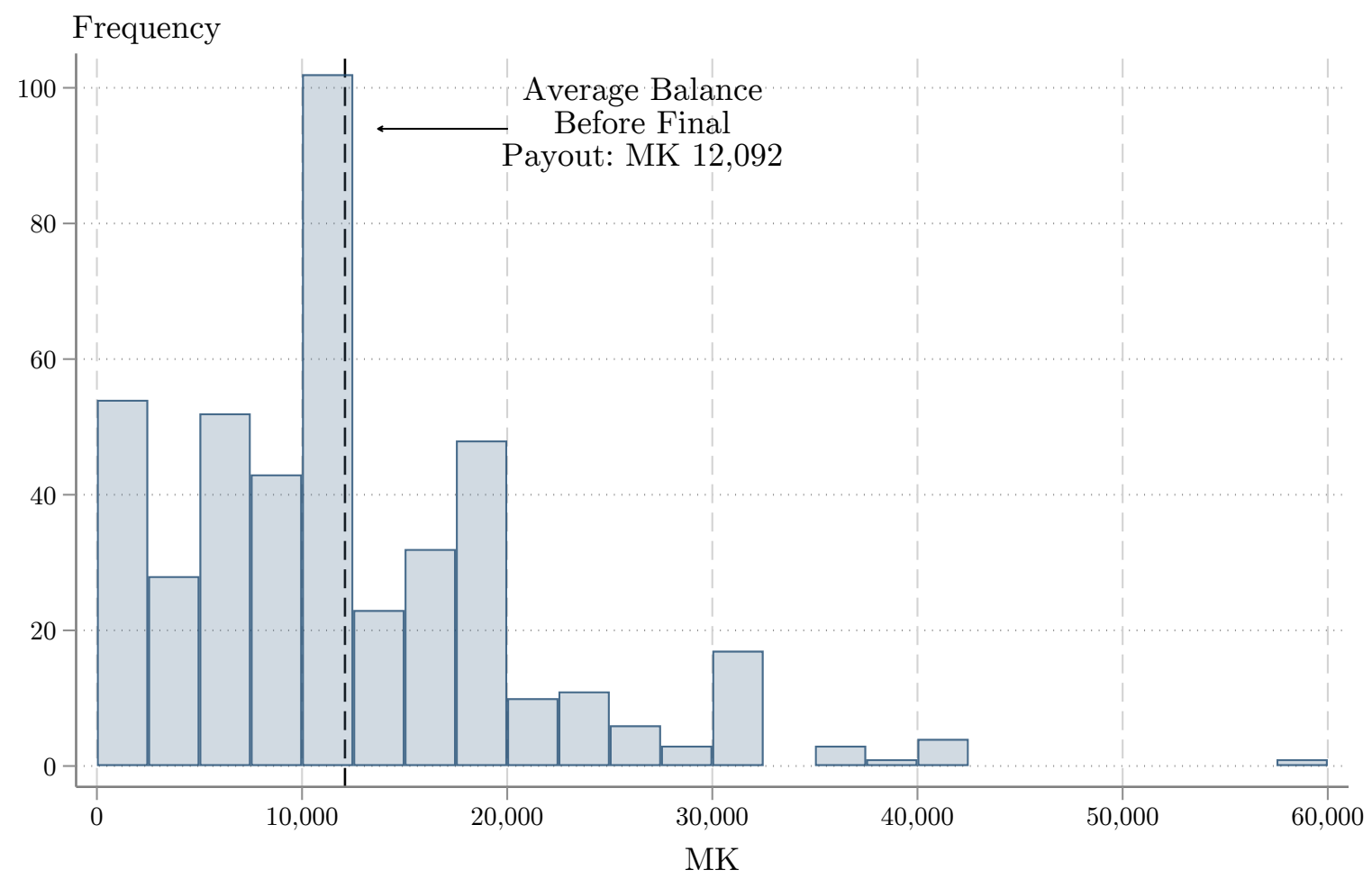

Notes: This figure provides a histogram of deferred wages account balances after the final deduction (and before the lump-sum payout). These balances are based on workers' contributions over six pay periods. The dashed line in black illustrates the average account balance. 


\section{Figure 4: Impacts on the Distribution of Total Savings}

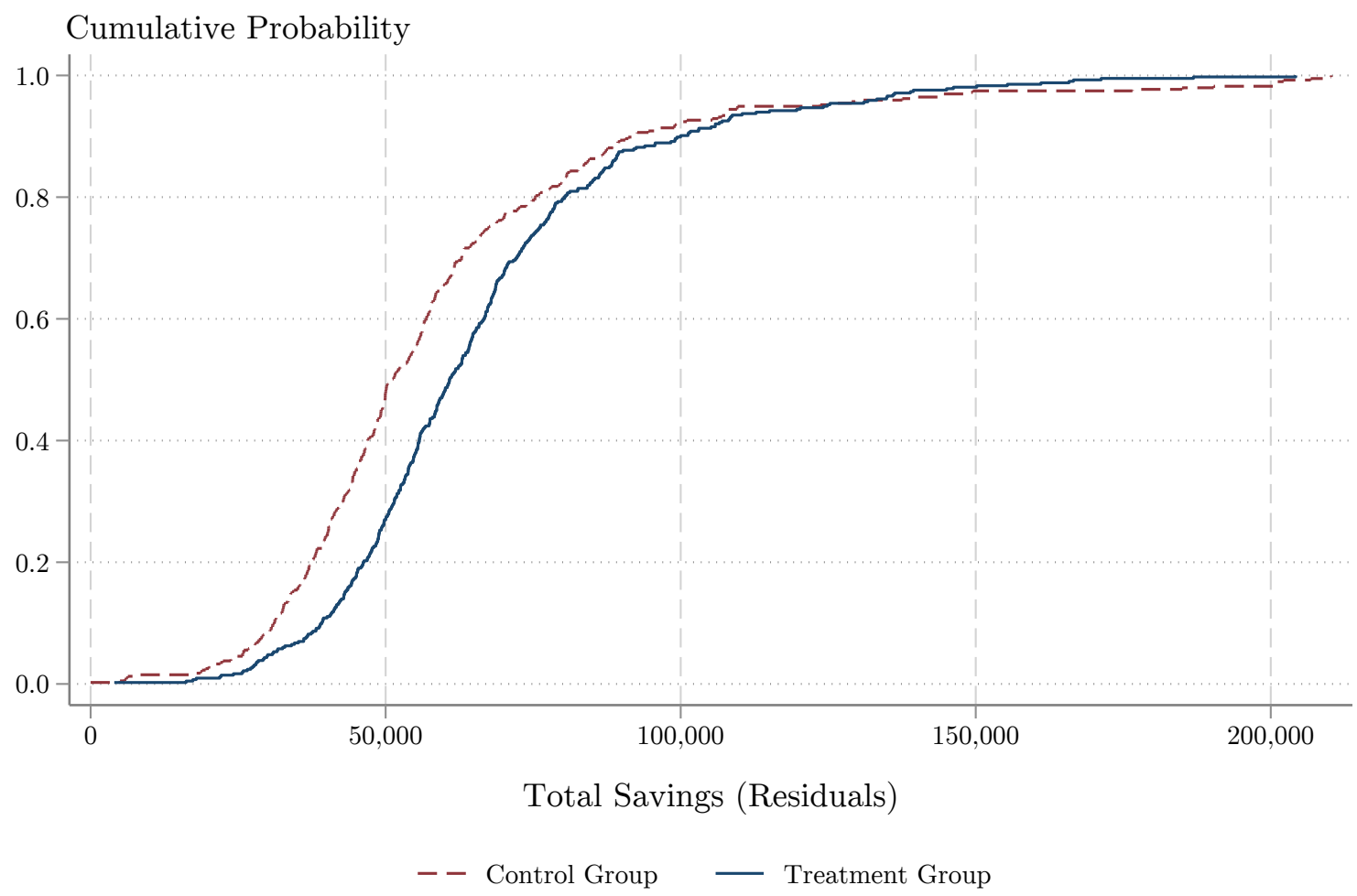

Notes: This figure plots cumulative density functions (CDFs) of the residuals of total reported savings (MK). We compute residuals by regressing total savings on the full set of controls listed in in Equation 1; we then subtract the minimum of the residuals to make the resulting distribution non-negative. See Appendix Figure A2 for the unresidualized distributions. CDFs are shown separately for the treatment and control groups, shown by the solid blue and dashed red lines, respectively. Total savings is calculated using data from the second follow-up survey and administrative data. Kolmogorov-Smirnov test of equality of distributions: $D$ $=0.219, p$-value $<0.001$. Anderson-Darling test of equality of distributions: $A^{2}=0.087, p$-value $<0.001$. 
Figure 5: Impacts on the Distribution of Total Assets Four Months After Payout

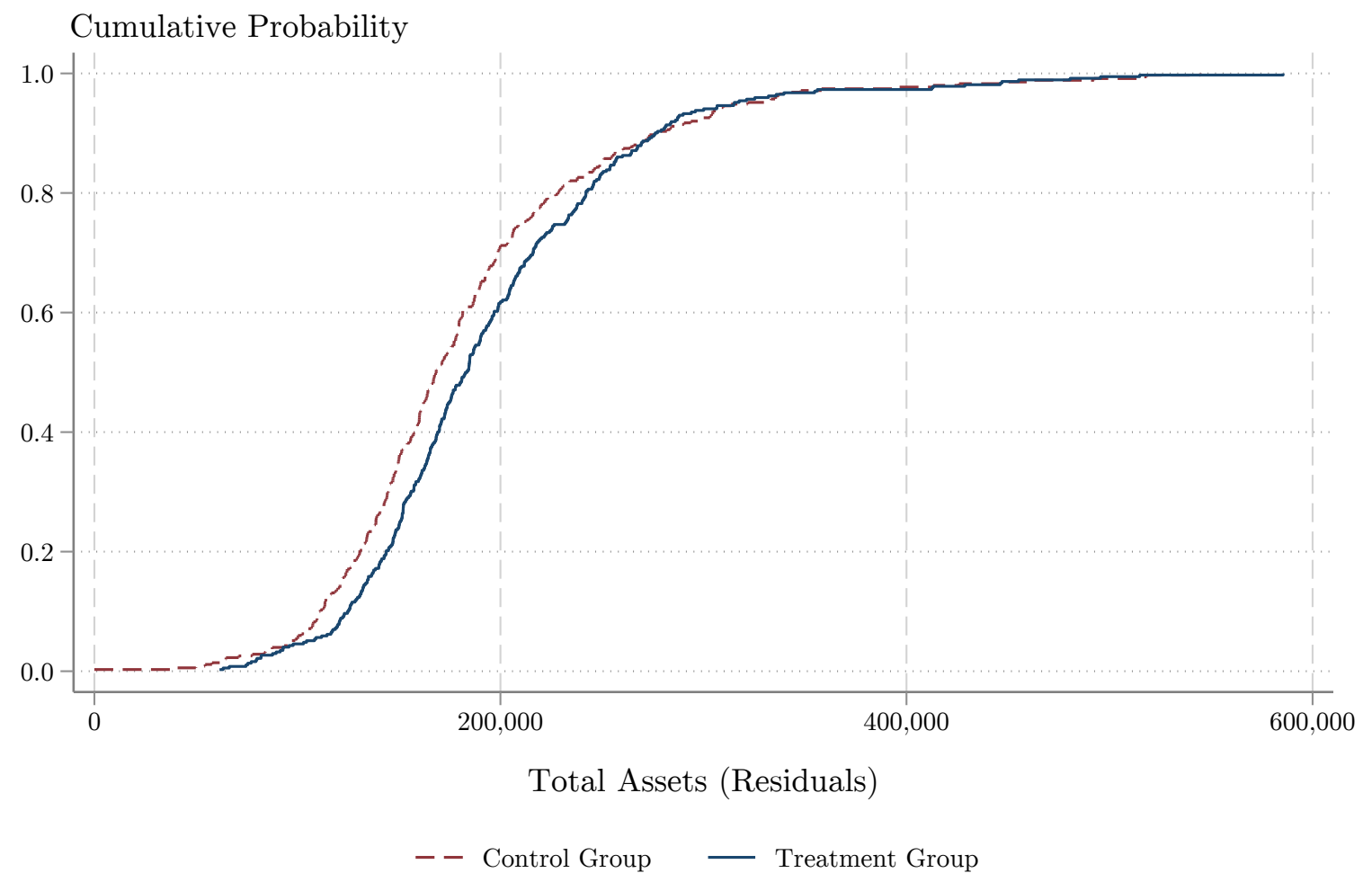

Notes: This figure plots cumulative density functions (CDFs) of the residuals of the total value of assets (MK). We compute residuals by regressing total assets on the full set of controls listed in in Equation 1; we then subtract the minimum of the residuals to make the resulting distribution non-negative. See Appendix Figure A4 for the unresidualized distributions. CDFs are shown separately for the treatment and control groups, shown by the solid blue and dashed red lines, respectively. Asset values are calculated using data from the fourth follow-up survey, which occurred four months after the lump-sum payout of the deferred wages scheme. Kolmogorov-Smirnov test of equality of distributions: $D=0.115, p$-value $=0.017$. Anderson-Darling test of equality of distributions: $A^{2}=0.028, p$-value $<0.001$. 
Figure 6: Impacts of Deferred Wages on Selected Outcomes
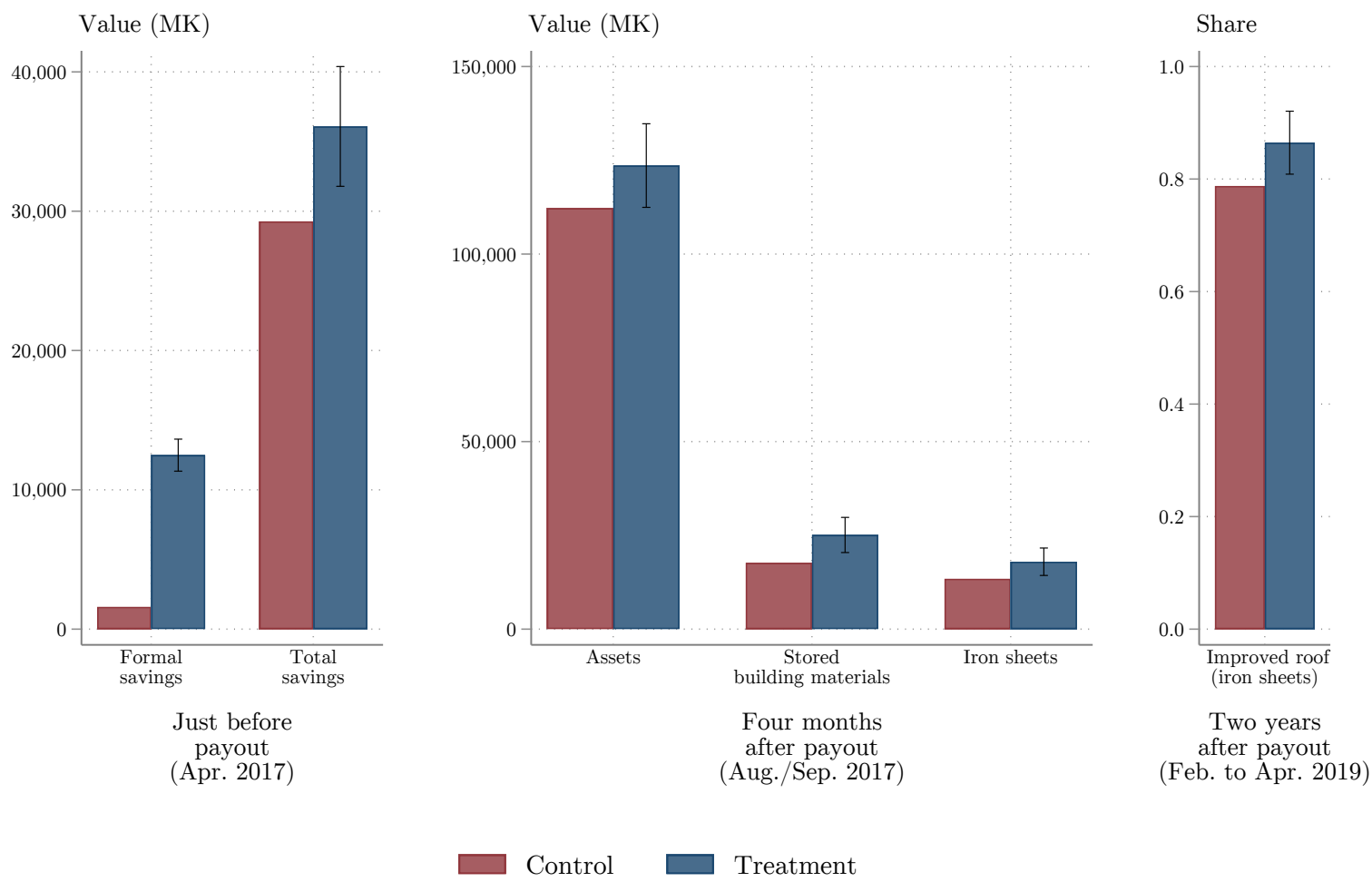

Notes: This figure summarizes the impact of the deferred payment scheme on our main outcomes. The maroon (left) bar for each outcome displays the average for workers in the control group. The navy (right) bar displays the estimated average outcome for the treatment group, based on our main regression specification (Equation 1). The black bars on the navy (right) bar show the 95-percent confidence interval for the treatment effect on each outcome. 
Table 1: Savings Scheme Take-up and Utilization

\begin{tabular}{|c|c|c|c|}
\hline & $\begin{array}{l}(1) \\
\text { Obs. }\end{array}$ & $\begin{array}{c}(2) \\
\text { Average }\end{array}$ & $\begin{aligned}(3) \\
\text { S.D. }\end{aligned}$ \\
\hline \multicolumn{4}{|c|}{ Panel A: Interest, assignment to treatment and actual sign-up } \\
\hline $\begin{array}{l}\text { Workers contacted via information sessions } \\
\text { Interested in scheme at information session }\end{array}$ & 1,897 & 0.654 & 0.476 \\
\hline $\begin{array}{l}\text { Interested and could be found for sign-up offers } \\
\text { Would enroll in product if offered }\end{array}$ & 1,092 & 0.797 & 0.403 \\
\hline $\begin{array}{l}\text { Final sample for randomization } \\
\text { Assigned to treatment group }\end{array}$ & 870 & 0.503 & 0.500 \\
\hline $\begin{array}{l}\text { Treatment group } \\
\text { Enrolled }\end{array}$ & 438 & 1.000 & 0.000 \\
\hline Panel B: Utilization & & & \\
\hline $\begin{array}{l}\text { Treatment group } \\
\text { Minimum take-home pay [MK] } \\
\text { Maximum deduction [MK] } \\
\text { Average two-weekly income from firm [MK] } \\
\text { Average two-weekly deduction }[\mathrm{MK}] \\
\text { Deductions as share of income } \\
\text { Savings balance before disbursement }[\mathrm{MK}]\end{array}$ & $\begin{array}{l}438 \\
438 \\
438 \\
438 \\
437 \\
438\end{array}$ & $\begin{array}{c}8,239 \\
2,832 \\
14,552 \\
2,054 \\
0.142 \\
12,092\end{array}$ & $\begin{array}{l}4,971 \\
1,395 \\
2,914 \\
1,386 \\
0.093 \\
8,512\end{array}$ \\
\hline Panel C: Changes after sign-up & & & \\
\hline $\begin{array}{l}\text { Treatment group } \\
\text { Early exit from savings scheme }\end{array}$ & 438 & 0.027 & 0.163 \\
\hline $\begin{array}{l}\text { Treatment group satisfaction survey subsample } \\
\text { Wants to drop out early right away } \\
\text { Wants to reduce contributions (incl. drop out) } \\
\text { Wants to increase contributions }\end{array}$ & $\begin{array}{l}207 \\
207 \\
207\end{array}$ & $\begin{array}{l}0.039 \\
0.097 \\
0.145\end{array}$ & $\begin{array}{l}0.193 \\
0.296 \\
0.353\end{array}$ \\
\hline
\end{tabular}

Notes: Panel A provides statistics on expressed interest in participating in the savings scheme at the Lujeri Tea Estates. Panel B presents statistics on product choices for the individuals that we randomly assigned to the treatment group, who had access to the deferred wages savings accounts in 2017. Panel C reports statistics for the treatment group and for a randomly-selected 50 percent subsample of treatment-group workers who were selected to answer questions about satisfaction with the scheme during the second followup survey. These workers were asked if they wanted to drop out early or change their deduction thresholds, and were informed that their choice would be implemented with a five percent probability. 
Table 2: Impacts on Savings Outcomes (February-April 2017)

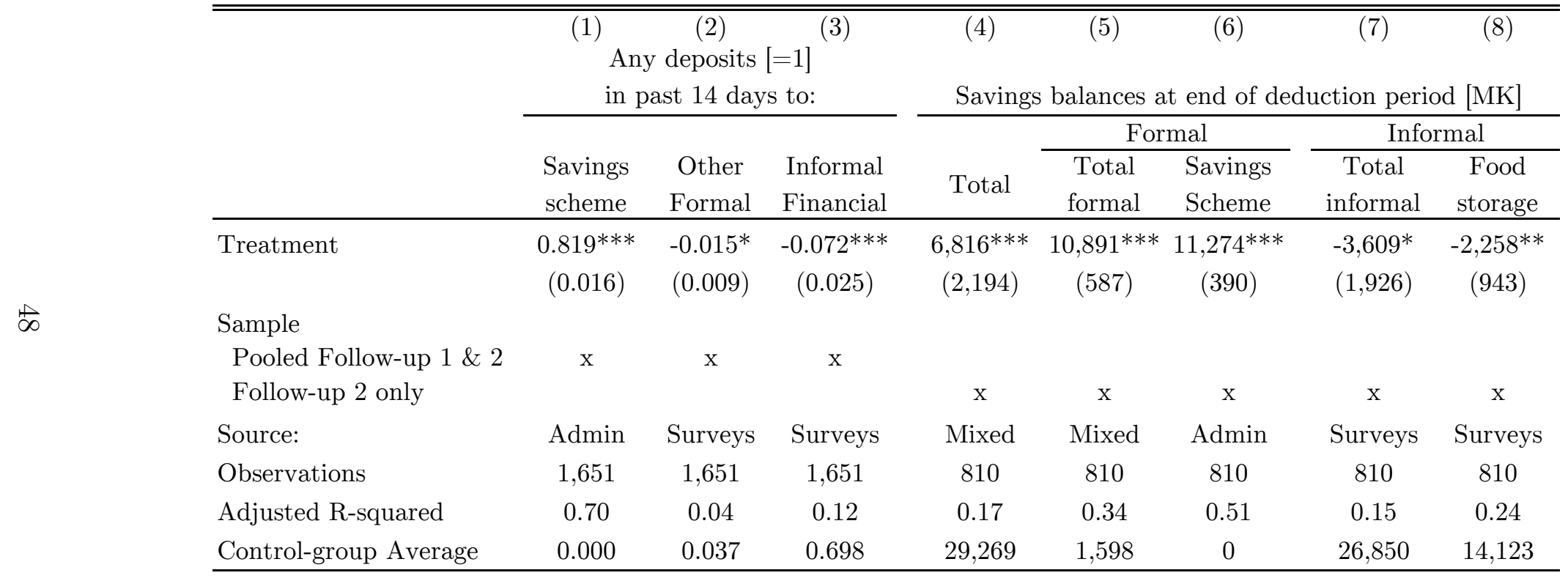

Notes: All measures of savings outcomes are recorded during the deductions period of the savings scheme, which ran from February to April 2017. Each outcome is an aggregate or detailed measure of savings. Monetary values are in Malawi Kwacha (MK); \$1 USD equalled approximately MK 750 at the time of the experiment. Heteroskedasticity-robust standard errors, clustered by worker, in parentheses: ${ }^{*} p<0.1 ; * * p<0.05$; $* * * p<0.01$. 
Table 3: Impacts on Work Outcomes

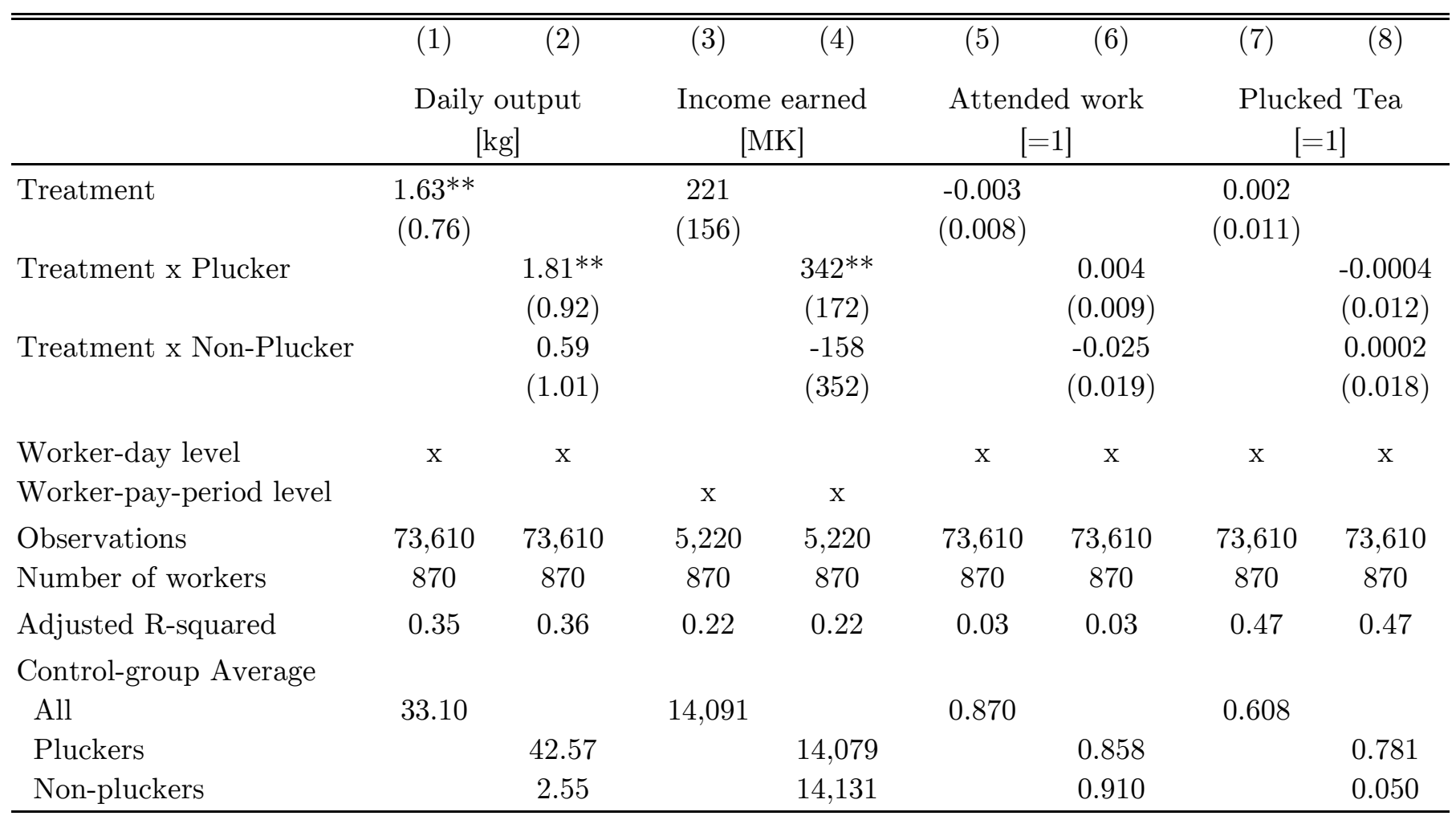

Notes: All results are based on administrative data for workers at the Lujeri Tea Estates covering the months of the deductions period for the savings scheme. Monetary values are in Malawi Kwacha; \$1 USD equalled approximately MK 750 at the time of the experiment.

Heteroskedasticity-robust standard errors, clustered by worker, in parentheses: ${ }^{*} p<0.1{ }^{* *} p<0.05 ;{ }^{* * *} p<0.01$. 
Table 4: Effects on Expenditures During Deduction Period (Pooled Across Follow-ups 1 and 2)

\begin{tabular}{|c|c|c|c|c|c|c|c|c|}
\hline & (1) & $(2)$ & $(3)$ & (4) & $(5)$ & (6) & $(7)$ & (8) \\
\hline & \multicolumn{6}{|c|}{ Detailed expenditures in past 14 days [MK] } & \multicolumn{2}{|c|}{$\begin{array}{c}\text { Bulk purchases in } \\
\text { past } 30 \text { days }\end{array}$} \\
\hline & \multirow[b]{3}{*}{ Total } & \multicolumn{3}{|c|}{ Food } & \multicolumn{2}{|c|}{ Durables } & \multirow{3}{*}{$\begin{array}{c}\text { Any } \\
\text { purchase } \\
>5 \mathrm{k} \\
{[=1]}\end{array}$} & \multirow{3}{*}{$\begin{array}{c}\text { Sum of } \\
\text { purchases } \\
>5 \mathrm{k} \\
{[\mathrm{MK}]}\end{array}$} \\
\hline & & \multirow[b]{2}{*}{$\begin{array}{c}\text { All } \\
\text { food }\end{array}$} & \multicolumn{2}{|c|}{ Storable } & \multirow[b]{2}{*}{$\begin{array}{c}\text { All } \\
\text { durables }\end{array}$} & \multirow{2}{*}{$\begin{array}{c}\text { House } \\
\text { improve- } \\
\text { ments }\end{array}$} & & \\
\hline & & & $\begin{array}{c}\text { All } \\
\text { storable }\end{array}$ & $\begin{array}{l}\text { Maize } \\
\text { grain }\end{array}$ & & & & \\
\hline Treatment & $\begin{array}{c}311 \\
(844)\end{array}$ & $\begin{array}{c}38 \\
(277)\end{array}$ & $\begin{array}{c}87 \\
(221)\end{array}$ & $\begin{array}{c}36 \\
(186)\end{array}$ & $\begin{array}{c}76 \\
(626)\end{array}$ & $\begin{array}{c}24 \\
(269)\end{array}$ & $\begin{array}{l}-0.025 \\
(0.025)\end{array}$ & $\begin{array}{c}748 \\
(786)\end{array}$ \\
\hline \multicolumn{9}{|l|}{ Observations: } \\
\hline From Follow-up 1 & 841 & 841 & 841 & 841 & 841 & 841 & 841 & 841 \\
\hline From Follow-up 2 & 810 & 810 & 810 & 810 & 810 & 810 & 810 & 810 \\
\hline Total & 1,651 & 1,651 & 1,651 & 1,651 & 1,651 & 1,651 & 1,651 & 1,651 \\
\hline Adjusted R-squared & 0.07 & 0.06 & 0.04 & 0.02 & 0.05 & 0.02 & 0.06 & 0.05 \\
\hline Control-group Average & 18,938 & 9,157 & 6,347 & 3,930 & 7,286 & 1,662 & 0.504 & 7,671 \\
\hline
\end{tabular}

Notes: All measures of expenditure outcomes are recorded during the deductions period of the savings scheme, which ran from February to April 2017. Each outcome is an aggregate or detailed measure of a type of expenditure. Monetary values are in Malawi Kwacha (MK); \$1 USD equalled approximately MK 750 at the time of the experiment. Heteroskedasticity-robust standard errors, clustered by worker, in parentheses: ${ }^{*} p<0.1 ;{ }^{* *} p<0.05 ;{ }^{* * *} p<0.01$. 
Table 5: Impacts on Short-term Expenditures Following Payout

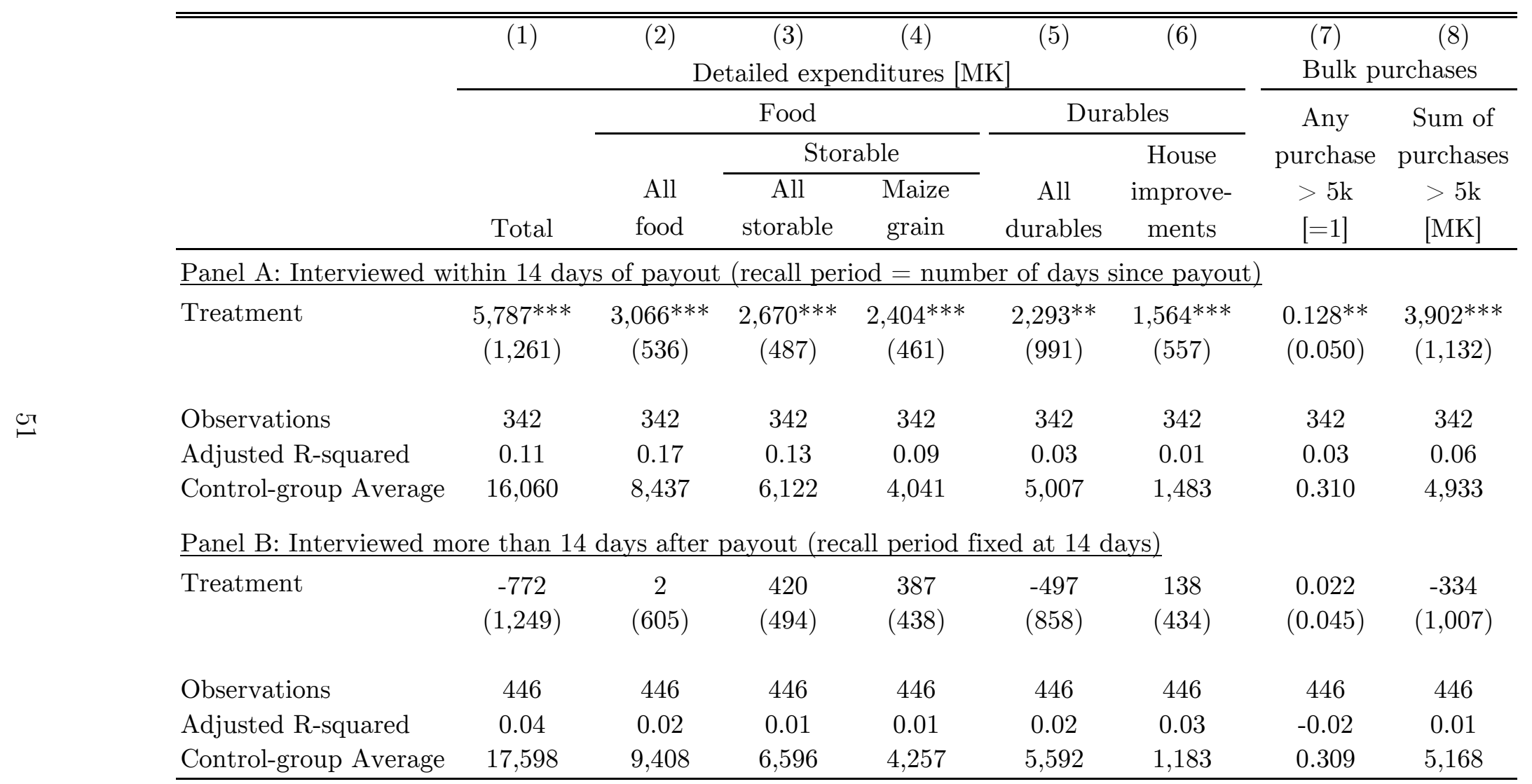

Notes: All measures of expenditure outcomes are recorded in the period after the lump-sum payout of the savings scheme, which happened on May 6, 2017. This data comes from the third follow-up survey (FS3). Each outcome is an aggregate or detailed measure of a type of expenditure. Monetary values are in Malawi Kwacha (MK); \$1 USD equalled approximately MK 750 at the time of the experiment. Heteroskedasticity-robust standard errors in parentheses: ${ }^{*} p<0.1 ; * * p<0.05 ;{ }^{* * *} p<0.01$. 
Table 6: Downstream Effects on Asset Ownership

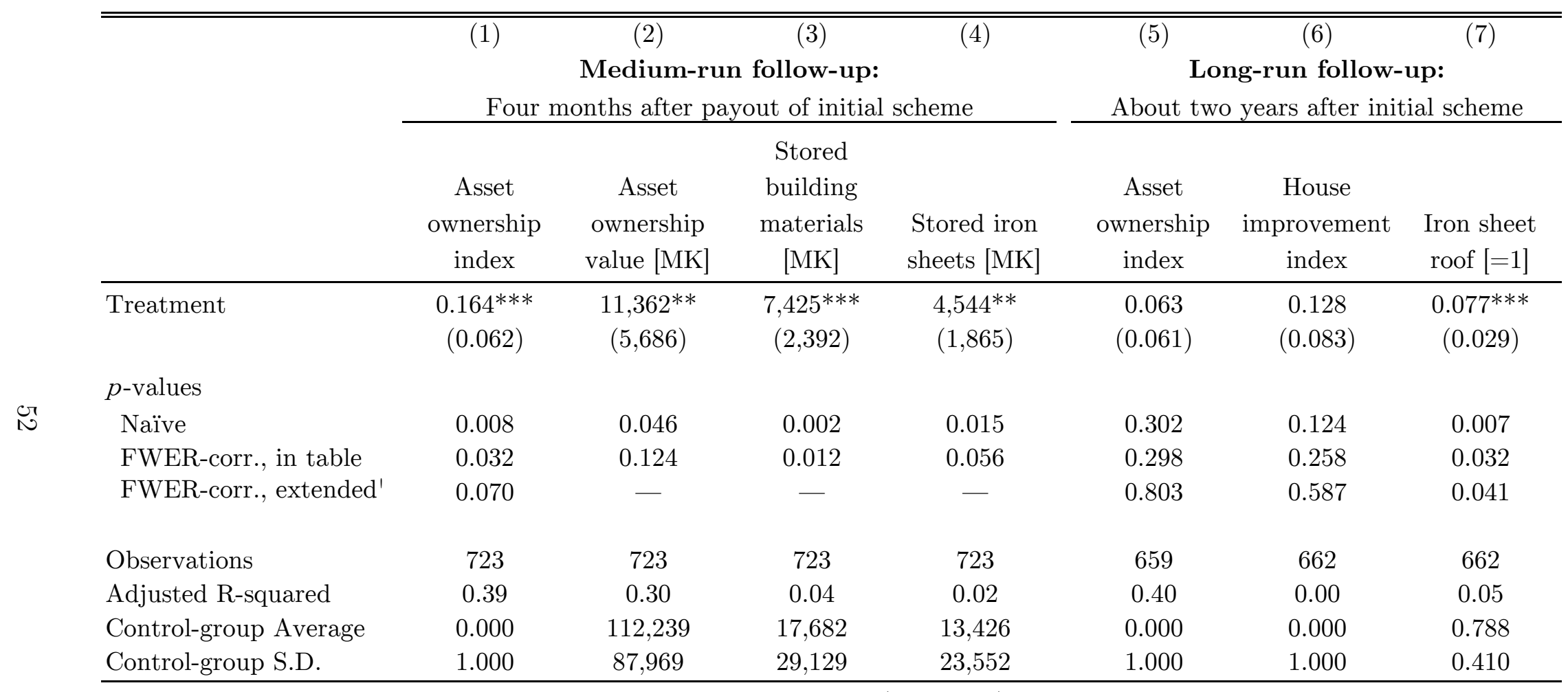

Notes: Outcomes are measured after four months and after about two years (22 months) of the payout of the initial scheme, using survey data from the fourth and fifth follow-up surveys, respectively. The treatment group was re-treated twice between the four-month and the two-year followup, and there was then a nine-month gap between data collection and the payout of the last round of the repeated schemes. Monetary values are in Malawi Kwacha (MK); $\$ 1$ USD equalled approximately MK 750 at the time of the experiment. Heteroskedasticity-robust standard errors in parentheses: ${ }^{*} p<0.1 ; * * p<0.05 ; * * *<0.01$.

$\dagger$ Extended FWER correction uses a more-comprehensive set of assets from Appendix Table A7, not all of which appear in this table; see text for details. 
Table 7: Effect of Manual Deposit Requirement on Take-up and Contribution Rates

\begin{tabular}{|c|c|c|c|c|}
\hline & $\begin{array}{l}\text { Interested in } \\
\text { enrolling }[=1]\end{array}$ & $\begin{array}{c}(2) \\
\text { Any deposit } \\
{[=1]}\end{array}$ & $\begin{array}{c}(3) \\
\text { Number of } \\
\text { deposits } \\
\text { (out of } 6 \text { ) }\end{array}$ & $\begin{array}{c}(4) \\
\text { Final balance } \\
\text { after } 6 \text { paydays } \\
{[\mathrm{MK}]}\end{array}$ \\
\hline \multicolumn{5}{|l|}{ Panel A: Average Effects } \\
\hline Manual Deposits & $\begin{array}{c}0.090 \\
(0.073)\end{array}$ & $\begin{array}{c}-0.303^{* * *} \\
(0.067)\end{array}$ & $\begin{array}{c}-1.9 * * * \\
(0.4)\end{array}$ & $\begin{array}{c}-3,516^{* *} \\
(1,477)\end{array}$ \\
\hline $\begin{array}{l}\text { Observations } \\
\text { Adjusted R-squared } \\
\text { Control-group Average }\end{array}$ & $\begin{array}{c}186 \\
0.00 \\
0.505\end{array}$ & $\begin{array}{c}186 \\
0.09 \\
0.505\end{array}$ & $\begin{array}{c}186 \\
0.12 \\
2.8\end{array}$ & $\begin{array}{c}186 \\
0.03 \\
6,930\end{array}$ \\
\hline \multicolumn{5}{|l|}{ Panel B: Heterogeneous Effects } \\
\hline $\begin{array}{l}\text { Manual Deposits (Low Self- } \\
\text { Control, High Kin Tax, No } \\
\text { Account) }\end{array}$ & $\begin{array}{c}0.020 \\
(0.183)\end{array}$ & $\begin{array}{c}-0.400^{* *} \\
(0.171)\end{array}$ & $\begin{array}{c}-2.6^{* * *} \\
(0.9)\end{array}$ & $\begin{array}{c}-8,215^{* *} \\
(3,768)\end{array}$ \\
\hline \multicolumn{5}{|l|}{ Manual Deposits $\times$} \\
\hline Medium Self-Control & $\begin{array}{l}-0.003 \\
(0.202)\end{array}$ & $\begin{array}{l}-0.080 \\
(0.186)\end{array}$ & $\begin{array}{c}0.1 \\
(1.0)\end{array}$ & $\begin{array}{c}3,600 \\
(3,076)\end{array}$ \\
\hline High Self-Control & $\begin{array}{c}0.160 \\
(0.175)\end{array}$ & $\begin{array}{c}0.191 \\
(0.161)\end{array}$ & $\begin{array}{l}1.6^{*} \\
(0.8)\end{array}$ & $\begin{array}{c}7,792^{* * *} \\
(2,927)\end{array}$ \\
\hline Medium Kin Tax & $\begin{array}{l}-0.245 \\
(0.243)\end{array}$ & $\begin{array}{l}-0.207 \\
(0.212)\end{array}$ & $\begin{array}{l}-0.8 \\
(1.1)\end{array}$ & $\begin{array}{l}-1,463 \\
(5,842)\end{array}$ \\
\hline Low Kin Tax & $\begin{array}{l}-0.003 \\
(0.178)\end{array}$ & $\begin{array}{c}0.100 \\
(0.153)\end{array}$ & $\begin{array}{c}0.3 \\
(0.8)\end{array}$ & $\begin{array}{c}-1,314 \\
(4,772)\end{array}$ \\
\hline $\begin{array}{l}\text { Any Formal Savings } \\
\text { Account }\end{array}$ & $\begin{array}{c}0.143 \\
(0.152)\end{array}$ & $\begin{array}{c}0.054 \\
(0.135)\end{array}$ & $\begin{array}{c}0.3 \\
(0.7)\end{array}$ & $\begin{array}{c}5,337 \\
(3,255)\end{array}$ \\
\hline \multicolumn{5}{|c|}{$p$-values of joint test of interactions with: } \\
\hline $\begin{array}{l}\text { Self-control } \\
\text { Kin Tax }\end{array}$ & $\begin{array}{l}0.581 \\
0.504\end{array}$ & $\begin{array}{l}0.239 \\
0.288\end{array}$ & $\begin{array}{l}0.096 \\
0.597\end{array}$ & $\begin{array}{l}0.031 \\
0.960\end{array}$ \\
\hline $\begin{array}{l}\text { Observations } \\
\text { Adjusted R-squared } \\
\text { Control-group Average }\end{array}$ & $\begin{array}{c}186 \\
-0.02 \\
0.505\end{array}$ & $\begin{array}{c}186 \\
0.08 \\
0.505\end{array}$ & $\begin{array}{c}186 \\
0.11 \\
2.8\end{array}$ & $\begin{array}{c}186 \\
0.04 \\
6,930\end{array}$ \\
\hline
\end{tabular}

Notes: This table reports the results of a supplementary experiment on a sample of 186 workers that were not involved in the main experiment, in which the treatment was having to make deposits manually instead of having them automatically deducted. Panel A presents the main effects of the treatment; Panel B presents treatment effect heterogeneity by baseline characteristics. Monetary values are in Malawi Kwacha (MK); $\$ 1$ USD equalled approximately MK 750 at the time of the experiment. Heteroskedasticity-robust standard errors in parentheses: ${ }^{*} p<0.1 ;{ }^{*} p<0.05 ;{ }^{* *} p<0.01$. 


\title{
Online Appendix
}

\author{
Pay Me Later: \\ Savings Constraints and the \\ Demand for Deferred Payments
}

\section{Lasse Brune, Eric Chyn, and Jason Kerwin}

March 19, 2021

\section{List of Figures}

A1 Labor Supply Effects Over Time . . . . . . . . . . . . . . . . . . . 1

A2 Impacts on the Distribution of Total Savings (Unresidualized) . . . . . . . 2

A3 Quantile Treatment Effects on Total Savings . . . . . . . . . . . . . . 3

A4 Impacts on the Distribution of Total Assets Four Months After Payout (Unresidualized $\ldots \ldots \ldots \ldots \ldots \ldots \ldots$. . . . . . . . . . . . . 4

A5 Quantile Treatment Effects on Total Assets Four Months After Payout . . . 5

\section{List of Tables}

A1 Baseline Descriptive Statistics and Balance . . . . . . . . . . . . . . 6

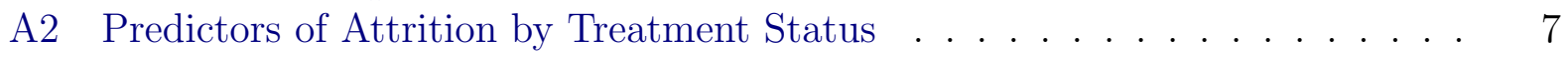

A2 Predictors of Attrition by Treatment Status (continued) . . . . . . . . 8

A3 Correlates of Enrollment . . . . . . . . . . . . . . . . . . . . 9

A4 Impacts on Informal Savings by Category (February-April 2017) . . . . . 10

A5 Flow of Funds After Lump-Sum Payout . . . . . . . . . . . . . . . . . 11

A6 Impacts on Short-term Expenditures Following Payout by Week . . . . . . . 12

A7 Downstream Effects on Asset Ownership - Full List of Outcomes . . . . . . . 13

A8 Downstream Effects on Asset Ownership - Adjusting for Potential Spillovers 14

A9 Downstream Effects on Asset Ownership - Full List of Outcomes, Adjusting for Potential Spillovers . . . . . . . . . . . . . . . . . 15

A10 Repeat Sign-up in Treatment Group . . . . . . . . . . . . . . . 16

A11 Impact of Payout and Access Features on Take-up . . . . . . . . . . . . 16 


\section{Appendix A: Additional Figures and Tables}

Figure A1: Labor Supply Effects Over Time

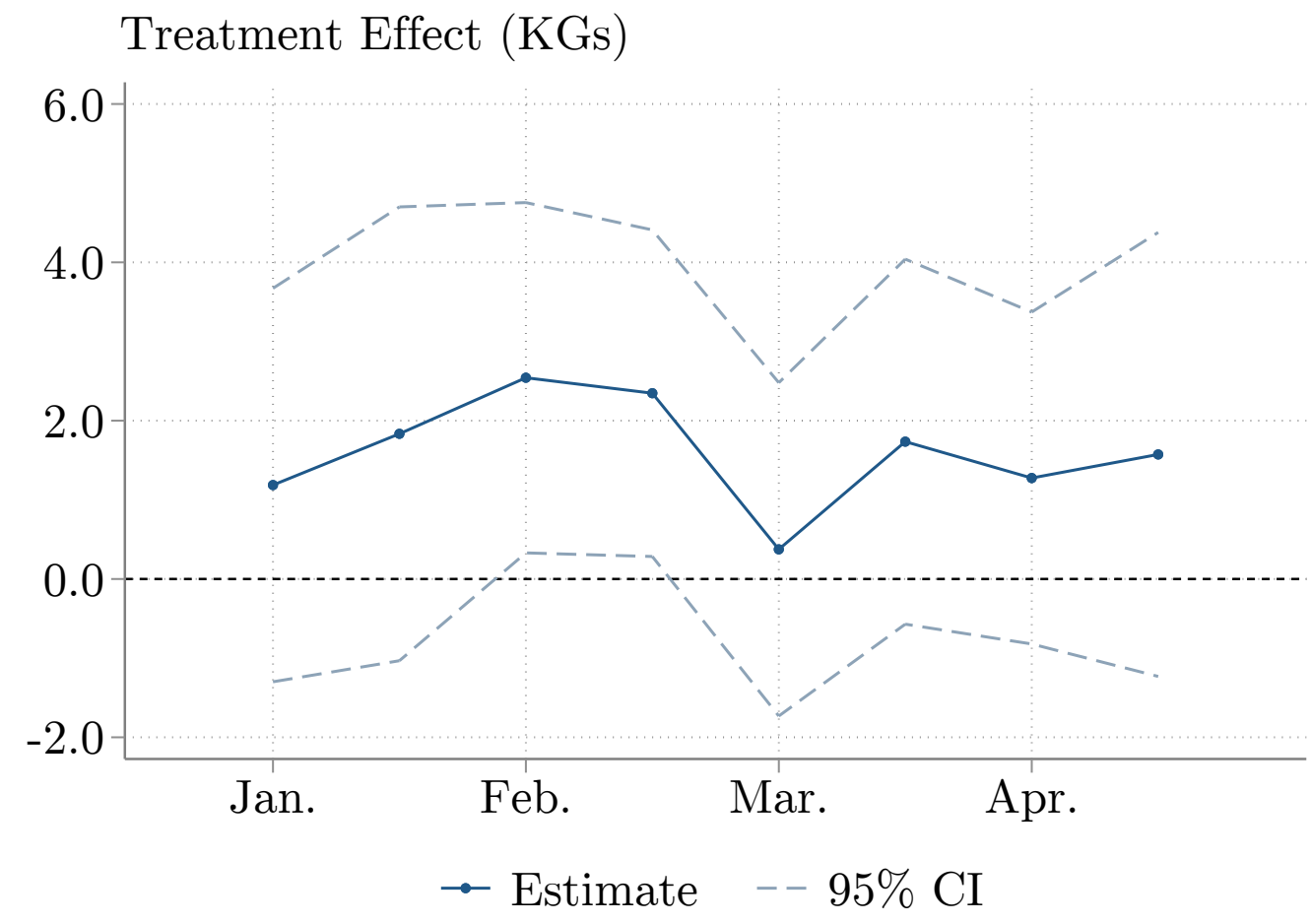

Notes: This figure shows treatment effects on kilograms (KGs) of tea plucked by for every two-week (fortnight) pay period. The specification that we use is:

$$
y_{i t}=\alpha+\delta_{s}+\gamma Z_{i}+y_{i s b}+\sum_{j}\left(\beta_{j}\left(\text { Treat }_{i} \times \text { Fortnight }_{j}\right)+\lambda_{j} \text { Fortnight }_{j}\right)+\epsilon_{i s t}
$$

where Fortnight ${ }_{j}$ is an indicator that day $t$ falls in a particular two-week period. The sample used for the analysis includes all dates on which labor supply could plausibly have been affected by the treatment. Therefore, the estimation sample includes the first day that workers learned their treatment status (which was before deductions began) and ends on the day the treated workers received their deferred wage payments (which was three weeks after the deductions ended). The figure plots the estimates of $\beta$ as solid dots in the connected series. The dashed lines illustrate the 95-percent confidence interval for the coefficients; standard errors are clustered by worker. 
Figure A2: Impacts on the Distribution of Total Savings (Unresidualized)

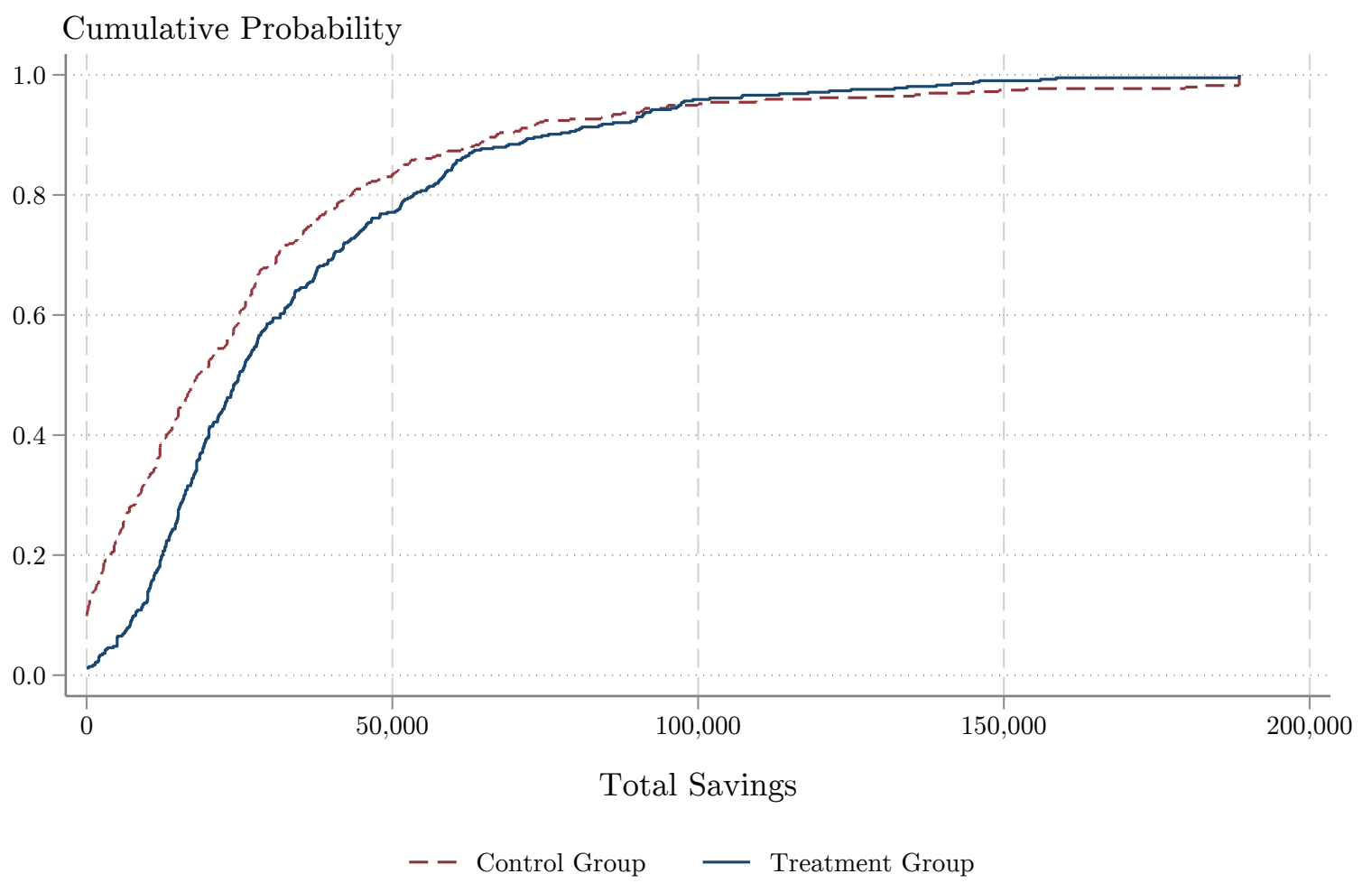

Notes: This figure plots cumulative density functions (CDFs) of total reported savings (MK). CDFs are shown separately for the treatment and control groups, shown by the solid blue and dashed red lines, respectively. Total savings is calculated using data from the second follow-up survey and administrative data. KolmogorovSmirnov test of equality of distributions: $D=0.201, p$-value $<0.001$. Anderson-Darling test of equality of distributions: $A^{2}=0.054, p$-value $<0.001$. 
Figure A3: Quantile Treatment Effects on Total Savings

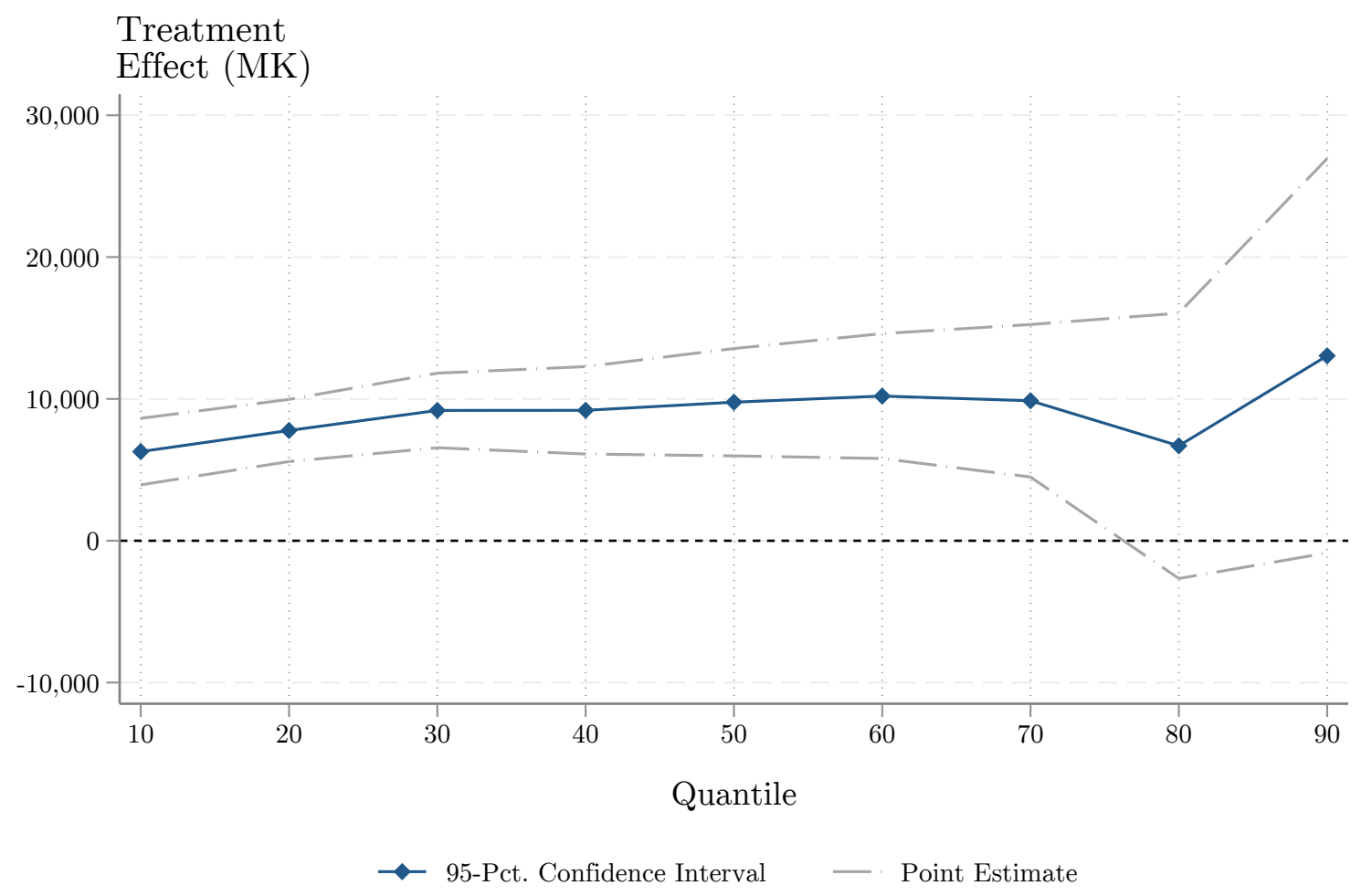

Notes: This figure the plots estimated quantile treatment effects (QTEs) of the deferred wages scheme on total savings. Total savings is calculated using data from the second follow-up survey and administrative data. The specification used to estimate the QTEs uses the same set of controls listed in Equation 1 
Figure A4: Impacts on the Distribution of Total Assets Four Months After Payout (Unresidualized)

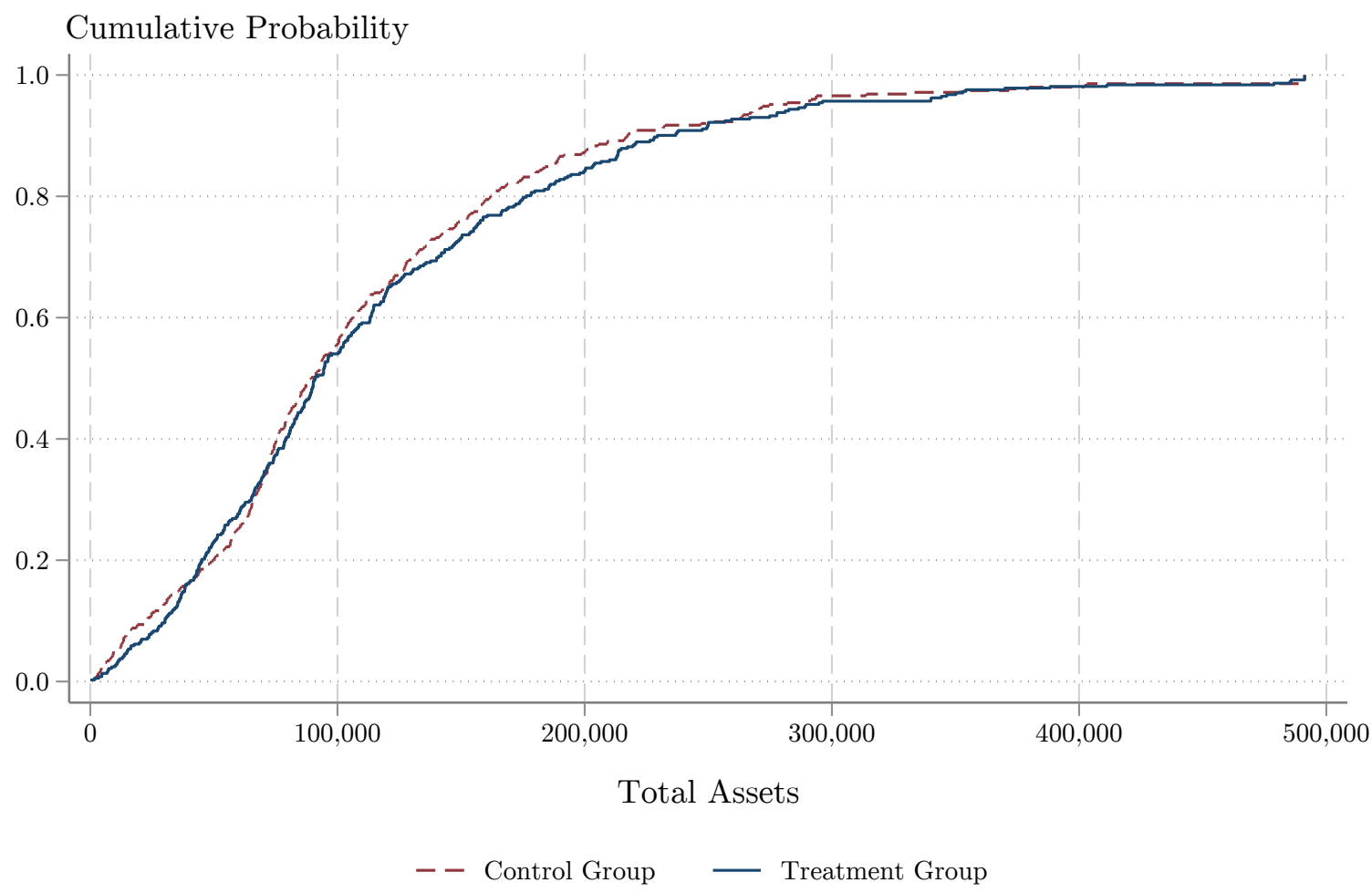

Notes: This figure plots cumulative density functions (CDFs) of the total value of assets (MK). CDFs are shown separately for the treatment and control groups, shown by the solid blue and dashed red lines, respectively. Asset values are calculated using data from the fourth follow-up survey, which occurred four months after the lump-sum payout of the deferred wages scheme. Kolmogorov-Smirnov test of equality of distributions: $D=0.046, p$-value $=0.839$. Anderson-Darling test of equality of distributions: $A^{2}=0.004$, $p$-value $=0.290$. 
Figure A5: Quantile Treatment Effects on Total Assets Four Months After Payout

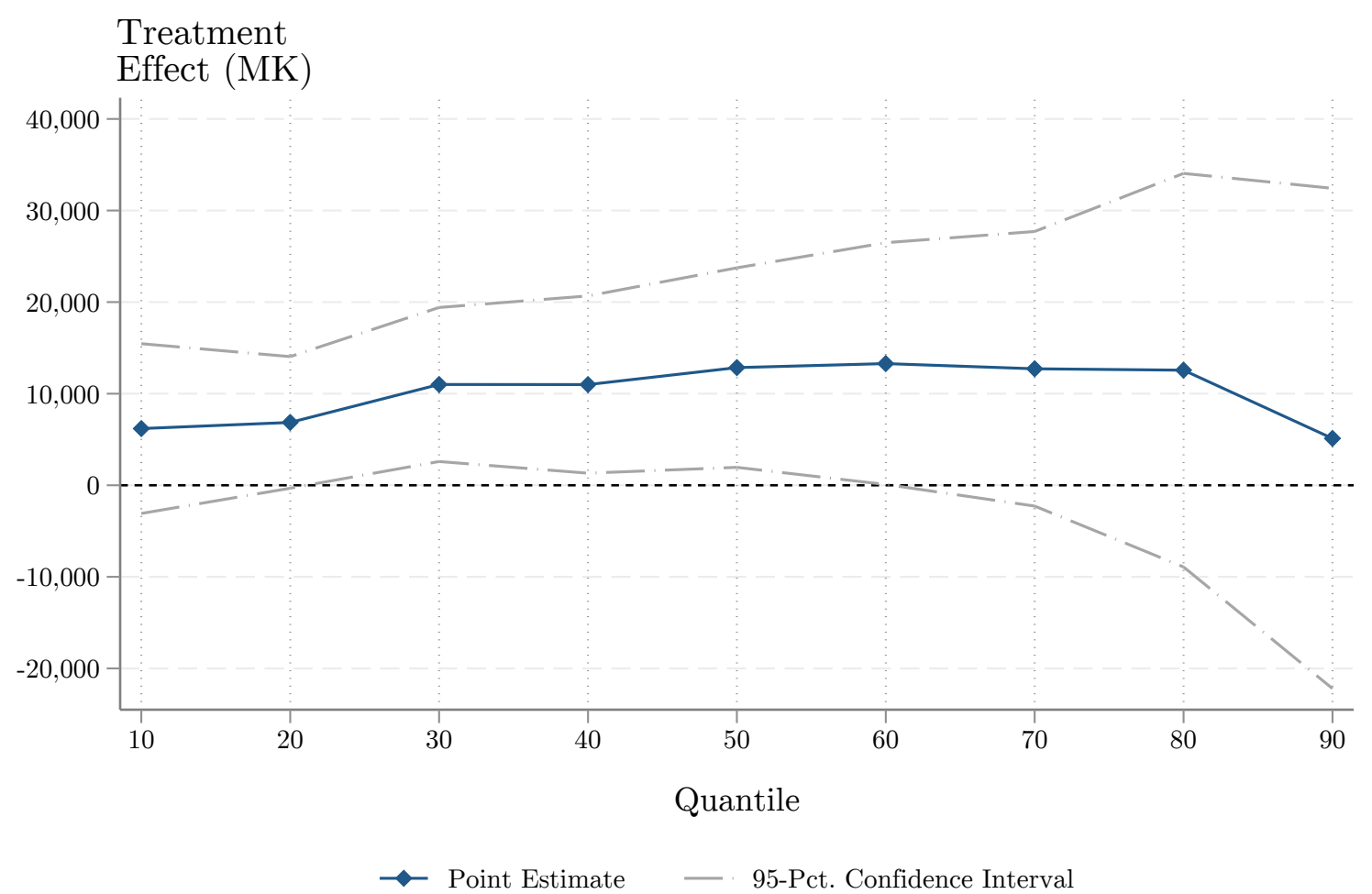

Notes: This figure the plots estimated quantile treatment effects (QTEs) of the deferred wages scheme on total assets. The specification used to estimate the QTEs uses the same set of controls listed in Equation 1. 
Table A1: Baseline Descriptive Statistics and Balance

\begin{tabular}{|c|c|c|c|c|c|}
\hline & (1) & $(2)$ & $(3)$ & $(4)$ & \multirow{3}{*}{$\begin{array}{c}(5) \\
p \text {-value } \\
(1)=(3)\end{array}$} \\
\hline & \multicolumn{2}{|c|}{ Control } & \multicolumn{2}{|c|}{ Treatment } & \\
\hline & Average & (S.D.) & Average & (S.D.) & \\
\hline \multicolumn{6}{|l|}{$\underline{\text { Panel A: Demographics }}$} \\
\hline Female & 0.35 & $(0.48)$ & 0.35 & $(0.48)$ & 0.952 \\
\hline Married & 0.69 & $(0.46)$ & 0.71 & $(0.46)$ & 0.624 \\
\hline Age & 39.5 & $(11.2)$ & 39.5 & $(10.3)$ & 0.986 \\
\hline Years of schooling & 4.9 & $(3.6)$ & 4.7 & $(3.4)$ & 0.599 \\
\hline Number of children in household & 2.5 & $(1.5)$ & 2.7 & $(1.5)$ & 0.055 \\
\hline \multicolumn{6}{|l|}{ Panel B: Work and Income } \\
\hline Plucker & 0.76 & $(0.43)$ & 0.77 & $(0.42)$ & 0.601 \\
\hline Share of days plucked tea, admin. & 0.41 & $(0.28)$ & 0.43 & $(0.28)$ & 0.448 \\
\hline Average daily Output [kg], admin. & 10.5 & $(10.0)$ & 11.1 & $(10.2)$ & 0.338 \\
\hline HH income past 14 days [MK], survey & 18,668 & $(21,053)$ & 19,425 & $(23,492)$ & 0.651 \\
\hline \multicolumn{6}{|l|}{$\underline{\text { Panel C: Financial Behaviors }}$} \\
\hline Total savings [MK] & 33,919 & $(54,154)$ & 30,236 & $(47,801)$ & 0.246 \\
\hline Formal savings $[\mathrm{MK}]$ & 1,553 & $(7,562)$ & 1,071 & $(5,944)$ & 0.270 \\
\hline Informal savings [MK] & 32,054 & $(50,509)$ & 29,101 & $(45,616)$ & 0.319 \\
\hline Asset index (PCA) & 0.000 & $(1.000)$ & -0.094 & $(1.018)$ & 0.151 \\
\hline Total 14-day expenditures [MK] & 16,737 & $(11,508)$ & 16,163 & $(12,041)$ & 0.415 \\
\hline Any purchase $>5 \mathrm{k}$, past 30 days & 0.01 & $(0.12)$ & 0.03 & $(0.16)$ & 0.241 \\
\hline Observations & 432 & & 438 & & \\
\hline$p$-value of joint test & & & & & 0.437 \\
\hline
\end{tabular}

Notes: Sample includes 870 permanent full-time employees who wanted to enroll in the deferred wages scheme at the social network survey. Treatment-control differences and $p$-values estimated by running Equation 1 with the balance variable on the left-hand side. The joint balance test is conducted by putting the treatment indicator on the left-hand side of Equation 1 and adding all the balance variables to the right-hand side. Monetary values are in Malawi Kwacha (MK); \$1 USD equalled approximately MK 750 at the time of the experiment. 
Table A2: Predictors of Attrition by Treatment Status

\begin{tabular}{|c|c|c|c|c|c|c|c|c|c|c|}
\hline & (1) & $(2)$ & (3) & $(4)$ & $(5)$ & (6) & (7) & (8) & (9) & $(10)$ \\
\hline & \multicolumn{10}{|c|}{ Outcome: Attrited [=1] } \\
\hline & \multicolumn{2}{|c|}{ Survey Round 1} & \multicolumn{2}{|c|}{ Survey Round 2} & \multicolumn{2}{|c|}{ Survey Round 3} & \multicolumn{2}{|c|}{ Survey Round 4} & \multicolumn{2}{|c|}{ Survey Round 5} \\
\hline Treatment & $\begin{array}{c}-0.007 \\
(0.013)\end{array}$ & $\begin{array}{l}-0.007 \\
(0.013)\end{array}$ & $\begin{array}{c}-0.030^{*} \\
(0.018)\end{array}$ & $\begin{array}{c}-0.030^{*} \\
(0.018)\end{array}$ & $\begin{array}{c}0.002 \\
(0.020)\end{array}$ & $\begin{array}{c}0.002 \\
(0.020)\end{array}$ & $\begin{array}{c}-0.031 \\
(0.026)\end{array}$ & $\begin{array}{c}-0.031 \\
(0.026)\end{array}$ & $\begin{array}{c}-0.005 \\
(0.029)\end{array}$ & $\begin{array}{c}-0.004 \\
(0.029)\end{array}$ \\
\hline Male & $\begin{array}{c}0.021 \\
(0.021)\end{array}$ & $\begin{array}{c}0.027 \\
(0.039)\end{array}$ & $\begin{array}{c}0.018 \\
(0.024)\end{array}$ & $\begin{array}{c}0.006 \\
(0.042)\end{array}$ & $\begin{array}{l}-0.025 \\
(0.028)\end{array}$ & $\begin{array}{l}-0.006 \\
(0.047)\end{array}$ & $\begin{array}{c}0.014 \\
(0.039)\end{array}$ & $\begin{array}{l}-0.013 \\
(0.066)\end{array}$ & $\begin{array}{l}-0.006 \\
(0.043)\end{array}$ & $\begin{array}{c}0.043 \\
(0.069)\end{array}$ \\
\hline Married & $\begin{array}{c}0.001 \\
(0.009)\end{array}$ & $\begin{array}{l}-0.006 \\
(0.017)\end{array}$ & $\begin{array}{c}0.011 \\
(0.012)\end{array}$ & $\begin{array}{l}-0.000 \\
(0.018)\end{array}$ & $\begin{array}{c}0.013 \\
(0.013)\end{array}$ & $\begin{array}{c}0.014 \\
(0.020)\end{array}$ & $\begin{array}{c}0.017 \\
(0.017)\end{array}$ & $\begin{array}{c}0.029 \\
(0.029)\end{array}$ & $\begin{array}{c}0.019 \\
(0.019)\end{array}$ & $\begin{array}{l}-0.028 \\
(0.030)\end{array}$ \\
\hline Age & $\begin{array}{c}0.001 \\
(0.001)\end{array}$ & $\begin{array}{c}0.000 \\
(0.001)\end{array}$ & $\begin{array}{l}0.002^{*} \\
(0.001)\end{array}$ & $\begin{array}{c}0.002 \\
(0.001)\end{array}$ & $\begin{array}{c}0.002 \\
(0.001)\end{array}$ & $\begin{array}{l}-0.000 \\
(0.002)\end{array}$ & $\begin{array}{c}0.002 \\
(0.001)\end{array}$ & $\begin{array}{c}0.001 \\
(0.002)\end{array}$ & $\begin{array}{c}0.001 \\
(0.002)\end{array}$ & $\begin{array}{c}0.003 \\
(0.002)\end{array}$ \\
\hline Years of schooling & $\begin{array}{c}0.002 \\
(0.002)\end{array}$ & $\begin{array}{l}-0.000 \\
(0.004)\end{array}$ & $\begin{array}{c}0.002 \\
(0.003)\end{array}$ & $\begin{array}{c}0.003 \\
(0.005)\end{array}$ & $\begin{array}{c}0.002 \\
(0.004)\end{array}$ & $\begin{array}{c}0.000 \\
(0.005)\end{array}$ & $\begin{array}{l}0.006 \\
(0.004)\end{array}$ & $\begin{array}{c}0.005 \\
(0.006)\end{array}$ & $\begin{array}{c}0.003 \\
(0.005)\end{array}$ & $\begin{array}{c}0.001 \\
(0.007)\end{array}$ \\
\hline Number of children in household & $\begin{array}{c}0.005 \\
(0.005)\end{array}$ & $\begin{array}{l}0.012^{*} \\
(0.007)\end{array}$ & $\begin{array}{c}0.002 \\
(0.008)\end{array}$ & $\begin{array}{c}0.004 \\
(0.012)\end{array}$ & $\begin{array}{l}-0.003 \\
(0.008)\end{array}$ & $\begin{array}{l}-0.001 \\
(0.010)\end{array}$ & $\begin{array}{l}-0.001 \\
(0.009)\end{array}$ & $\begin{array}{c}0.006 \\
(0.014)\end{array}$ & $\begin{array}{l}-0.016 \\
(0.011)\end{array}$ & $\begin{array}{l}-0.019 \\
(0.015)\end{array}$ \\
\hline Plucker & $\begin{array}{c}0.005 \\
(0.034)\end{array}$ & $\begin{array}{c}0.014 \\
(0.045)\end{array}$ & $\begin{array}{l}-0.027 \\
(0.042)\end{array}$ & $\begin{array}{l}-0.074 \\
(0.051)\end{array}$ & $\begin{array}{c}0.008 \\
(0.045)\end{array}$ & $\begin{array}{l}-0.035 \\
(0.057)\end{array}$ & $\begin{array}{l}-0.006 \\
(0.053)\end{array}$ & $\begin{array}{l}-0.080 \\
(0.075)\end{array}$ & $\begin{array}{c}0.025 \\
(0.059)\end{array}$ & $\begin{array}{c}0.101 \\
(0.078)\end{array}$ \\
\hline Share of days plucked tea, admin. & $\begin{array}{l}-0.107 \\
(0.068)\end{array}$ & $\begin{array}{l}-0.136^{*} \\
(0.078)\end{array}$ & $\begin{array}{c}-0.193^{* *} \\
(0.086)\end{array}$ & $\begin{array}{l}-0.178^{*} \\
(0.094)\end{array}$ & $\begin{array}{c}-0.188^{* *} \\
(0.092)\end{array}$ & $\begin{array}{c}-0.260^{* *} \\
(0.118)\end{array}$ & $\begin{array}{l}-0.027 \\
(0.115)\end{array}$ & $\begin{array}{l}-0.037 \\
(0.156)\end{array}$ & $\begin{array}{l}-0.255^{*} \\
(0.139)\end{array}$ & $\begin{array}{l}-0.281 \\
(0.186)\end{array}$ \\
\hline Average daily output [10 kg], admin. & $\begin{array}{c}0.001 \\
(0.001)\end{array}$ & $\begin{array}{c}0.002 \\
(0.001)\end{array}$ & $\begin{array}{c}0.002 \\
(0.001)\end{array}$ & $\begin{array}{c}0.002 \\
(0.002)\end{array}$ & $\begin{array}{l}0.003^{*} \\
(0.002)\end{array}$ & $\begin{array}{c}0.007^{* * *} \\
(0.003)\end{array}$ & $\begin{array}{l}-0.000 \\
(0.002)\end{array}$ & $\begin{array}{c}0.003 \\
(0.003)\end{array}$ & $\begin{array}{l}0.005^{*} \\
(0.003)\end{array}$ & $\begin{array}{c}0.005 \\
(0.004)\end{array}$ \\
\hline $\mathrm{HH}$ inc. past 14 days $[1,000 \mathrm{MK}]$, survey & $\begin{array}{c}0.001 \\
(0.004)\end{array}$ & $\begin{array}{c}0.006 \\
(0.008)\end{array}$ & $\begin{array}{l}-0.002 \\
(0.005)\end{array}$ & $\begin{array}{c}0.002 \\
(0.009)\end{array}$ & $\begin{array}{c}0.004 \\
(0.005)\end{array}$ & $\begin{array}{c}0.011 \\
(0.009)\end{array}$ & $\begin{array}{c}0.002 \\
(0.007)\end{array}$ & $\begin{array}{c}0.003 \\
(0.011)\end{array}$ & $\begin{array}{l}-0.006 \\
(0.007)\end{array}$ & $\begin{array}{c}-0.002 \\
(0.010)\end{array}$ \\
\hline Formal savings $[1,000 \mathrm{MK}]$ & $\begin{array}{c}0.002 \\
(0.012)\end{array}$ & $\begin{array}{c}0.013 \\
(0.019)\end{array}$ & $\begin{array}{c}-0.028^{* * *} \\
(0.008)\end{array}$ & $\begin{array}{c}-0.032^{* * *} \\
(0.010)\end{array}$ & $\begin{array}{c}-0.031^{* * *} \\
(0.009)\end{array}$ & $\begin{array}{c}-0.022^{*} \\
(0.012)\end{array}$ & $\begin{array}{c}-0.034^{* *} \\
(0.014)\end{array}$ & $\begin{array}{l}-0.024 \\
(0.021)\end{array}$ & $\begin{array}{c}0.004 \\
(0.025)\end{array}$ & $\begin{array}{l}-0.022 \\
(0.027)\end{array}$ \\
\hline Informal savings $[1,000 \mathrm{MK}]$ & $\begin{array}{l}-0.001 \\
(0.001)\end{array}$ & $\begin{array}{l}-0.001 \\
(0.002)\end{array}$ & $\begin{array}{c}0.003 \\
(0.003)\end{array}$ & $\begin{array}{c}0.003 \\
(0.004)\end{array}$ & $\begin{array}{l}-0.001 \\
(0.003)\end{array}$ & $\begin{array}{l}-0.004 \\
(0.003)\end{array}$ & $\begin{array}{c}0.003 \\
(0.004)\end{array}$ & $\begin{array}{l}-0.004 \\
(0.004)\end{array}$ & $\begin{array}{l}-0.001 \\
(0.004)\end{array}$ & $\begin{array}{l}-0.001 \\
(0.005)\end{array}$ \\
\hline Asset index (PCA) & $\begin{array}{c}0.007 \\
(0.007)\end{array}$ & $\begin{array}{l}-0.000 \\
(0.010)\end{array}$ & $\begin{array}{c}0.010 \\
(0.010)\end{array}$ & $\begin{array}{l}-0.004 \\
(0.016)\end{array}$ & $\begin{array}{c}0.031^{* *} \\
(0.013)\end{array}$ & $\begin{array}{l}0.035^{*} \\
(0.019)\end{array}$ & $\begin{array}{c}0.016 \\
(0.015)\end{array}$ & $\begin{array}{c}0.010 \\
(0.023)\end{array}$ & $\begin{array}{c}0.038^{* *} \\
(0.018)\end{array}$ & $\begin{array}{c}0.057^{* *} \\
(0.026)\end{array}$ \\
\hline Total 14-day expenditures $[1,000 \mathrm{MK}]$ & $\begin{array}{c}-0.008^{*} \\
(0.004)\end{array}$ & $\begin{array}{c}-0.014^{* *} \\
(0.007)\end{array}$ & $\begin{array}{l}-0.005 \\
(0.007)\end{array}$ & $\begin{array}{l}-0.013 \\
(0.012)\end{array}$ & $\begin{array}{l}-0.000 \\
(0.009)\end{array}$ & $\begin{array}{l}-0.004 \\
(0.014)\end{array}$ & $\begin{array}{c}0.002 \\
(0.013)\end{array}$ & $\begin{array}{c}0.012 \\
(0.020)\end{array}$ & $\begin{array}{c}0.011 \\
(0.013)\end{array}$ & $\begin{array}{c}0.006 \\
(0.019)\end{array}$ \\
\hline Any purchase $>5 \mathrm{k}$, past 30 days & $\begin{array}{c}-0.042^{* * *} \\
(0.013)\end{array}$ & $\begin{array}{c}-0.045^{* *} \\
(0.023)\end{array}$ & $\begin{array}{l}-0.017 \\
(0.061)\end{array}$ & $\begin{array}{c}0.108 \\
(0.160)\end{array}$ & $\begin{array}{c}0.027 \\
(0.077)\end{array}$ & $\begin{array}{c}-0.064^{*} \\
(0.038)\end{array}$ & $\begin{array}{c}-0.157^{* * *} \\
(0.024)\end{array}$ & $\begin{array}{c}-0.146^{* * *} \\
(0.050)\end{array}$ & $\begin{array}{l}-0.113 \\
(0.071)\end{array}$ & $\begin{array}{c}-0.218^{* * *} \\
(0.049)\end{array}$ \\
\hline
\end{tabular}


Table A2: Predictors of Attrition by Treatment Status (continued)

\begin{tabular}{|c|c|c|c|c|c|c|c|c|c|c|}
\hline & (1) & $(2)$ & $(3)$ & (4) & (5) & (6) & (7) & (8) & (9) & (10) \\
\hline & \multicolumn{10}{|c|}{ Outcome: Attrited $[=1]$} \\
\hline & \multicolumn{2}{|c|}{ Survey Round 1} & \multicolumn{2}{|c|}{ Survey Round 2} & \multicolumn{2}{|c|}{ Survey Round 3} & \multicolumn{2}{|c|}{ Survey Round 4} & \multicolumn{2}{|c|}{ Survey Round 5} \\
\hline \multicolumn{11}{|l|}{ Treatment interacted with: } \\
\hline Male & & $\begin{array}{l}-0.015 \\
(0.044)\end{array}$ & & $\begin{array}{c}0.017 \\
(0.052)\end{array}$ & & $\begin{array}{l}-0.053 \\
(0.059)\end{array}$ & & $\begin{array}{c}0.036 \\
(0.083)\end{array}$ & & $\begin{array}{l}-0.067 \\
(0.088)\end{array}$ \\
\hline Married & & $\begin{array}{c}0.015 \\
(0.019)\end{array}$ & & $\begin{array}{c}0.028 \\
(0.024)\end{array}$ & & $\begin{array}{c}0.002 \\
(0.025)\end{array}$ & & $\begin{array}{l}-0.017 \\
(0.036)\end{array}$ & & $\begin{array}{c}0.080^{* *} \\
(0.038)\end{array}$ \\
\hline Age & & $\begin{array}{c}0.001 \\
(0.001)\end{array}$ & & $\begin{array}{l}-0.001 \\
(0.002)\end{array}$ & & $\begin{array}{c}0.003 \\
(0.002)\end{array}$ & & $\begin{array}{c}0.002 \\
(0.003)\end{array}$ & & $\begin{array}{l}-0.003 \\
(0.003)\end{array}$ \\
\hline Years of schooling & & $\begin{array}{c}0.004 \\
(0.005)\end{array}$ & & $\begin{array}{l}-0.002 \\
(0.006)\end{array}$ & & $\begin{array}{c}0.003 \\
(0.007)\end{array}$ & & $\begin{array}{c}0.001 \\
(0.009)\end{array}$ & & $\begin{array}{c}0.003 \\
(0.010)\end{array}$ \\
\hline Number of children in household & & $\begin{array}{l}-0.015 \\
(0.010)\end{array}$ & & $\begin{array}{l}-0.004 \\
(0.015)\end{array}$ & & $\begin{array}{l}-0.002 \\
(0.015)\end{array}$ & & $\begin{array}{l}-0.014 \\
(0.019)\end{array}$ & & $\begin{array}{c}0.003 \\
(0.021)\end{array}$ \\
\hline Plucker & & $\begin{array}{l}-0.013 \\
(0.063)\end{array}$ & & $\begin{array}{c}0.093 \\
(0.078)\end{array}$ & & $\begin{array}{c}0.082 \\
(0.085)\end{array}$ & & $\begin{array}{c}0.126 \\
(0.101)\end{array}$ & & $\begin{array}{l}-0.140 \\
(0.115)\end{array}$ \\
\hline Share of days plucked tea, admin. & & $\begin{array}{c}0.055 \\
(0.115)\end{array}$ & & $\begin{array}{c}-0.021 \\
(0.147)\end{array}$ & & $\begin{array}{c}0.179 \\
(0.172)\end{array}$ & & $\begin{array}{c}0.051 \\
(0.219)\end{array}$ & & $\begin{array}{c}0.078 \\
(0.255)\end{array}$ \\
\hline Average daily output [10 kg], admin. & & $\begin{array}{l}-0.002 \\
(0.002)\end{array}$ & & $\begin{array}{l}-0.001 \\
(0.002)\end{array}$ & & $\begin{array}{c}-0.009^{* * *} \\
(0.003)\end{array}$ & & $\begin{array}{l}-0.006 \\
(0.004)\end{array}$ & & $\begin{array}{l}-0.001 \\
(0.005)\end{array}$ \\
\hline $\mathrm{HH}$ inc. past 14 days $[1000 \mathrm{MK}]$, survey & & $\begin{array}{l}-0.010 \\
(0.008)\end{array}$ & & $\begin{array}{c}-0.009 \\
(0.010)\end{array}$ & & $\begin{array}{l}-0.015 \\
(0.011)\end{array}$ & & $\begin{array}{c}-0.004 \\
(0.014)\end{array}$ & & $\begin{array}{l}-0.008 \\
(0.014)\end{array}$ \\
\hline Formal savings [1000 MK] & & $\begin{array}{l}-0.024 \\
(0.020)\end{array}$ & & $\begin{array}{c}0.015 \\
(0.017)\end{array}$ & & $\begin{array}{l}-0.019 \\
(0.018)\end{array}$ & & $\begin{array}{l}-0.025 \\
(0.028)\end{array}$ & & $\begin{array}{c}0.072 \\
(0.050)\end{array}$ \\
\hline Informal savings [1000 MK] & & $\begin{array}{c}0.000 \\
(0.002)\end{array}$ & & $\begin{array}{c}0.000 \\
(0.005)\end{array}$ & & $\begin{array}{c}0.006 \\
(0.005)\end{array}$ & & $\begin{array}{r}0.016^{* *} \\
(0.007)\end{array}$ & & $\begin{array}{l}-0.001 \\
(0.007)\end{array}$ \\
\hline Asset index (PCA) & & $\begin{array}{c}0.015 \\
(0.014)\end{array}$ & & $\begin{array}{c}0.029 \\
(0.020)\end{array}$ & & $\begin{array}{l}-0.005 \\
(0.026)\end{array}$ & & $\begin{array}{c}0.012 \\
(0.031)\end{array}$ & & $\begin{array}{l}-0.042 \\
(0.035)\end{array}$ \\
\hline Total 14-day expenditures [1000 MK] & & $\begin{array}{c}0.012 \\
(0.009)\end{array}$ & & $\begin{array}{c}0.015 \\
(0.014)\end{array}$ & & $\begin{array}{c}0.008 \\
(0.018)\end{array}$ & & $\begin{array}{l}-0.021 \\
(0.024)\end{array}$ & & $\begin{array}{c}0.015 \\
(0.026)\end{array}$ \\
\hline Any purchase $>5 \mathrm{k}$, past 30 days & & $\begin{array}{c}0.009 \\
(0.031)\end{array}$ & & $\begin{array}{l}-0.177 \\
(0.163)\end{array}$ & & $\begin{array}{c}0.176 \\
(0.123)\end{array}$ & & $\begin{array}{c}0.016 \\
(0.062)\end{array}$ & & $\begin{array}{c}0.112 \\
(0.112)\end{array}$ \\
\hline Observations & 870 & 870 & 870 & 870 & 870 & 870 & 870 & 870 & 870 & 870 \\
\hline $\begin{array}{l}\text { Adjusted R-squared } \\
p \text {-values for: }\end{array}$ & 0.00 & 0.00 & 0.04 & 0.04 & 0.02 & 0.02 & 0.02 & 0.02 & 0.04 & 0.04 \\
\hline Treatment indicator & 0.603 & 0.601 & 0.094 & 0.091 & 0.930 & 0.921 & 0.229 & 0.231 & 0.865 & 0.889 \\
\hline Interactions & & 0.871 & & 0.441 & & 0.180 & & 0.578 & & 0.259 \\
\hline Treatment and interactions & & 0.907 & & 0.382 & & 0.229 & & 0.473 & & 0.316 \\
\hline Control-group Average & 0.037 & 0.037 & 0.086 & 0.086 & 0.095 & 0.095 & 0.188 & 0.188 & 0.248 & 0.248 \\
\hline
\end{tabular}

Notes: Sample includes 870 permanent full-time employees who wanted to enroll in the deferred wages scheme at the social network survey. Heteroskedasticity-robust standard errors in parentheses: ${ }^{*} p<0.1 ;{ }^{* *} p<0.05$; $* * * p<0.01$. 
Table A3: Correlates of Enrollment

\begin{tabular}{|c|c|c|c|c|}
\hline & $(1)$ & (2) & $(3)$ & (4) \\
\hline & \multirow{2}{*}{\multicolumn{2}{|c|}{ Summary statistics }} & \multicolumn{2}{|c|}{ Regression Results } \\
\hline & & & \multicolumn{2}{|c|}{$\begin{array}{l}\text { Dep. var.: } \\
\text { Found for offer interview } \\
\text { and wants to sign up }[=1]\end{array}$} \\
\hline & Average & S.D. & Coef. & (S.E.) \\
\hline \multicolumn{5}{|l|}{ Demographics } \\
\hline Female & 0.38 & 0.48 & $-0.06^{* *}$ & $(0.02)$ \\
\hline Age [10s of years] & 3.95 & 1.14 & 0.00 & $(0.01)$ \\
\hline Married & 0.68 & 0.47 & 0.03 & $(0.02)$ \\
\hline \multicolumn{5}{|l|}{ Economic status } \\
\hline Worried about having enough food in off-season & 0.73 & 0.44 & $-0.15^{* * *}$ & $(0.03)$ \\
\hline Expected income in typical pay period [10000 MK] & 1.68 & 0.43 & $0.16^{* * *}$ & $(0.03)$ \\
\hline \multicolumn{5}{|l|}{ Savings group participation } \\
\hline Currently participating & 0.87 & 0.34 & $0.42^{* * *}$ & $(0.02)$ \\
\hline Participated in last main season & 0.68 & 0.47 & -0.02 & $(0.02)$ \\
\hline \multicolumn{5}{|l|}{ Main savings goal for the next 12 months } \\
\hline Build/improve house & 0.34 & 0.47 & $0.08^{* * *}$ & $(0.02)$ \\
\hline Food & 0.26 & 0.44 & $-0.10^{* * *}$ & $(0.03)$ \\
\hline School fees & 0.15 & 0.36 & $-0.12^{* * *}$ & $(0.03)$ \\
\hline Household asset & 0.12 & 0.33 & $0.11^{* * *}$ & $(0.04)$ \\
\hline Other & 0.13 & 0.34 & 0.05 & $(0.03)$ \\
\hline \multicolumn{5}{|l|}{ Biggest challenge for saving } \\
\hline Temptation to spend & 0.37 & 0.48 & $0.12^{* * *}$ & $(0.02)$ \\
\hline No money / Need to eat / Other spending needs & 0.34 & 0.47 & $-0.18^{* * *}$ & $(0.02)$ \\
\hline Pressure from relatives or friends to give money & 0.10 & 0.30 & 0.01 & $(0.04)$ \\
\hline Health shocks & 0.07 & 0.25 & 0.04 & $(0.05)$ \\
\hline Fear of theft (from family or non-family) & 0.04 & 0.20 & 0.07 & $(0.06)$ \\
\hline Other & 0.09 & 0.28 & $0.07^{*}$ & $(0.04)$ \\
\hline Observations & $1,897^{\dagger}$ & & $1,897^{\dagger}$ & \\
\hline Average of outcome variable & & & 0.458 & \\
\hline
\end{tabular}

Notes: This table presents correlations of eventual enrollment in the deferred wage scheme offered for the main intervention. Heteroskedasticity-robust standard errors in parentheses: ${ }^{*} p<0.1$; ${ }^{* *} p<0.05$; ${ }^{* * *}$ $p<0.01$.

$\dagger:$ "Expected income" has one missing observation. We deal with the missing observation by creating an indicator for missing and setting the missing value equal to zero for the respondent. 
Table A4: Impacts on Informal Savings by Category (February-April 2017)

\begin{tabular}{|c|c|c|c|c|c|c|c|c|c|c|c|}
\hline & $(1)$ & $(2)$ & $(3)$ & $(4)$ & $(5)$ & $(6)$ & $(7)$ & $(8)$ & $(9)$ & $(10)$ & $(11)$ \\
\hline & \multicolumn{11}{|c|}{ Informal Savings } \\
\hline & \multicolumn{6}{|c|}{ Financial Savings } & \multicolumn{5}{|c|}{ Non-Financial Savings } \\
\hline & $\begin{array}{c}\text { Total } \\
\text { Informal } \\
\text { Savings }\end{array}$ & Total & $\begin{array}{c}\text { Cash at } \\
\text { Home or } \\
\text { Hidden }\end{array}$ & $\begin{array}{c}\text { Held by } \\
\text { Someone } \\
\text { Else for } \\
\text { Safekeeping }\end{array}$ & $\begin{array}{l}\text { Cash in } \\
\text { Pockets }\end{array}$ & $\begin{array}{l}\text { Savings } \\
\text { Groups }\end{array}$ & Total & $\begin{array}{c}\text { Business } \\
\text { Inventory }\end{array}$ & $\begin{array}{c}\text { Stored } \\
\text { Food }\end{array}$ & Maize & $\begin{array}{l}\text { Other } \\
\text { Food }\end{array}$ \\
\hline \multicolumn{12}{|c|}{ Panel A: Any Deposit in past 14 days [=1] (Pooled Follow-up 1 \& 2) } \\
\hline Treatment & $\begin{array}{l}-0.001 \\
(0.001)\end{array}$ & $\begin{array}{c}-0.072^{* * *} \\
(0.025)\end{array}$ & $\begin{array}{c}-0.016 \\
(0.019)\end{array}$ & $\begin{array}{c}0.001 \\
(0.009)\end{array}$ & $\begin{array}{c}0.036^{* *} \\
(0.018)\end{array}$ & $\begin{array}{c}-0.063^{* *} \\
(0.028)\end{array}$ & $\begin{array}{c}0.000 \\
(0.002)\end{array}$ & $\begin{array}{c}0.001 \\
(0.009)\end{array}$ & $\begin{array}{c}0.000 \\
(0.002)\end{array}$ & $\begin{array}{c}0.021 \\
(0.022)\end{array}$ & $\begin{array}{c}0.000 \\
(0.003)\end{array}$ \\
\hline Source: & Surveys & Surveys & Surveys & Surveys & Surveys & Surveys & Surveys & Surveys & Surveys & Surveys & Surveys \\
\hline Observations & 1,651 & 1,651 & 1,651 & 1,651 & 810 & 1,651 & 1,651 & 1,651 & 1,651 & 1,651 & 1,651 \\
\hline Adjusted R-squared & 0.00 & 0.12 & 0.04 & 0.00 & 0.00 & 0.12 & 0.00 & 0.02 & 0.00 & 0.05 & 0.00 \\
\hline Control-group Average & 1.000 & 0.698 & 0.201 & 0.030 & 0.051 & 0.597 & 0.999 & 0.027 & 0.999 & 0.732 & 0.996 \\
\hline \multicolumn{12}{|c|}{ Panel B: Savings balances at end of deduction period [MK] (Follow-up 2 Only) } \\
\hline Treatment & $\begin{array}{c}-3,609^{*} \\
(1,926)\end{array}$ & $\begin{array}{l}-1,340 \\
(1,195)\end{array}$ & $\begin{array}{r}-1,161 \\
(717)\end{array}$ & $\begin{array}{c}180 \\
(199)\end{array}$ & $\begin{array}{c}28 \\
(103)\end{array}$ & $\begin{array}{l}-328 \\
(797)\end{array}$ & $\begin{array}{c}-2,305^{* *} \\
(1,116)\end{array}$ & $\begin{array}{c}20 \\
(426)\end{array}$ & $\begin{array}{c}-2,258^{* *} \\
(943)\end{array}$ & $\begin{array}{c}-2,161^{* *} \\
(838)\end{array}$ & $\begin{array}{l}-236 \\
(215)\end{array}$ \\
\hline Source: & Surveys & Surveys & Surveys & Surveys & Surveys & Surveys & Surveys & Surveys & Surveys & Surveys & Surveys \\
\hline Observations & 810 & 810 & 810 & 810 & 810 & 810 & 810 & 810 & 810 & 810 & 810 \\
\hline Adjusted R-squared & 0.150 & 0.06 & 0.04 & 0.01 & 0.01 & 0.03 & 0.21 & 0.01 & 0.24 & 0.22 & 0.10 \\
\hline Control-group Average & 26,850 & 11,281 & 5,057 & 436 & 380 & 5,102 & 15,256 & 996 & 14,123 & 12,328 & 1,601 \\
\hline
\end{tabular}

Notes: All measures of reported savings outcomes are recorded during the deductions period of the savings scheme, which ran from February to April 2017. Each outcome is an aggregate or detailed measure of reported savings. Monetary values are in Malawi Kwacha (MK); \$1 USD equalled approximately MK 750 at the time of the experiment. Heteroskedasticity-robust standard errors, clustered by worker, in parentheses: ${ }^{*} p<0.1 ; * * \quad p<0.05 ; * * *<0.01$. 
Table A5: Flow of Funds After Lump-Sum Payout

\begin{tabular}{|c|c|c|c|c|}
\hline & $(1)$ & $(2)$ & $\overline{(3)}$ & $(4)$ \\
\hline & $\begin{array}{c}\text { Total } \\
\text { expenditures } \\
{[\mathrm{MK}]}\end{array}$ & $\begin{array}{c}\text { Net savings } \\
\text { deposits } \\
\text { (excluding } \\
\text { savings scheme) } \\
{[\mathrm{MK}]} \\
\end{array}$ & $\begin{array}{c}\text { Net money } \\
\text { loaned } \\
{[\mathrm{MK}]} \\
\end{array}$ & $\begin{array}{c}\text { Net transfers } \\
\text { made } \\
{[\mathrm{MK}]}\end{array}$ \\
\hline \multicolumn{5}{|c|}{ Panel A: Interviewed within 14 days of payout (recall period = days since payout) } \\
\hline Treatment & $\begin{array}{c}5,787^{* * *} \\
(1,261)\end{array}$ & $\begin{array}{c}291 \\
(710)\end{array}$ & $\begin{array}{l}712^{* *} \\
(361)\end{array}$ & $\begin{array}{c}153 \\
(175)\end{array}$ \\
\hline Observations & 342 & 342 & 342 & 342 \\
\hline Adjusted R-squared & 0.11 & 0.02 & -0.03 & -0.01 \\
\hline Control-group Average & 16,060 & 1,783 & -305 & 9 \\
\hline \multicolumn{5}{|c|}{ Panel B: Interviewed more than 14 days after payout (recall period $=14$ days, fixed) } \\
\hline Treatment & $\begin{array}{c}-772 \\
(1,249)\end{array}$ & $\begin{array}{c}-151 \\
(698)\end{array}$ & $\begin{array}{c}640^{* *} \\
(305)\end{array}$ & $\begin{array}{c}-102 \\
(164)\end{array}$ \\
\hline Observations & 446 & 446 & 446 & 446 \\
\hline Adjusted R-squared & 0.04 & 0.01 & 0.00 & -0.01 \\
\hline Control-group Average & 17,598 & 738 & -124 & 27 \\
\hline
\end{tabular}

Notes: The lump sum payout of the workers' deferred wages occurred on May 6, 2017. The data for postpayout outcomes comes from the third follow-up survey. Monetary values are in Malawi Kwacha (MK); $\$ 1$ USD equalled approximately MK 750 at the time of the experiment. Heteroskedasticity-robust standard errors in parentheses: ${ }^{*} p<0.1 ;{ }^{* *} p<0.05 ;{ }^{* * *} p<0.01$. 
Table A6: Impacts on Short-term Expenditures Following Payout by Week

\begin{tabular}{|c|c|c|c|c|c|c|c|c|c|c|c|c|}
\hline \multirow[b]{5}{*}{ Treeatment interactions } & \multirow[b]{5}{*}{ Interview dates } & \multirow{5}{*}{$\begin{array}{l}\text { Recall period } \\
\text { for questions } \\
\quad \text { (days) }\end{array}$} & \multirow{5}{*}{$\begin{array}{c}\text { Recall period } \\
\text { includes day } \\
\text { of payout? }\end{array}$} & \multirow[b]{5}{*}{$\mathrm{N}$} & (1) & (2) & (3) & (4) & (5) & (6) & \multirow{2}{*}{\multicolumn{2}{|c|}{$\begin{array}{cc}(7) & (8) \\
\text { Bulk purchases/day }\end{array}$}} \\
\hline & & & & & \multicolumn{6}{|c|}{ Spending per day [MK] } & & \\
\hline & & & & & \multirow[b]{3}{*}{ Total } & \multicolumn{3}{|c|}{ Food } & \multicolumn{2}{|c|}{ Durables } & \multirow{3}{*}{$\begin{array}{c}\text { Any } \\
\text { purchase } \\
>5 \mathrm{k} \\
{[=1]}\end{array}$} & \multirow{3}{*}{$\begin{array}{c}\text { Sum of } \\
\text { purchases } \\
>5 \mathrm{k} \\
{[\mathrm{MK}]}\end{array}$} \\
\hline & & & & & & & \multicolumn{2}{|c|}{ Storable } & \multirow{2}{*}{\multicolumn{2}{|c|}{$\begin{array}{cc} & \text { House } \\
\text { All } & \text { improve- } \\
\text { durables } & \text { ments }\end{array}$}} & & \\
\hline & & & & & & All food & $\begin{array}{c}\text { All } \\
\text { Storable }\end{array}$ & $\begin{array}{l}\text { Maize } \\
\text { grain }\end{array}$ & & & & \\
\hline Treatment $\times$ week 1 & May $10-13$ & $4-7$ & Yes & 179 & $\begin{array}{c}973^{* * *} \\
(318)\end{array}$ & $\begin{array}{c}573^{* * *} \\
(141)\end{array}$ & $\begin{array}{c}509^{* * *} \\
(133)\end{array}$ & $\begin{array}{c}536^{* * *} \\
(129)\end{array}$ & $\begin{array}{l}218 \\
(238)\end{array}$ & $\begin{array}{c}221 \\
(140)\end{array}$ & $\begin{array}{c}0.016 \\
(0.013)\end{array}$ & $\begin{array}{l}525^{* *} \\
(267)\end{array}$ \\
\hline Treatment $\times$ week 2 & May $16-20$ & $10-14$ & Yes & 163 & $\begin{array}{c}676^{* * *} \\
(174)\end{array}$ & $\begin{array}{c}338^{* * *} \\
(77)\end{array}$ & $\begin{array}{c}283^{* * *} \\
(68)\end{array}$ & $\begin{array}{c}212^{* * *} \\
(61)\end{array}$ & $\begin{array}{l}325^{* *} \\
(138)\end{array}$ & $\begin{array}{c}169^{* *} \\
(85)\end{array}$ & $\begin{array}{c}0.019^{* * *} \\
(0.007)\end{array}$ & $\begin{array}{c}498^{* * *} \\
(160)\end{array}$ \\
\hline Treatment $\times$ week 3 & May $22-27$ & 14 & No & 218 & $\begin{array}{l}-115 \\
(133)\end{array}$ & $\begin{array}{l}-77 \\
(63)\end{array}$ & $\begin{array}{l}-26 \\
(53)\end{array}$ & $\begin{array}{l}-18 \\
(48)\end{array}$ & $\begin{array}{l}-11 \\
(86)\end{array}$ & $\begin{array}{c}25 \\
(45)\end{array}$ & $\begin{array}{l}0.000 \\
(0.005)\end{array}$ & $\begin{array}{l}-67 \\
(112)\end{array}$ \\
\hline Treatment $\times$ week 4 & May 29 - June 3 & 14 & No & 115 & $\begin{array}{l}-131 \\
(183)\end{array}$ & $\begin{array}{l}51 \\
(99)\end{array}$ & $\begin{array}{l}80 \\
(77)\end{array}$ & $\begin{array}{c}72 \\
(66)\end{array}$ & $\begin{array}{l}-148 \\
(115)\end{array}$ & $\begin{array}{l}-20 \\
(60)\end{array}$ & $\begin{array}{l}-0.001 \\
(0.006)\end{array}$ & $\begin{array}{l}-56 \\
(124)\end{array}$ \\
\hline Treatment $\times$ week 5 & June 5-10 & 14 & No & 115 & $\begin{array}{l}128 \\
(209)\end{array}$ & $\begin{array}{l}142 \\
(90)\end{array}$ & $\begin{array}{l}130^{*} \\
(69)\end{array}$ & $\begin{array}{l}106^{*} \\
(61)\end{array}$ & $\begin{array}{l}-53 \\
(157)\end{array}$ & $\begin{array}{l}-25 \\
(64)\end{array}$ & $\begin{array}{c}0.008 \\
(0.007)\end{array}$ & $\begin{array}{l}112 \\
(177)\end{array}$ \\
\hline \multicolumn{13}{|l|}{ Control-group Averages } \\
\hline Week 1 & & & & & 2,771 & 1,401 & 987 & 654 & 860 & 228 & 0.047 & 720 \\
\hline Week 2 & & & & & 1,563 & 847 & 633 & 421 & 498 & 169 & 0.034 & 557 \\
\hline Week 3 & & & & & 1,272 & 668 & 479 & 317 & 405 & 88 & 0.023 & 378 \\
\hline Week 4 & & & & & 1,282 & 748 & 523 & 350 & 344 & 77 & 0.023 & 340 \\
\hline Week 5 & & & & & 1,203 & 603 & 404 & 233 & 446 & 86 & 0.019 & 381 \\
\hline Adjusted R-squared & & & & & 0.23 & 0.25 & 0.18 & 0.13 & 0.06 & 0.02 & 0.05 & 0.06 \\
\hline
\end{tabular}

Notes: All measures of expenditure outcomes are recorded in the period after the lump-sum payout of the savings scheme, which happened on May 6, 2017. This data comes from the third follow-up survey (FS3). Each outcome is an aggregate or detailed measure of a type of expenditure. Monetary values are in Malawi Kwacha (MK); \$1 USD equalled approximately MK 750 at the time of the experiment. Heteroskedasticity-robust standard errors in parentheses: ${ }^{*} p<0.1 ;{ }^{* *} p<0.05 ;{ }^{* * *} p<0.01$. 
Table A7: Downstream Effects on Asset Ownership_Full List of Outcomes

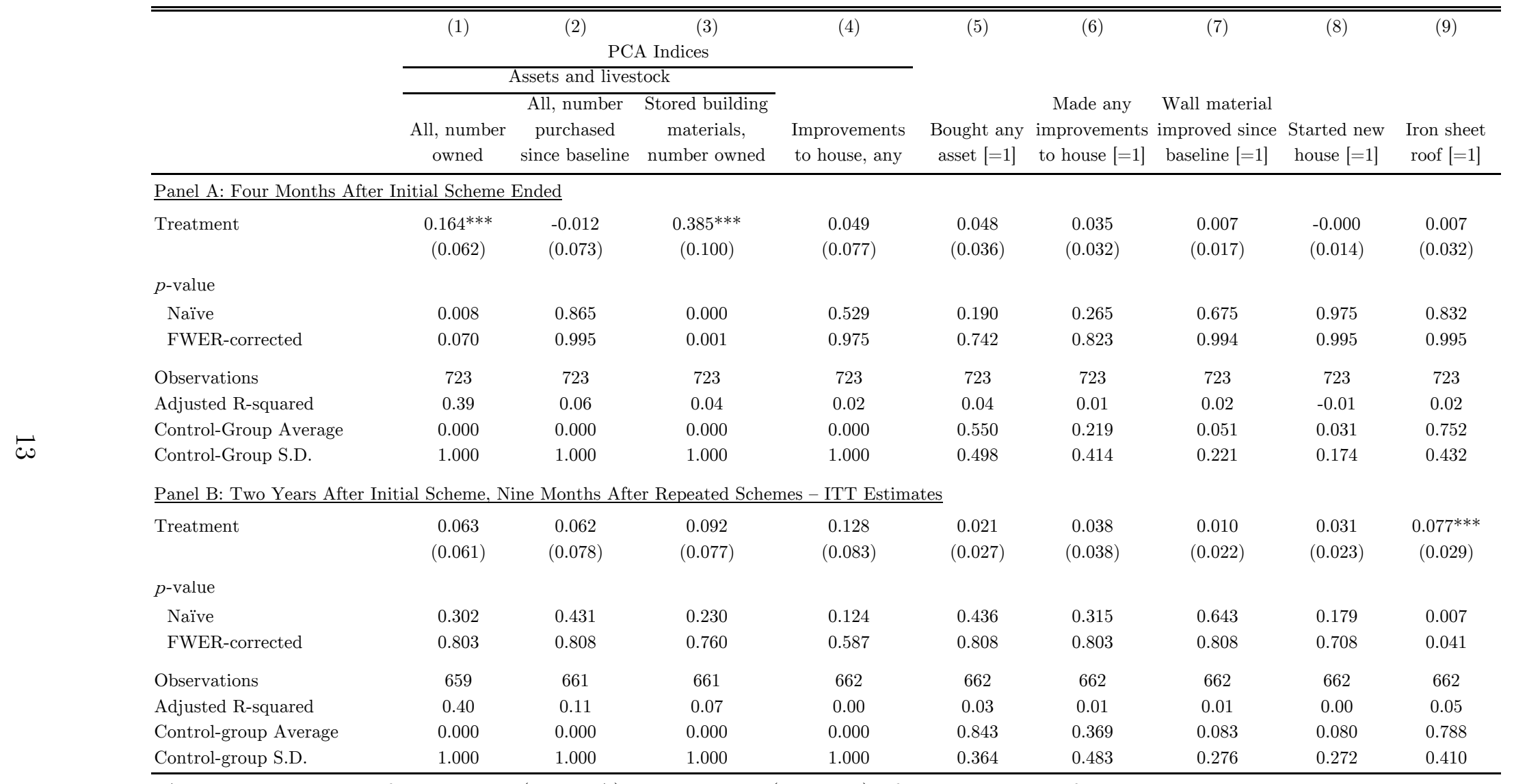

Notes: Assets are measured four months (Panel A) or two years (Panel B) after the payout of the initial savings scheme, using survey data from the fourth and fifth follow-up surveys, respectively. The treatment group was re-treated twice between the four-month and the two-year follow-up, and there was then a nine-month delay before data collection. Monetary values are in Malawi Kwacha (MK); \$1 USD equalled approximately MK 750 at the time of the experiment. Heteroskedasticity-robust standard errors in parentheses: ${ }^{*} p<0.1 ;{ }^{* *} p<0.05 ;{ }^{* * *}$ $p<0.01$. 
Table A8: Downstream Effects on Asset Ownership-Adjusting for Potential Spillovers

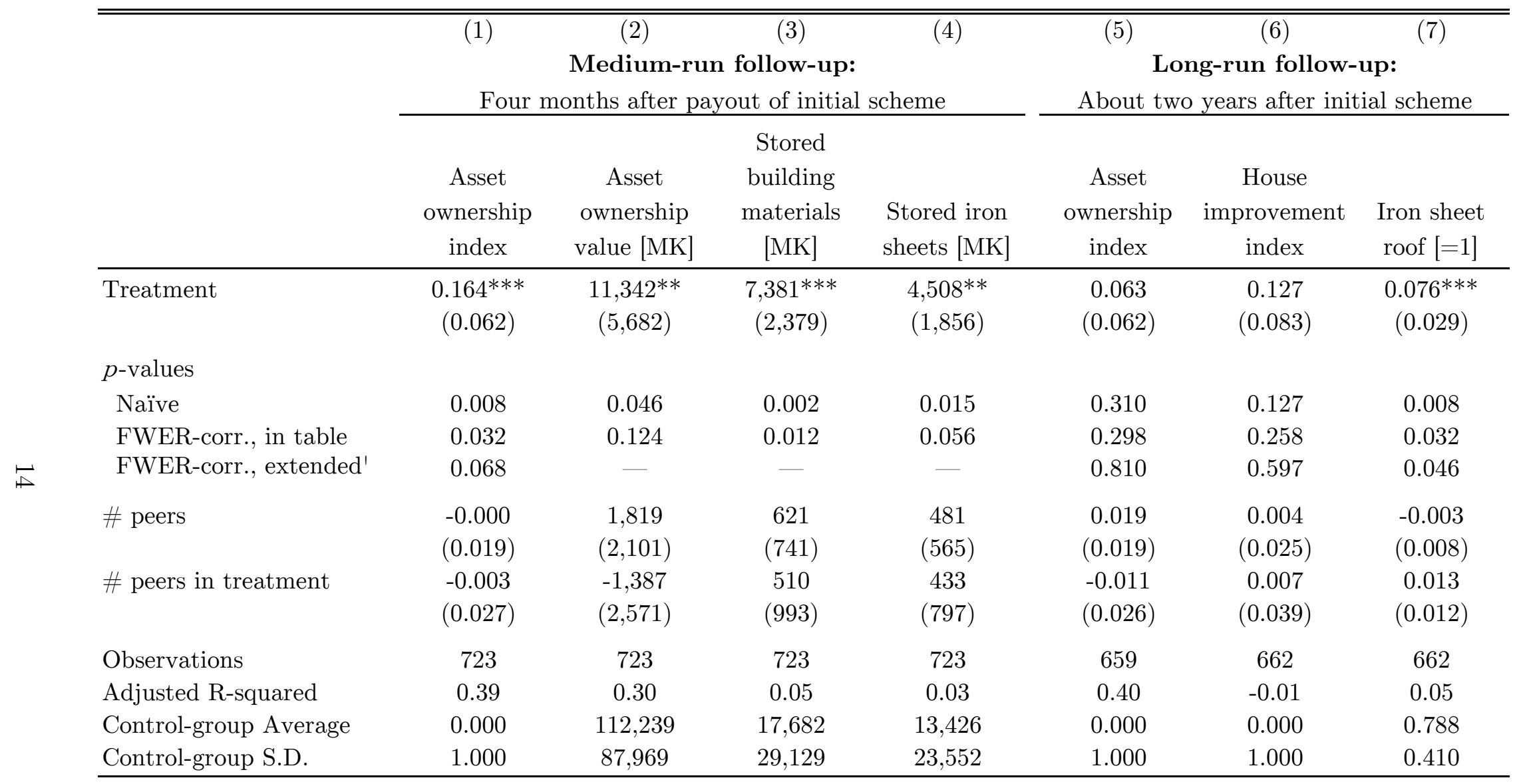

Notes: Assets are measured four months (Panel A) or two years (Panel B) after the payout of the initial savings scheme, using survey data from the fourth and fifth follow-up surveys, respectively. The treatment group was re-treated twice between the four-month and the two-year followup, and there was then a nine-month delay before data collection. Monetary values are in Malawi Kwacha (MK); \$1 USD equalled approximately MK 750 at the time of the experiment. Heteroskedasticity-robust standard errors in parentheses: ${ }^{*} p<0.1 ;{ }^{* *} p<0.05 ;{ }^{* * *}$ $p<0.01$.

$\dagger$ Extended FWER correction uses a more-comprehensive set of assets from Appendix Table A7, not all of which appear in this table; see text for details 
Table A9: Downstream Effects on Asset Ownership_Full List of Outcomes, Adjusting for Potential Spillovers

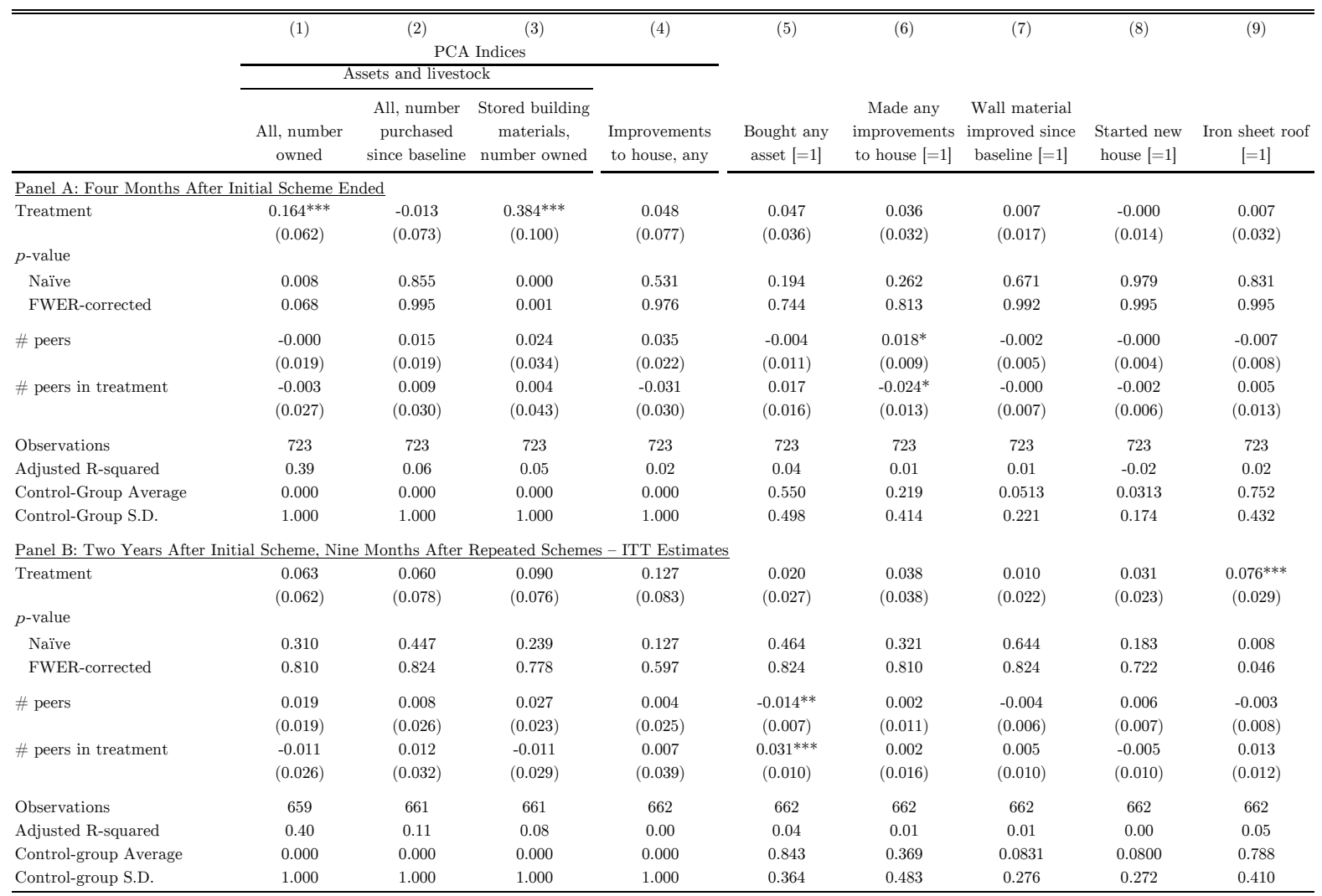

Notes: Assets are measured four months (Panel A) or two years (Panel B) after the payout of the initial savings scheme, using survey data from the fourth and fifth follow-up surveys, respectively. The treatment group was re-treated twice between the four-month and the two-year followup, and there was then a nine-month delay before data collection. Monetary values are in Malawi Kwacha (MK); \$1 USD equalled approximately MK 750 at the time of the experiment. Heteroskedasticity-robust standard errors in parentheses: ${ }^{*} p<0.1 ; * * p<0.05 ; * * *$ $p<0.01$. 
Table A10: Repeat Sign-up in Treatment Group

\begin{tabular}{|c|c|c|c|}
\hline & $\begin{array}{l}(1) \\
\text { Obs. }\end{array}$ & $\begin{array}{c}(2) \\
\text { Average }\end{array}$ & $\begin{array}{c}(3) \\
\text { S.D. }\end{array}$ \\
\hline \multicolumn{4}{|c|}{ Panel A. Repeat take-up of savings scheme } \\
\hline Off-season 2017 & 372 & 0.812 & 0.391 \\
\hline Main season 2018 & 372 & 0.780 & 0.415 \\
\hline \multicolumn{4}{|c|}{ Panel B. Threshold choices among 2017 off-season repeat takers } \\
\hline Minimum take-home pay $[\mathrm{MK}]$ & 302 & 7,559 & 4,855 \\
\hline Maximum deduction [MK] & 302 & 3,476 & 1,796 \\
\hline \multicolumn{4}{|c|}{ Panel C. Threshold choices among 2018 main season repeat takers } \\
\hline Minimum take-home pay $[\mathrm{MK}]$ & 290 & 8,453 & 5,565 \\
\hline Maximum deduction $[\mathrm{MK}]$ & 290 & 4,195 & 2,156 \\
\hline
\end{tabular}

Notes: This table reports repeat sign-up and savings choice statistics for the original treatment group of workers in the 2017 off-season and 2018 main agricultural season. Monetary values are in Malawi Kwacha (MK); \$1 USD equalled approximately MK 750 at the time of the experiment.

Table A11: Impact of Payout and Access Features on Take-up

\begin{tabular}{lc}
\hline \hline & $(1)$ \\
& Would Enroll [=1] \\
\hline Smooth payout & $-0.197^{* * *}$ \\
More access & $(0.052)$ \\
& -0.041 \\
Observations & $(0.052)$ \\
Adjusted R-squared & 542 \\
Control-group Average & 0.025 \\
\hline
\end{tabular}

Notes: This table reports an analysis of sign-up decisions for a sample of workers that were not part of the original savings scheme. These workers made choices to participate in a version of the savings scheme offered during the 2018 main agricultural season. Workers received offers to join either the original version of the deferred wages scheme or one of two modified versions. "Smooth payout" is an offer to participate in a version of the savings scheme where payout would occur as six separate payouts in two-week intervals at the end of the deduction period. "More access" is an offer to participate in a version of the savings scheme where workers could withdraw accumulated funds at any point during the deduction period. Heteroskedasticityrobust standard errors in parentheses: ${ }^{*} p<0.1{ }^{* *} p<0.05 ;^{* * *} p<0.01$. 


\section{Appendix B: Details of Information Sessions}

To recruit the sample for our experiment, field staff visited divisions at the firm and conducted product information sessions with all workers who were present at work. Information sessions were typically held in small groups, with four participants in the average session. About 17 percent of sessions were conducted one-on-one. Most information sessions lasted between 10 and 30 minutes. The text below reproduces the guide that field staff used during the information sessions.

\section{B1 Field Staff Guide for Information Sessions}

1. Introduction:

- This is a new program with limited places.

- The Deferred Wages program is a new scheme under consideration by Lujeri.

- This would be an agreement between you and Lujeri.

- At this stage only some people can participate. In the future, the program may be expanded to include more workers.

- To be fair, we choose who participates by using a lottery among those people who state they are interested.

- We will explain the program to you now and we ask you if you're interested. If you are, then we will come back once more to tell you if you have been chosen and - if you were chosen - what your final deferred wages election is.

2. Explain-How does it work?

- If (and only if) you are interested AND you are selected for participation (which is determined by chance):

- You would be allowed to deduct a portion of your net pay each fortnight 
- At the end of the main season - after 6 fortnights of deductions - you receive a single lump sum of all deductions at once, on the 7 th payday.

- You set the minimum amount of your net pay that you want to receive each payday.

- You also set a maximum amount to be deducted each from each payday. This is the most money that would be delayed until the later lump sum payment.

3. Explain -Use the following examples when giving "Presentation Dialogue":

\section{- Scenario 1: No deductions}

- Suppose you choose a minimum payout of MK 8,000 - this means that every pay day you would get at least MK 8,000 before any part of your wages are deferred.

- Suppose you choose a maximum deduction of MK 3,000 - this means that after your minimum payout of MK 8,000 is reached, part of your wages will get deducted, up to MK 3,000.

- Suppose after tax and other deductions your net pay for a fortnight is MK 6,500 .

* In this example, since your net income is MK 6,500 and you chose MK 8,000 as your min payout and MK 13,000 as your maximum deduction, you would receive MK 6,500 in cash on the regular payday.

* MK 0 would get deferred until the final payout date.

\section{- Scenario 2: Partial deductions}

- Suppose you choose a minimum payout of MK 8,000 - this means that every payday you would get at least MK 8,000 before any part of your wages are deferred. 
- Suppose you choose a maximum deduction of MK 3,000-this means that after your minimum payout of MK 8,000 is reached, part of your wages will get deducted, up to MK 3,000.

- Suppose after tax and other deductions your net pay for a fortnight is MK 10,000 .

* In this example, since your net income is MK 10,000 and you chose MK 8,000 as your min payout and MK 3,000 as your maximum deduction, you would receive MK 8,000 in cash on the regular payday.

* MK 2,000 would get deferred until the final payout date.

\section{- Scenario 3: Maximum deductions}

- Suppose you choose a minimum payout of MK 8,000 - this means that every pay day you would get at least MK 8,000 before any part of your wages are deferred.

- Suppose you choose a maximum deduction of MK 3,000-this means that after your minimum payout of MK 8,000 is reached, part of your wages will get deducted, up to MK 3,000.

- Suppose after tax and other deductions your net pay for a fortnight is MK 15,000 .

* In this example, since your net income is MK 15,000 and you chose MK 8,000 as your min payout and MK 3,000 as your maximum deduction, you would receive MK 12,000 in cash on the regular payday.

* MK 3,000 would get deferred until the final payout date.

4. Explain-When will the scheme start?

- Deductions would begin in late January or early February 2017, and they would stop at the end of the main season.

- The lump sum payout would happen in May or June 2017. 
- The final dates will be chosen soon.

- We will come back to see you in January or February to let you know if you've been selected.

5. Explain-Emergency exit procedure:

- In the event of a serious emergency, participants can withdraw their deductions on a payday prior to the end of the main season - but they must follow the Emergency Exit Protocol

- Meets the division head clerk, present the reason for early withdrawal, and fill and signs "Emergency Exit Procedures Form." The head clerk must notify the payroll office at least 7 days before the next payday.

- All these things must happen at least 7 days before the next payday.

6. Explain - It is important to remember that selection is done by lottery.

- If you are interested in participating in the Deferred Wages scheme, your name will be entered into a lottery. The program will not be available to everyone interested - only some people will have the opportunity to partake in Deferred Wages at this stage.

- Remember: we explain the program to you now and we ask you if you're interested. If you are, then we will come back once more to tell you if you have been chosen and - if you were chosen - we will ask what your final deferred wages election is.

7. FAQ:

(a) Are taxes deducted from lump sum of deferred wages?

No, taxes will not be deducted from lump sum payments at the end of the deduction period. Taxes will be deducted each fortnight from full Basic Pay as usual. DW deductions will be applied to Net Pay. So deductions for DW are already NET of taxes and will not be taxed again. 
(b) On the lump sum payout date, can I receive my lump sum of deductions separately from my regular wages?

No, the lump sum of deferred wages will be given in the same envelope on the day of the lump sum payout in which regular wages will be paid in.

(c) What if I have an emergency and I need to withdraw before the lump sum payout date?

Serious emergencies include termination of work contract, death, illness, illness or death of immediate family member, loss of shelter. In these situations, you may meet division head clerk, present the reason for early withdrawal and fill and sign "Emergency Exit Procedures form." The head clerk must notify the payroll office at least 7 days before the next payday. Deductions will stop at the start of the next working fortnight. Any previous deductions can only be collected at the following payday, provided that the necessary steps were completed at least 7 days before the payday. If you withdraw from the program, your deductions will be canceled for the rest of the season.

(d) Can I decide to increase or decrease my deduction thresholds later?

Workers will have the option of increasing or decreasing their Deduction Thresholds once during the deduction period.

(e) When will I find out if I've been chosen?

We will come back to see you in late January or early February to let you know if you've been selected.

(f) Will I earn interest on my deductions? No, interest will not be offered for this program. 


\title{
Appendix C: Details on Variable Definitions
}

\author{
C1 Measures of Peers
}

As detailed in Section II, we collected a social network survey to investigate potential spillover effects. Our approach is based on Tjernstrom (2017). The network questions were introduced as follows:

We want to ask about people you know at work. We want to know which of your co-workers are your good friends, and also other people you interact with financially. People you interact with financially are people who you give loans to or receive loans from, or give to or receive gifts or transfers from, or who you are in a savings group with.

We then showed people pictures of all their co-workers, defined as a member of the same gang at work. Respondents were asked "Which of these people are your good friends or people you interact with financially (loans/gifts/savings groups)?"

Next, they then were asked to select all the faces of people who were good friends and/or people they interacted with financially. For each person selected, they identified whether this was:

- A good friend?

- A friend? [but not a good friend]

- A relative?

- A neighbor?

- Other

They also were asked:

- Did you have a loan with this person? 
- Did the person have a loan with you?

- Did you receive any gifts of any kind - small, large, cash or in-kind - from this person?

- Did you give any gifts of any kind - small, large, cash or in-kind - to this person?

Finally, there were follow-up questions for affirmative answers to each financial tie:

- What was the value of the (last) loan you had from this person?

- What was the value of the (last) loan you gave to this person?

- What was the value of the (last) transfer or gift you received from this person?

- What was the value of the (last) transfer or gift you gave to this person?

We define as a peer any co-worker selected by the respondent from the grid of faces, which indicates that the person was either a good friend or someone they interacted with financially.

\section{C2 Measures of Self-Control Problems}

In our supplementary experiment on the impact of manual deposits, we collected survey data on regret and past consumption choices as a proxy for whether the respondent had self-control problems. The survey asked respondents the following question:

Which of the following statements would best describe your situation? When you buy things:

(A) You usually regret buying them afterwards because you did not think enough about the purchase beforehand and you bought the item on impulse;

(B) You sometimes regret buying them;

(C) You rarely regret buying them.

In the sample $(N=186)$, we found that 38 percent agreed with (A), 23 percent agreed with (B), and 39 percent agreed with (C). We code individuals who selected (A) as having "high" self-control problems, who selected (B) as having "medium" self-control problems, and who selected (C) as having "low" self control problems. 


\section{C3 Measures of Kin Taxes}

In our supplementary experiment on the impact of manual deposits, we also collected survey data to create a proxy for kin taxes. Each respondent was asked the following question on their preferences over an unexpected gift:

Q1 If you had the choice between receiving an unexpected gift of MK 5,000 privately without anyone knowing that you received any money or receiving MK 8,000 in front of everybody at the office during payday, which one would you prefer?

(A) 5,000 privately;

(B) 8,000 publicly.

Based on their responses to this question, they were asked one of two follow-up questions. If they chose 5,000 privately, they were asked:

Q2-V1 If you had the choice between receiving an unexpected gift of $M K$ 5,000 privately without anyone knowing that you received any money or receiving MK 10,000 in front of everybody at the office during payday, which one would you prefer?
(A) 5,000 privately;
(B) 10,000 publicly.

If they chose 8,000 publicly, they were asked:

Q2-V2 If you had the choice between receiving an unexpected gift of $M K$ 5,000 privately without anyone knowing that you received any money or receiving MK 6,000 in front of everybody at the office during payday, which one would you prefer?

(A) 5,000 privately;

(B) 6,000 publicly. 
These questions were motivated by evidence that publicly-received money is more likely to be taxed by kin (Goldberg, 2017) and that people are willing to forgo part of their earnings in order to hide money from kin (Jakiela and Ozier, 2016). On the initial question Q1, 114 respondents (61 percent) chose to receive MK 8,000 publicly and 72 (39 percent) chose to receive MK 5,000. For the 114 workers who were asked Q2-V1, 104 (91 percent) chose to receive MK 6,000 publicly and 10 (9 percent) chose to receive MK 5,000. For the 72 workers who were asked Q2-V2, 52 (72 percent) chose to receive MK 5,000 privately and 20 (28 percent) chose to receive MK 10,000 publicly. For the 114 respondents that received question Q2-V1, we code respondents as having "low" kin taxes if they chose to receive MK 6,000 publicly and "medium" kin taxes if they chose to receive MK 5,000 privately. For the 72 respondents that received Q2-V2, we code respondents as having "high" kin taxes if they chose MK 5,000 and "medium" kin taxes if they chose MK 10,000. Based on these rules, 28 percent, 16 percent and 56 percent of respondents had high, medium and low kin taxes, respectively. 


\section{References}

Goldberg, Jessica. 2017. "The Effect of Social Pressure on Expenditures in Malawi." Journal of Economic Behavior \& Organization, 143: 173-185.

Jakiela, Pamela, and Owen Ozier. 2016. "Does Africa Need a Rotten Kin Theorem? Experimental Evidence from Village Economies." Review of Economic Studies, 83(1): 231268.

Tjernstrom, Emilia. 2017. "Learning from Others in Heterogeneous Environments." University of Wisconsin Working Paper. 